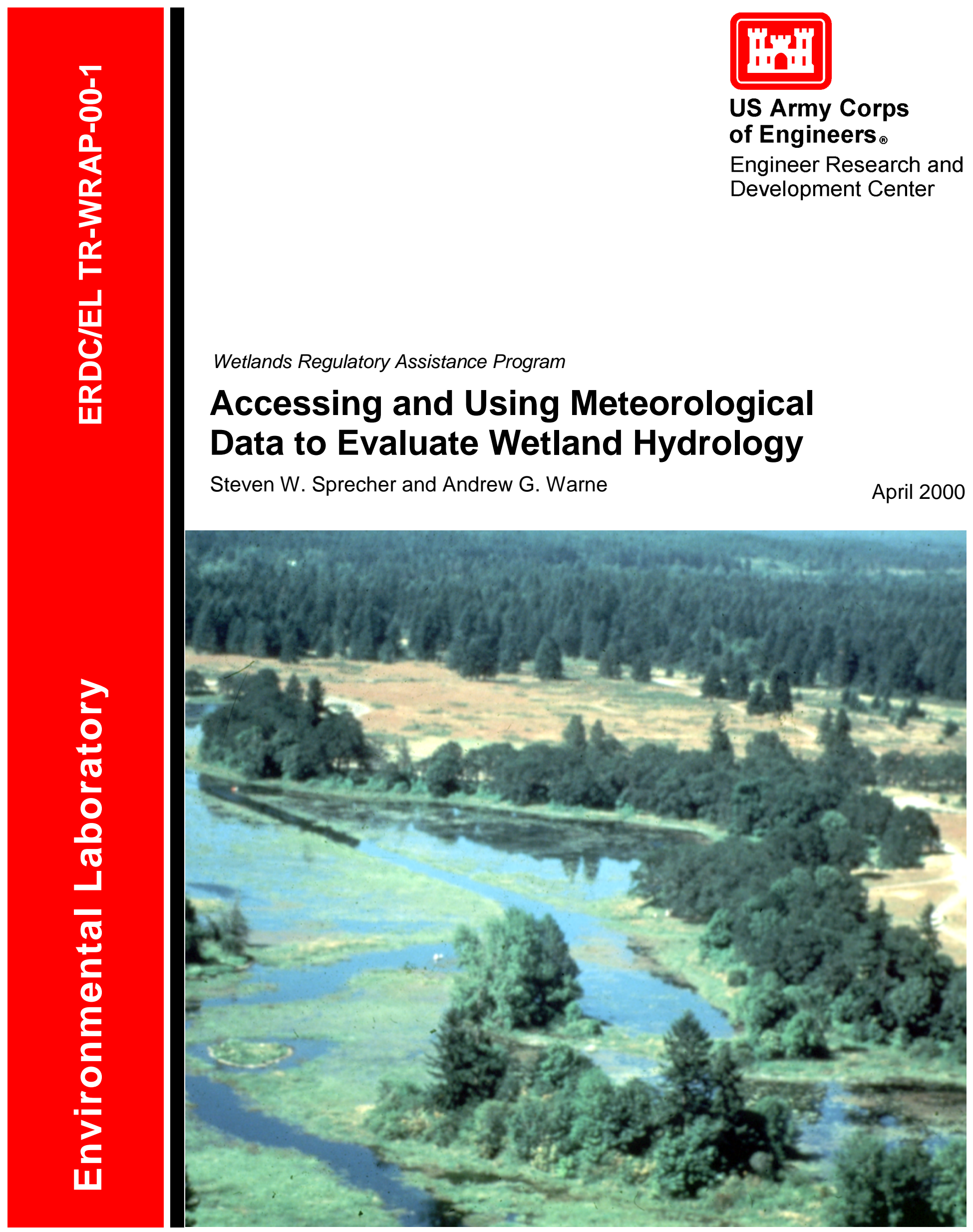


The contents of this report are not to be used for advertising, publication, or promotional purposes. Citation of trade names does not constitute an official endorsement or approval of the use of such commercial products.

The findings of this report are not to be construed as an official Department of the Army position, unless so designated by other authorized documents. 


\title{
Accessing and Using Meteorological Data to Evaluate Wetland Hydrology
}

by Steven W. Sprecher

\author{
Environmental Laboratory \\ U.S. Army Engineer Research and Development Center \\ 3909 Halls Ferry Road \\ Vicksburg, MS 39180-6199 \\ Andrew G. Warne \\ University of Texas \\ Bureau of Economic Geology \\ P.O. Box X, University Station \\ Austin, TX 78713
}

Final report

Approved for public release; distribution is unlimited 


\section{U.S. Army Engineer Research and Development Center Cataloging-in-Publication Data}

Sprecher, Steven W.

Accessing and using meteorological data to evaluate wetland hydrology / by Steven W. Sprecher, Andrew G. Warne ; sponsored by Headquarters, U.S. Army Corps of Engineers, Operations Division, Regulatory Branch.

96 p. : ill. ; $28 \mathrm{~cm}$. - (ERDC/EL ; TR-WRAP-00-1)

Includes bibliographic references.

1. Wetland hydrology. 2. Hydrology. 3. Rainfall probabilities. 4. Weather forecasting. 5. Precipitation (Meteorology) - Measurement - Databases. I. Warne, Andrew G.

II. United States. Army. Corps of Engineers. III. Engineer Research and Development Center (U.S.) IV. Wetlands Regulatory Assistance Program (U.S.) V. Title. VI. Series: ERDC/EL TR-WRAP ; 00-1.

TA7 E8 no.ERDC/EL TR-WRAP-00-1 


\section{Contents}

Preface vii

Overview viii

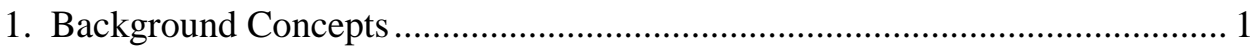

1.1 Why be concerned with antecedent precipitation .................................... 1

1.2 What is "normal precipitation" ................................................................. 1

1.2.1 "Normal precipitation" as a single value ........................................ 1

1.2.2 "Ranges of normal precipitation".................................................... 1

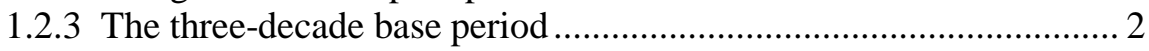

2. Range of Normal from the "WETS Tables" .................................................. 3

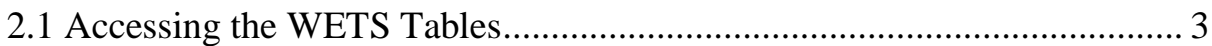

2.2 Important information in the WETS Tables .............................................. 3

2.3 Interpreting "zero" precipitation levels in the WETS Tables ..................... 5

2.4.Graphical presentation of the information on WETS Tables...................... 5

3. Finding Recent Precipitation Data ................................................................ 7

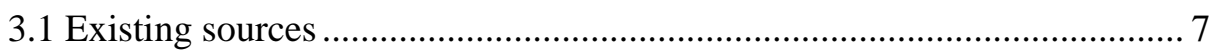

3.2 Unified Climate Access Network (UCAN) ….................................... 7

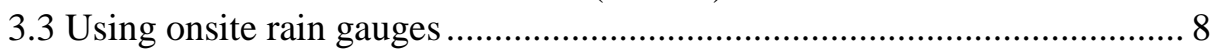

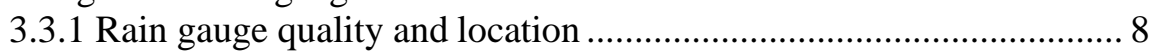

3.3.2 Interpreting onsite precipitation data.............................................. 9

3.3.3 Summary of use of onsite rain gauges............................................ 14

4. Evaluating Antecedent Precipitation Conditions at a Site ............................ 15

4.1 NRCS Engineering Field Handbook .................................................... 15

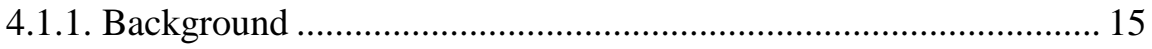

4.1.2. NRCS procedure for estimating antecedent moisture

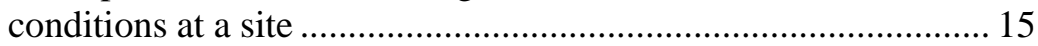

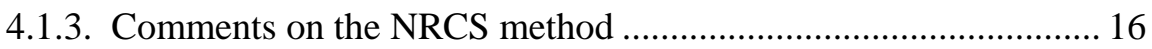

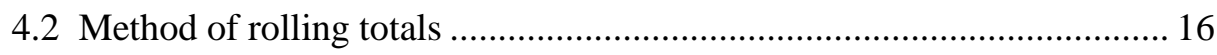

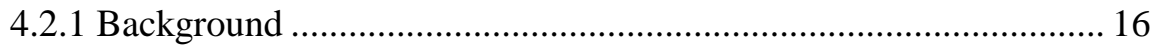

4.2.2. Procedure of 30-day rolling totals ................................................ 18

4.2.3. Determining whether tallied precipitation was within

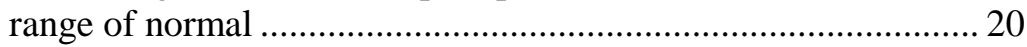


4.2.4. Comments on the method of 30-day rolling totals

4.3 Combined method of 30-day rolling totals and NRCS Engineering

Field Handbook weighting factors

4.3.1 Procedure for combining the methods of 30-day rolling totals and Engineering Field Handbook weighting factors ................... 21

4.3.2 Comments on the combined method ............................................ 21

4.4 General Observations on Assessments of Antecedent Precipitation......... 23

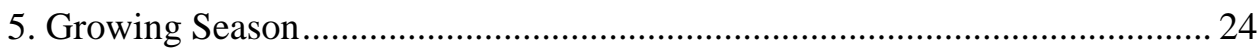

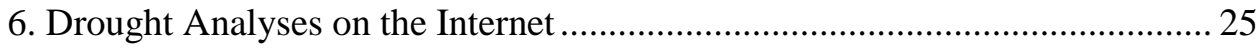

6.1 Preliminary nature of near-real time analyses......................................... 25

6.2 Palmer Drought Indices ..................................................................... 25

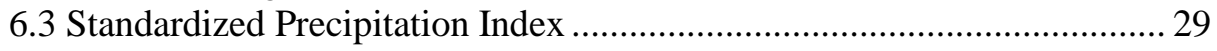

6.4 USGS Stream Gauge Data .................................................................. 32

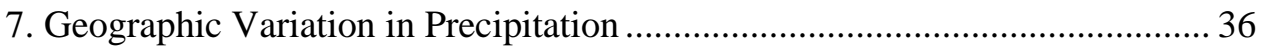

8. Comparing Data from Monitoring Wells and Rain Gauges .......................... 38

9. Statistical Background and Common Problems ........................................... 43

9.1 Gamma distribution: Introduction to the statistics of normal

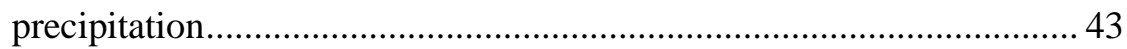

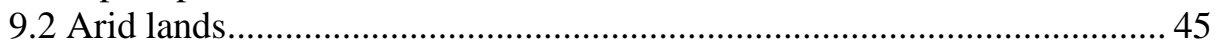

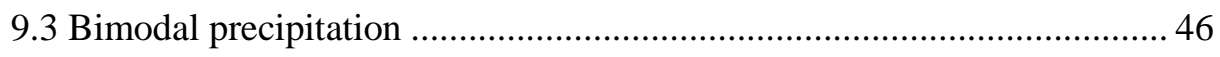

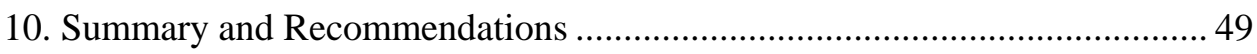

10.1 Summary

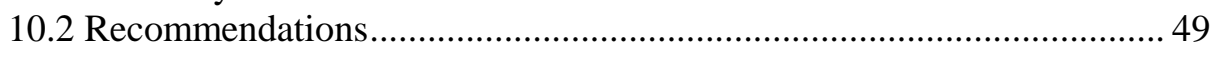

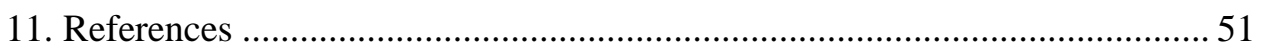

Appendix A Addresses for Collection and Analysis of Meteorological

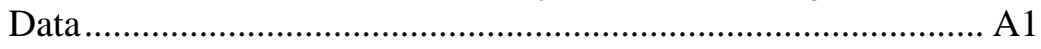

Appendix B NWS guide on rain gauges .................................................... 1

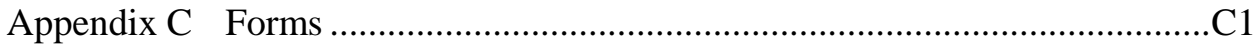

Appendix D Comparison of probability distributions, for temperature and precipitation data................................................................ D1

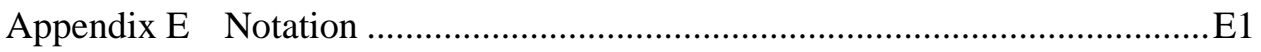

SF 298 


\section{List of Figures}

Figure 1. WETS Table for Grand Island, NE

Figure 2. Graphic presentation of WETS Table information plus

monthly precipitation totals for a particular year......

Figure 3. Example of comparison of data from an unofficial weather station .. 10

Figure 4. A. Ranges of normal for monthly precipitation at three NWS stations in Indiana. B. Actual monthly precipitation totals at three NWS stations and a research station in Indiana, superimposed on a graph of average range of normal monthly precipitation at the NWS stations

Figure 5. Worksheet to determine whether precipitation was within the range of normal prior to a site visit

Figure 6. 30-day rolling totals of precipitation at Grand Island, NE, overlaid on graph of daily precipitation and monthly precipitation 18

Figure 7. Three 30-day periods prior to May 15, superimposed on Figure 6.... 22

Figure 8. Growing season information as presented in WETS Tables, for Wooster, $\mathrm{OH}$

Figure 9. Palmer drought indices for Climate Division 5, NE (includes Grand Island) for 1991

Figure 10. Example of Palmer Drought Severity Index by climate division for the Nation from provisional data at the Climate Prediction Center.

Figure 11. Period of record for Palmer Drought Severity Index for Climate Division 5, NE (includes Grand Island).

Figure 12. Example of precipitation percentiles for Division 1 of Nevada, for periods of 1 to 72 months.

Figure 13. Example of USGS streamflow graph at USGS website, including table of exceedence thresholds

Figure 14. Precipitation patterns across the Sierra Nevada divide expressed as percentiles of monthly precipitation

Figure 15. Daily precipitation and water well data near Columbus, OH, 1997 .. 39

Figure 16. Daily precipitation and water well data near McHenry, IL, 1995-1996 
Figure 17. Histogram and gamma distribution for same set of precipitation data, Aprils 1961-1990, Grand Island, NE

Figure 18. Histogram of July precipitation at Mojavé, CA, for 1961 to 1990 .... 46

Figure 19. Frequency distributions of June precipitation at Raleigh, NC 48

\section{List of Tables}

Table 1. Upper and Lower Percentile Thresholds for Middle Ranges

of Precipitation Models. 2

Table 2. Daily Precipitation and 30-day Rolling Totals for Jan-May 1991

at Grand Island, NE

Table 3. Comparison of Engineering Field Handbook Method and

Combined Method, Grand Island, Hall County, NE, 1991

Table 4. Palmer Classes for Wet and Dry Periods ......................................... 29

Table 5. Exceedence Thresholds and Percentiles for SPI Values .................... 32

Table 6. Characteristics for Contrasting Weather Stations in the

Tahoe/Reno Region 37 


\section{Preface}

This report was authorized and funded by Headquarters, U.S. Army Corps of Engineers (HQUSACE), as part of the Wetlands Regulatory Assistance Program (WRAP). HQUSACE representatives for this report were Mr. Charles Hess, Chief, Operations Division (CECW-O); Mr. John Studt, Chief, Regulatory Branch (CECW-OR); and Mr. Ted Rugiel, Regulatory Branch (CECW-OR). Dr. Russell F. Theriot, U.S. Army Engineer Research and Development Center (ERDC), Environmental Laboratory (EL), was the WRAP Program Manager. Mr. Mike Smith, HQUSACE Regulatory Branch, was the wetland delineation point on contact. General supervision of this work was provided by Dr. Morris Mauney, Chief, Wetlands Branch, EL; Dr. Conrad Kirby, Chief, Environmental Resources Division, EL; and Dr. John Keeley, Director, EL.

The report was prepared by Dr. Steven W. Sprecher, U.S. Army Engineer District, Detroit, South Bend, IN, and by Dr. Andrew G. Warne, Texas Bureau of Economic Geology.

The authors wish to acknowledge the efforts of the following people, without whom this report would not have been possible: Phil Pasteris, USDA National Water and Climate Center; Dr. Jay Grymes, South Regional Climate Center; Dr. Jim Richardson, North Dakota State University; Dr. James Wakeley, ERDC; Don Woodward, USDA Natural Resources Conservation Service; and, for his administrative assistance, Dr. Russell F. Theriot, ERDC.

At the time of publication of this report, Dr. Lewis E. Link was Acting Director of ERDC, and COL Robin R. Cababa, EN, was Commander.

This report should be cited as follows:

Sprecher, Steven W., and Warne, Andrew G. (2000).

"Accessing and using meteorological data to evaluate wetland hydrology," ERDC/EL TR-WRAP-00-1, U.S. Army Engineer Research and Development Center, Vicksburg, MS. 


\section{OVERVIEW}

Investigators of wetland hydrology need to know whether they are making their observations during normal weather conditions or during abnormal conditions of drought or excess precipitation. Such decisions require knowledge both of current precipitation inputs and of the frequency distribution of precipitation over the long-term record at or near the site. Information pertinent to accessing and using these meteorological data to evaluate wetland hydrology is presented in various sections of this report. Also, much of this information is now easily available on the Internet at the Websites shown below.

\section{SITE-SPECIFIC FREQUENCY DISTRIBUTIONS OF PRECIPITATION}

The USDA National Water and Climate Center publishes the ranges of normal monthly precipitation for over 8000 National Weather Service (NWS) weather stations. These analyses are called WETS Tables and are available for one to several weather stations in most counties in the Nation. The range of normal is reported as a " 30 percent chance will have less than" ( $30^{\text {th }}$ percentile) and a " 30 percent chance will have more than" $\left(70^{\text {th }}\right.$ percentile). The WETS Tables provide the user with the ability to determine whether precipitation inputs were within the range of normal at a particular NWS weather station and, by inference, in the immediately surrounding area. These tables are discussed and available at:

WETS Tables Section $2 \quad$ http://www.wcc.nrcs.usda.gov/water/wetlands.html

\section{SITE-SPECIFIC REAL-TIME DATA}

The WETS Tables do not supply real-time precipitation data. The National Water and Climate Center (NWCC) is working on an Internet Web site (UCAN) that will publish real-time data for the 8000+ weather stations used in the WETS Tables, but until that site is established, rainfall records for the current and immediately preceding months are most readily obtained from State Climatologists and the Regional Climate Centers. They can be contacted at:

State Climatologists Section 3.1 http://www.ncdc.noaa.gov/ol/climate/aasc.html\#STAT

\section{Regional Climate Centers Section 3.1 http://met-www.cit.cornell.edu/other_rcc.html}

Weekly and monthly precipitation data for approximately 225 cities in the Nation can be obtained at the following Web site. Click on "Weekly Precipitation Table" or "Monthly Precipitation Table."

Climate Prediction Center Section 3.1

http://www.cpc.ncep.noaa.gov/products/analysis_monitoring/cdus/prcp_temp_tables/

UCAN (site in progress) Section $3.2 \quad$ http://www.wcc.nrcs.usda.gov/bbook/bb20.html 


\section{ONSITE RAIN GAUGES}

Onsite rain gauges are occasionally used at projects in order to document precipitation patterns that may not be the same as those recorded at the nearest NWS stations included in the WETS Tables. To assure reliability, data collected onsite must be compared to the long-term precipitation record collected at NWS stations. A method for comparing onsite data with NWS data is presented in

Using Onsite Rain Gauges

Portions of NWS Observing Handbook No. 2

\section{Section 3.3}

Appendix B

\section{EVALUATING ANTECEDENT PRECIPITATION}

The Natural Resources Conservation Service (NRCS) Engineering Field Handbook uses monthly precipitation data in conjunction with the WETS Tables to evaluate the preceding two or three months' precipitation input; the major weakness of the NRCS method is that it does not evaluate daily changes in precipitation patterns, especially for the current month of analysis. A method of computing 30-day rolling totals has also been devised to incorporate daily data into the analysis, but this method considers antecedent precipitation for only 30 days. Therefore, a third method is presented that combines the methods of the NRCS and 30-day rolling totals. These methods are discussed as follows:

Hydrology Tools Method Section 4

http://www.wcc.nrcs.usda.gov/water/quality/text/hydrolog.html

\section{0-day Rolling Totals Method Section 4.2}

Combined Method Section 4.3

\section{THE REGULATORY GROWING SEASON}

The growing season is defined for wetland hydrology on the basis of soil temperatures, which in turn are estimated based on NRCS reports of 50 percent likelihood of last and first $28^{\circ} \mathrm{F}$ frost. These dates are available in NRCS soil survey reports, but more current dates are available in the WETS Tables.

\section{Growing Season Dates $\quad$ Section $5 \quad$ http://www.wcc.nrcs.usda.gov/water/wetlands.html}

\section{DROUGHT ANALYSES ON THE INTERNET}

Several Web sites present real-time data on drought and precipitation excess. These data are presented for Climate Divisions, which are regions of states that are meteorologically similar. The advantages of these drought indices are that they are statistically based information available for the current or preceding month. The disadvantages are that they are not site-specific and that the real-time data have not undergone official quality control procedures. The most widely used drought index is the Palmer drought index, which evaluates evapotranspiration and soil water content as well as precipitation. The Standardized Precipitation Index avoids some of the assumptions of the Palmer Index and provides frequency analyses for twenty different time periods leading up to a month of observation, ranging from one month prior to five years prior. The US Geological Survey reports percentile frequency analyses of 
stream gauge levels around the Nation, which often serve as independent measures of climatic patterns. The appropriateness of individual tools to a specific site depends on the hydrologic controls of that site. Wetlands with a strong groundwater control need to be assessed with some of these longer term drought indices as well as with the WETS Tables. The drought indices are discussed and available at:

$\begin{aligned} & \text { Palmer Drought Indices } \\ & \text { Previous month and prior }\end{aligned}$
http://www.ncdc.noaa.gov/onlineprod/drought/main.html

Current week (provisional)

http://www.cpc.ncep.noaa.gov/products/analysis_monitoring/regional_monitoring/palmer.gif

\begin{tabular}{|c|c|}
\hline Standardized Precipitation Index & Section 6.3 \\
\hline Percentiles for climate divisions & s $\quad$ http://www.wrcc.sage.dri.edu/spi/spi.html \\
\hline National and archival & http://enso.unl.edu/ndmc/watch/watch.htm \\
\hline tream Gauge Analyses & Section 6.4 http://water.usgs.gov/realtime.html \\
\hline
\end{tabular}

\section{SPATIAL VARIATION IN PRECIPITATION}

Spatial variability of precipitation is greater for individual storms than for precipitation averaged over a month or season. The National Climatic Data Center (NCDC) estimates missing values in weather data by interpolating between reporting stations within 30 miles. If a project does not have an onsite rain gauge, one should estimate monthly precipitation by averaging or interpolating between nearby NWS weather stations.

Geographic Variation in Precipitation $\quad$ Section 7

\section{COMBINING DATA FROM MONITORING WELLS AND RAIN GAUGES}

Data from shallow monitoring wells can be overlain on time series plots of daily precipitation data. Thirty-day rolling totals can also be plotted on these graphs. These graphs serve to clarify the relationship between local precipitation and site hydrology and provide a basis for determining the longterm hydrology of a site.

\section{STATISTICAL BACKGROUND TO PRECIPITATION FREQUENCY ANALYSIS}

Precipitation data do not fit a bell curve but instead fit a gamma distribution. The reason for this is that a site cannot experience less than zero precipitation in any day or week or month, but in theory it can always experience a larger rainfall amount than the last record high. Consequently, the frequency distribution is skewed to the right. Precipitation frequency distributions are skewed more strongly in arid regions and for short-term analyses (for example, a month vs a year). These and related problems are discussed at:

\section{Statistical Background}

\section{Section 9}




\section{BACKGROUND CONCEPTS}

\subsection{WHY BE CONCERNED WITH ANTECEDENT PRECIPITATION?}

Water levels in wetlands are influenced by the various components of the hydrologic budget, including precipitation. Because precipitation exerts such a strong control of the input side of the hydrologic budget, a variety of wetland assessments need information about the prior precipitation inputs influencing water levels observed on a site. The Corps of Engineers Wetlands Delineation Manual (Environmental Laboratory 1987) advises that

"because seasonal conditions and recent weather conditions can contribute to surface water being present on a nonwetland site, both should be considered when applying this indicator" [visual observation of inundation] (para. 49.b(1)), and

"[w]hen applying this indicator [visual observation of soil saturation], both the season of the year and preceding weather conditions must be considered" (para. 49.b(2)).

\subsection{WHAT IS "NORMAL" PRECIPITATION?}

"Normal" has two different meanings when used to describe precipitation. One is a single-value estimate of the mean and the other is a range of precipitation amounts.

1.2.1 "Normal Precipitation" as a Single Value The National Climatic Data Center (NCDC 1995) defines "normal" as the "arithmetic mean of a climatological element computed over three consecutive decades." Therefore, normal precipitation is the average of the precipitation amounts for the period of interest, for instance, for a particular month. For example, using this definition, normal April precipitation in Grand Island, NE, is 2.50 inches, because that is the average amount of rain that fell in all Aprils evaluated at that recording station during the previous three decades. Any April precipitation amounts greater than or less than 2.50 inches in Grand Island would be reported as deviations from normal for that month. Although this definition is useful for maintaining climatological records, it has little utility for classifying meteoric inputs into broad classes such as "normal," "below normal," or "above normal." For that purpose, the concept of a "range of normal" precipitation amounts is more appropriate.

1.2.2 "Ranges of Normal Precipitation" The concept of a "range of normal precipitation" is useful for grouping precipitation inputs into broad classes. The boundaries of these classes depend on the number of classes desired, the purpose of the classification, and tradition in the discipline. The NCDC ${ }^{1}$ computes several different probability ranges for different purposes, including quintiles $\left(0-20^{\text {th }}\right.$ percentile, $20^{\text {th }}$ $40^{\text {th }}$ percentile, etc. $)$, deciles $\left(0-10^{\text {th }}\right.$ percentile, $10^{\text {th }}-20^{\text {th }}$ percentile, etc. $)$, and others oriented toward extreme events. Some meteorologists prefer to assign the label of "normal" to the middle two quartiles $\left(25^{\text {th }}\right.$ to $75^{\text {th }}$ percentiles of probability). Various frequency analyses use slightly different cutoff thresholds for their middle range of precipitation frequencies (Table 1).

The Standardized Precipitation Index (SPI) has the widest range of normal, but intermediate percentiles are also available at their Web site. The $30^{\text {th }}$ to $70^{\text {th }}$ percentile thresholds are used in this report as the range of normal because those are the ones used in the only analysis that was specifically designed for wetland regulation (Food Security Act). The user of this report, however, should recognize that local climatologists may prefer slightly different ranges of normal. The technical definition of the WETS Tables range of normal can be found in Appendix D.

1 For convenience, abbreviations are listed in the Notation (Appendix E). 


\begin{tabular}{|c|c|c|}
\hline Model & Lower Threshold & Upper Threshold \\
\hline $\begin{array}{l}\text { USDA National Water and Climate } \\
\text { Center WETS Tables }\end{array}$ & $30^{\text {th }}$ percentile & $70^{\text {th }}$ percentile \\
\hline $\begin{array}{l}\text { National Climate Data Center Palmer } \\
\text { drought indices }\end{array}$ & $28^{\text {th }}$ percentile & $72^{\text {nd }}$ percentile \\
\hline $\begin{array}{l}\text { National Drought Mitigation Center } \\
\text { Standardized Precipitation Index }\end{array}$ & $16^{\text {th }}$ percentile ${ }^{1}$ & $84^{\text {th }}$ percentile ${ }^{1}$ \\
\hline $\begin{array}{l}\text { US Geological Survey Stream Gauge } \\
\text { analyses }\end{array}$ & $25^{\text {th }}$ percentile & $74^{\text {th }}$ percentile \\
\hline
\end{tabular}

1.2.3 The Three-Decade Base Period Many climatological probabilities, including the USDA WETS Tables discussed below, are calculated on the basis of the most recent three decades of data. The current base period is 1961-1990. On January 1, 2001, the new base period for calculations will become 19712000. The reasons for choosing the most recent three decades are both statistical and historical (Kunkel and Court 1990). For example, comparisons between different recording stations need to be made for the same time period; climatic change may alter probabilities of occurrence over the decades; recording technologies have been upgraded around the Nation at roughly comparable times; etc. Longer records are available at many weather stations, and these longer records are useful for calculating extreme events, such as 100-year floods, but the range of most likely precipitation is currently calculated on the basis of the most recent three decades of record. 


\section{RANGE OF NORMAL FROM THE "WETS Tables"}

A WETS Table (Figure 1) is a statistical summary of monthly precipitation and temperature for any of the 8000+ reporting stations of the National Weather Service (NWS) Cooperative Network. The Tables are available for free on the Internet and from District Offices of the Natural Resources Conservation Service (NRCS). They present the ranges of normal precipitation, growing season dates as recommended for wetlands regulation, and monthly and annual precipitation totals for the period of record of each NWS reporting station.

\subsection{ACCESSING THE WETS TABLES}

The Internet address for the WETS Tables is:

http://www.wcc.nrcs.usda.gov/water/wetlands.html

The sequence of menu selections from this Web site is:

1. "Select desired region"; "Go to county selection"

2. "Select desired county"; "Go to FTP download"

3. "Select this line to receive the information for county from our FTP site"

The WETS Table for a particular county may include tables for several weather stations in that county, so one may have to scroll through a series of tables to find the desired locations. These can be saved to a computer word-processing file by cut-and-paste techniques. For word processing they format best as Courier 10-point text with 0.5-inch margins.

\subsection{IMPORTANT INFORMATION ON THE WETS TABLES (FIGURE 1)}

Key elements of a WETS Table are

- $\quad$ Station location (name, latitude, longitude, and elevation)

e.g., Grand Island WSO AP, NE; 4058 lat, 09819 long, $1840 \mathrm{ft}$ elev.

- "Starting year" and "ending year" tell the time period used to calculate ranges of normal and means

e.g., 1961 to 1990

- $\quad$ Temperature averages are arithmetic means of the monthly records e.g., mean April temperature is $50.8^{\circ} \mathrm{F}$

- $\quad$ Precipitation data

i) monthly average (arithmetic mean)

e.g., mean April precipitation is 2.50 inches

ii) range of normal ( $30 \%$ chance will have "less than" and "more than") e.g., normal April rainfall is between 1.37 inches and 3.05 inches

- $\quad$ Growing season dates

e.g., April 15 to October 16, for $50 \%$ likelihood of last and first $28^{\circ} \mathrm{F}$ frost

- $\quad$ Page (Sheet) 2 of the output shows monthly precipitation totals for the long-term record for the station. 


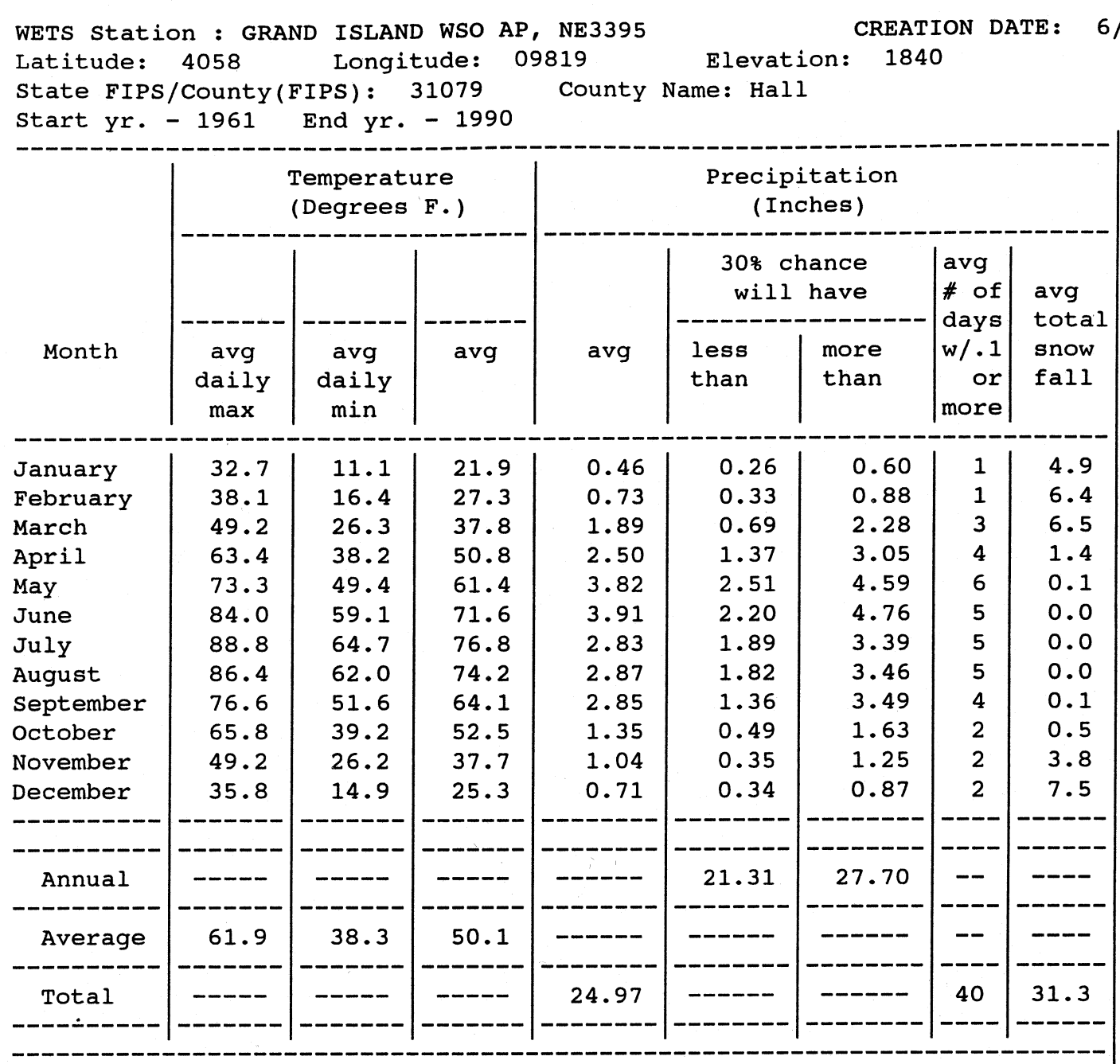

GROWING SEASON DATES

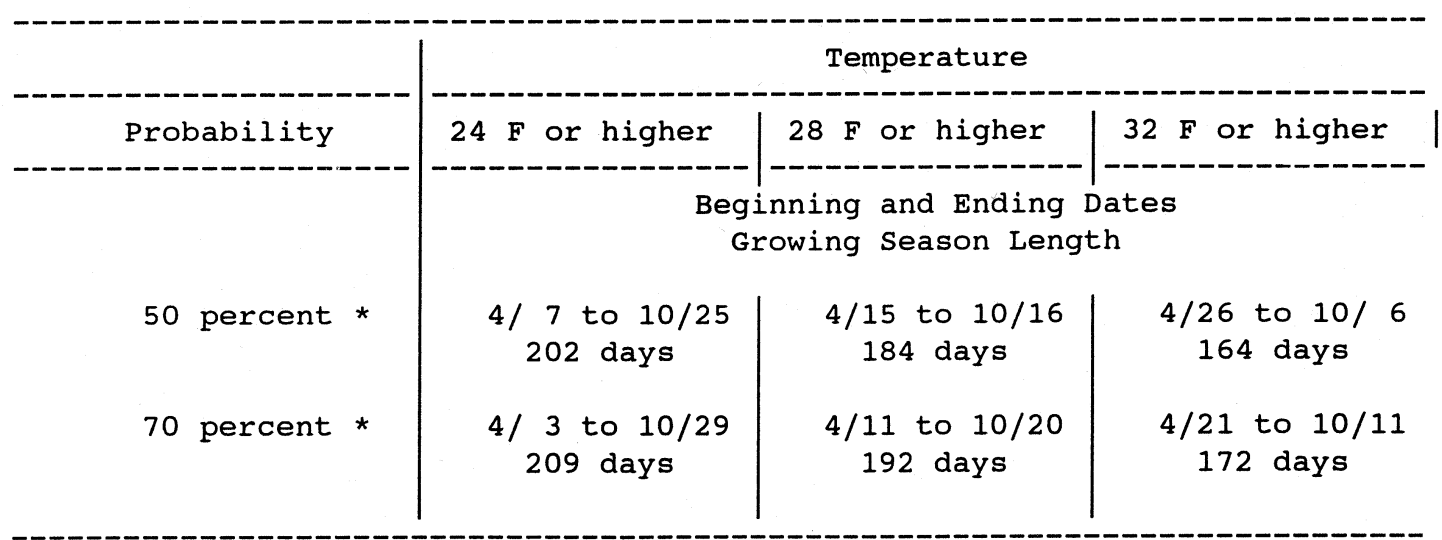

* Percent chance of the growing season occurring between the Beginning and Ending dates.

total 1903-1996 prop

Figure 1. WETS table for Grand Island, NE (NWC 1996) (Continued) 


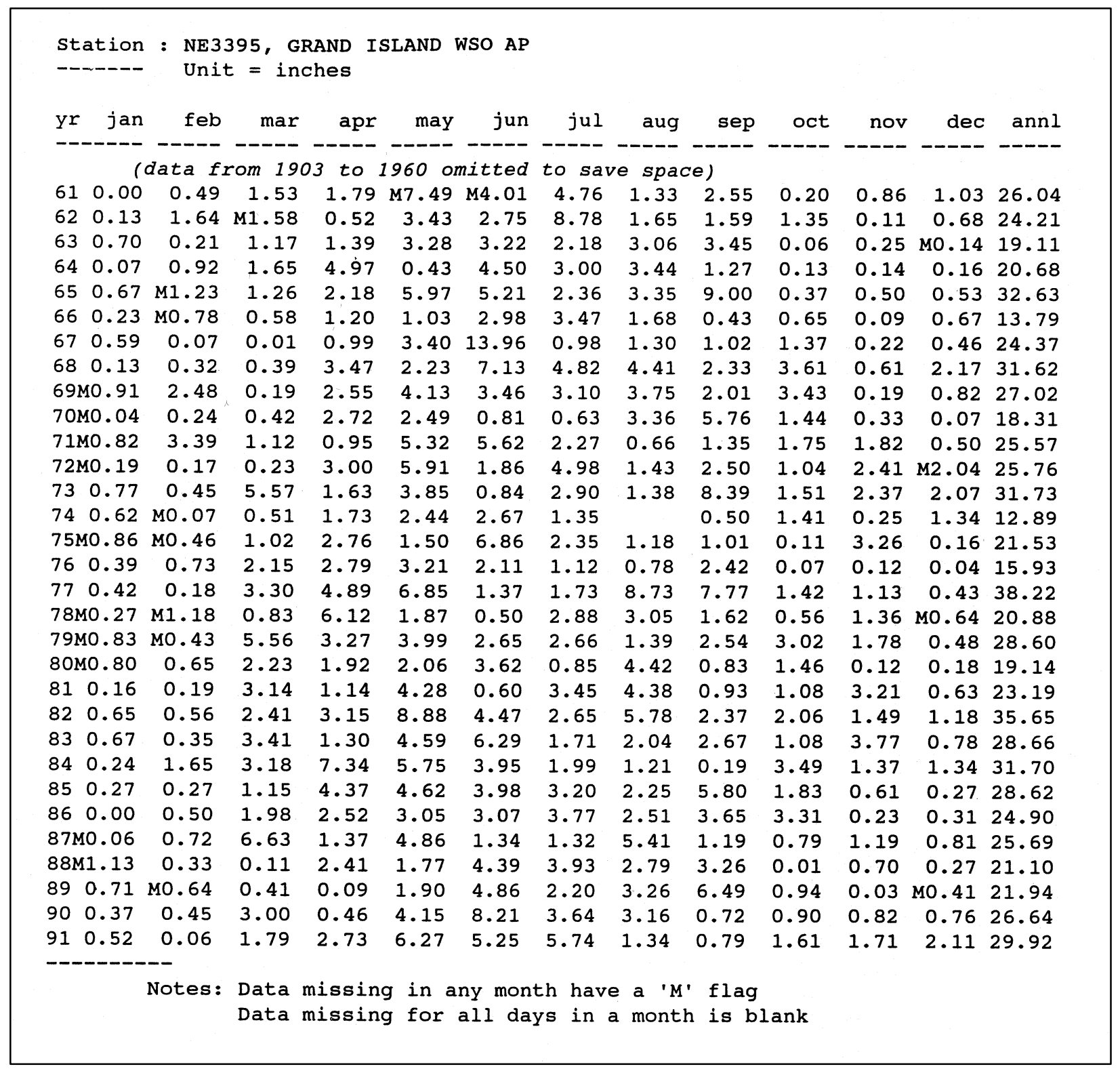

Figure 1. (Concluded)

\subsection{INTERPRETING “ZERO” PRECIPITATION LEVELS IN THE WETS TABLES}

The WETS Tables report missing precipitation data in two ways, either with an "M" beside the monthly value (for example, "M1.25"), or with a blank for the month. An "M" is used if one or more days of data have been recorded as "missing." A blank monthly total is shown if no data are available for that month. " $0.00 "$ is entered for a month that has a full record of data but in which no precipitation fell.

\subsection{GRAPHICAL PRESENTATION OF THE INFORMATION ON WETS TABLES}

Changes in monthly precipitation data and their deviation with respect to range of normal are often more understandable when presented in a graphic format, such as Figure 2. This graph shows monthly precipitation totals for a particular year, the range of normal precipitation for each calendar 


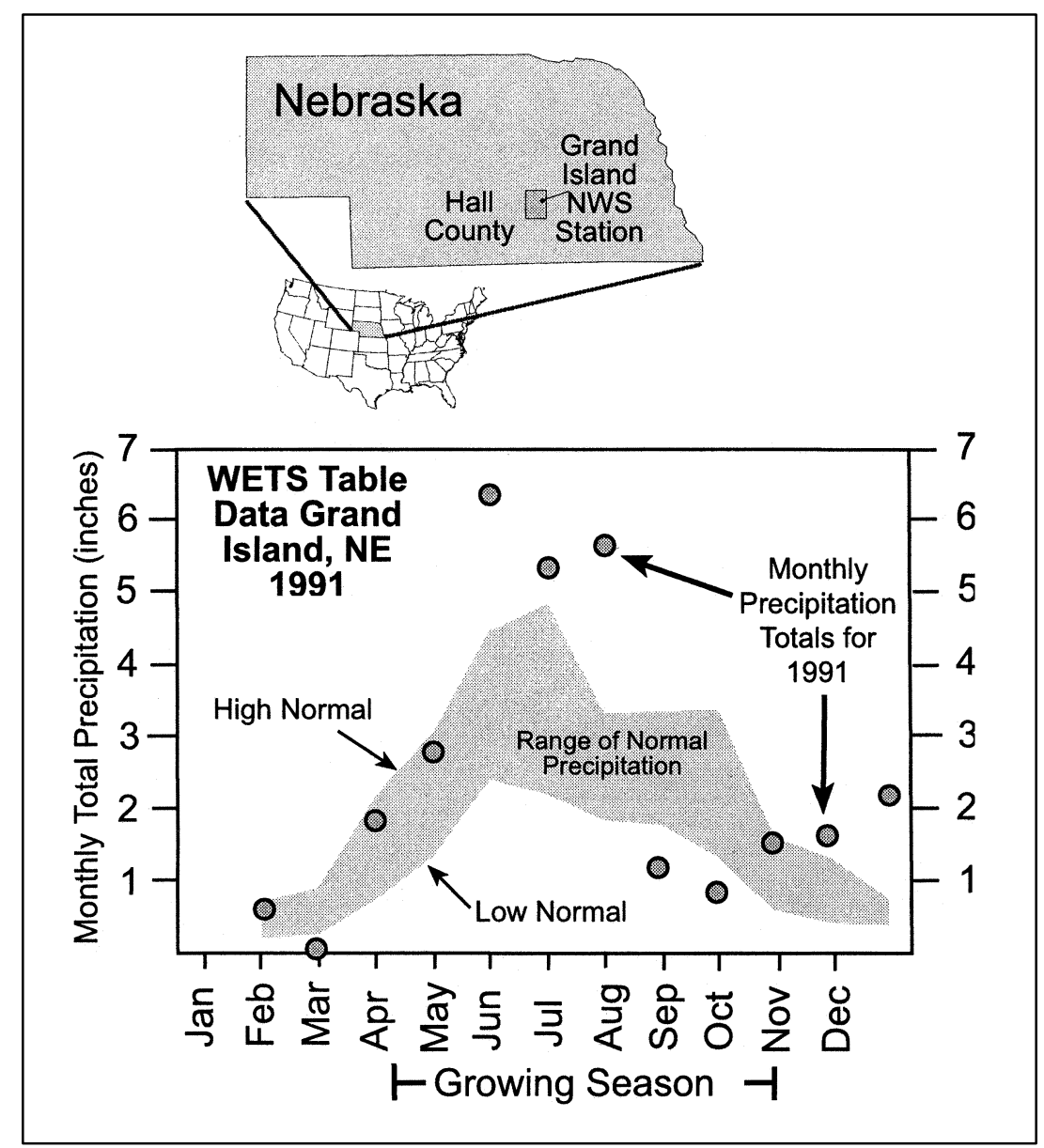

Figure 2. Graphic presentation of WETS Table information plus monthly precipitation totals for a particular year. This presentation format allows rapid assessment of rainfall conditions for the period of interest. See text for further discussion

month based on the preceding three decades, and the duration of the growing season. It is easy to plot the range of normal precipitation (shaded area in Figure 2) for the weather stations that are within the area of responsibility of the field office. These can then serve as templates, be photocopied, and be used to plot monthly totals on a case-by-case basis. Plotting of WETS Table and monthly total precipitation data in a standard format reduces ambiguities when evaluating precipitation conditions during the period of concern. 


\section{FINDING RECENT PRECIPITATION DATA}

\subsection{EXISTING SOURCES}

As of this writing, finding recent precipitation data is the most cumbersome part of determining whether precipitation was normal during the two or three months prior to a site visit. There currently is a several month delay between the date of collection and final release of data to the public by the National Oceanic and Atmospheric Administration (NOAA). The delay results from quality-control protocols used by the NCDC. Raw data are usually very similar to those finally published, but data should undergo NCDC quality control steps before being used for legal purposes. All data published in the Climatologic Data Summaries and in the WETS Tables have undergone this process.

Excellent sources of recent data are the Regional Climate Centers (RCC) and the state climatologists.

- $\quad$ Regional Climate Centers: $\quad$ http://met-www.cit.cornell.edu/other_rcc.html

- $\quad$ State Climatologists: $\quad$ http://www.ncdc.noaa.gov/ol/climate/aasc.html

These offices may be able to provide data from stations that are not part of the WETS network as well as raw data from official recording stations. Recent precipitation information may also be available from unofficial sources outside of the NWS network, such as newspapers, research sites, etc. Caution should be used with data from non-NWS sources, as turbulence at improperly located instruments, equipment used, and data transcription are all potential sources of error that may not be monitored as closely as done by the NCDC. To determine their reliability, unofficial data should be correlated with long-term data from surrounding official weather stations using procedures described in Section 3.3.

A great number of Internet Web sites claim to provide recent weather data. Users of climatic data are encouraged to explore city, state, and university Web sites for locally useful information that may be accessed on a continuing basis. On a national basis, the Climate Prediction Center publishes weekly and monthly precipitation data for approximately 225 cities around the Nation at

$\underline{\text { http://www.cpc.ncep.noaa.gov/products/analysis_monitoring/cdus/prcp_temp_tables/ }}$

The US Geological Survey (USGS) publishes precipitation data from various rain gauges around the Nation. This information is published on a state-by-state basis. The national index for the Web site is found at:

http://water.usgs.gov/realtime.html

\subsection{UNIFIED CLIMATE ACCESS NETWORK (UCAN) ${ }^{2}$}

The NRCS, six RCC's (NOAA), and NCDC (NOAA) are currently designing and constructing the Unified Climate Access Network (UCAN). UCAN is a consortium of Federal and state agencies whose focus is to unify access and availability of climate data and information for natural resource management. UCAN will allow user access to quality-controlled climate information more quickly, easily, and efficiently than previously possible.

2 Contributed by P. Pasteris, National Water and Climate Center, Portland, OR. 
This Internet-based climate system will provide access to climate information as current as a month old for $8000+$ climate stations and historical data from over 25,000 stations collected by Federal, state, and county networks located throughout the U.S. As of October 1998 a prototype UCAN demonstration Web site has been established at the following Uniform Resource Location (URL):

\section{http://www.srcc.lsu.edu/ucan.net/UCAN.html}

A major goal of this project is to enable climate information users to obtain information from a UCAN Web page. The UCAN system will automatically send requests for specific data sets and climate products to a network of regional and national climate center computer systems that maintain the data archive for the requested product.

In addition to access to multiple data sets and output formats, users will be able to run a variety of climatic data analysis programs. These include statistical averages, frequency analyses, spatial mapping, risk analyses, and modeling applications that require specialized climatic information.

\subsection{USING ONSITE RAIN GAUGES}

It is a common practice on research projects to collect precipitation data on or near an investigation site in order to record differences between rainfall onsite and that recorded at the nearest NWS station. This is done because rainfall can vary considerably over short distances, particularly in locations and seasons where meteorology is dominated by convective thunderstorms. When using onsite rain gauges, however, caution is required for several reasons:

- The previous three-decade precipitation record is usually not available at project sites, so one must compare onsite data with official NWS data from nearby stations to determine whether onsite precipitation was outside the range of normal.

- $\quad$ Onsite precipitation data seldom undergo the same quality-control procedures as those applied to the NWS database.

- $\quad$ Onsite rain gauges may be unreliable due to poor quality, improper installation, or infrequent readings.

\subsubsection{Rain Gauge Quality and Location}

Of the above-mentioned problems, the easiest to address is quality of the rain gauge. Automatic, recording rain gauges are available from numerous scientific and environmental supply houses. Most of these meet the minimum standards specified for Cooperative Weather Station observations (NWS 1989; section on rain gauges reproduced herein in Appendix B). Whatever rain gauge is chosen, it should be read daily because it is necessary to compare onsite and nearby NWS data for daily differences in order to interpret the source of discrepancies. Gauge quality and installation should be reported in studies using unofficial data; a sample form for such reporting is included in Appendix C.

Because wind turbulence varies with shelter and topographic setting (Smith 1993), a rain gauge should be located with care. The NWS recommends that

Gages should not be located close to isolated obstructions such as trees and buildings, which may deflect precipitation due to erratic turbulence. Gages should not be located in wide-open spaces or on elevated sites, such as tops of buildings, because of wind and the resulting turbulence problems. The best location is where the gage is uniformly protected in all directions, such as in an opening 
in a grove of trees. The height of the protection should not exceed twice its distance from the gage. As a general rule, the windier the gage location is, the greater the precipitation error will be. (NWS 1989, p. 6)

This advice is essentially the same as the more recent recommendations by the World Meteorological Organization (1996) and the US Environmental Protection Agency (Finkelstein et al. 1983). Advice regarding installation in forests has not been located, but a knowledge of rainfall interception by forest canopies suggests that rain gauges should not be located under trees, because precipitation interception will vary with canopy closure and age and with storm intensity and duration (Smith 1993).

\subsubsection{Interpreting Onsite Precipitation Data}

In order to check the accuracy of records from unofficial rain gauges it is necessary to plot daily precipitation data from both the unofficial and nearby official weather stations on the same graph (Figure 3). If practicable, several official weather stations should be used, even if they are located fairly far apart. This way it can be determined how much rainfall varies in the geographic region and whether the unofficial rain gauge varies by comparable amounts. Topographic variability between stations should be taken into account when comparing one station with another. Generally, rain gauges closer to one another report more similar records than those further apart. Using this method, anomalies in the unofficial record should be obvious.

Figure 3 shows such a plot for an unofficial rain gauge in southeast Indiana (Wetland Research Site, black bars) and for three official sites within 20 miles of the research site. A year's worth of data is presented. Note the variability among official weather stations, for example, in the first week in January. All stations had over an inch of precipitation on the $4^{\text {th }}$ and $5^{\text {th }}$ of January, but the precipitation fell over two days at North Vernon and Seymore and fell in one day at Scottsburg.

On February 16 and 17 the research station reported two precipitation events, one as snow and one as rainfall; temperatures on both days remained below freezing. Only one event was reported at the official stations. A subsequent telephone call to the operator showed that the second record was a conversion to wet precipitation amounts; the erroneous entry was left in Figure 3 to illustrate such problems with raw data. Two lessons can be learned here: (1) Raw field data are bound to have inconsistencies and need to be scrutinized before final publication. This is why the NWS submits all data to quality-control procedures. (2) Temporarily installed rain gauges bought from environmental supply houses are often unheated and therefore do not record snowfall accurately, as was the case with this unofficial rain gauge, too.

There seem to be no inconsistencies in the March records. The lone precipitation record at North Vernon on the $31^{\text {st }}$ was probably part of the same system that delivered precipitation at all four stations on April $1^{\text {st }}$. One wonders whether precipitation on April 10-12 was accurately reported; temporal distributions would have been more consistent had the April 12 rainfall at the research site occurred on the same day as the three official stations. Rainfall on May 13, July 2, and November 15 was higher at the research site than at the official stations, but not so high as to seriously question the accuracy of the readings without statistical analyses of variance for the entire period of record..

Such informal comparisons of readings at the unofficial and official sites indicate that precipitation fell at all four stations in the same patterns. Therefore, antecedent precipitation at the research site could be evaluated using analyses from the surrounding official weather stations, as in Figure 4. 

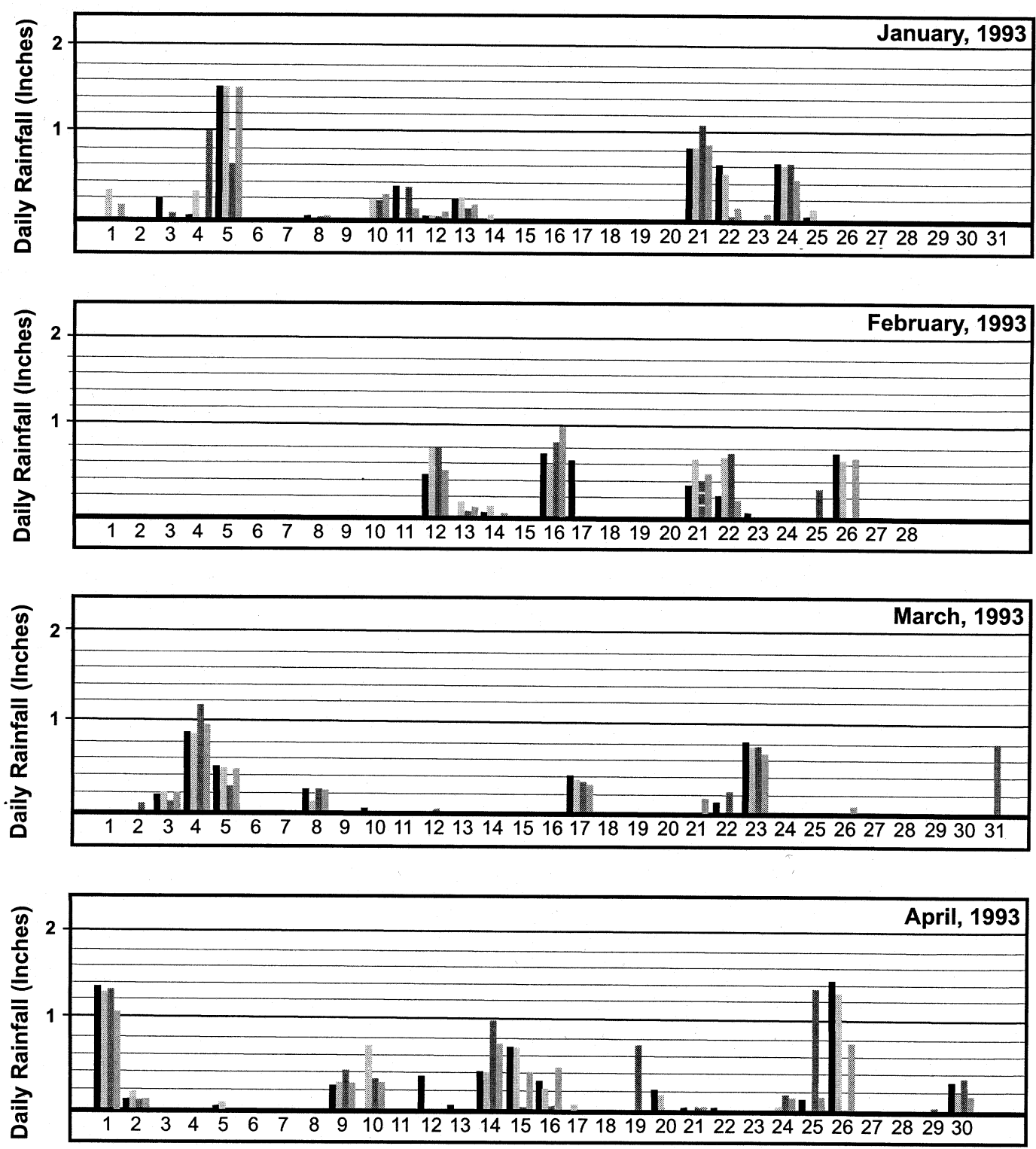

Wetland Research Site, Jackson and Jennings Counties, IN Seymour NWS Station, Jackson County, IN

II North Vernon NWS Station, Jennings County, IN

Scottsburg NWS Station, Scott County, IN

Figure 3. Example of comparison of data from unofficial weather station (black bars; Jenkinson and Franzmeier 1996) and from surrounding official NWS weather stations (gray bars; NOAA 1994). The data from the unofficial station are plotted from uncorrected field sheets (Jenkinson, personal communication, 1998). Note variability between NWS sites. Precipitation amounts recorded at the unofficial site were similar to those reported at the NWS stations and could therefore be accepted as reasonably accurate (Sheet 1 of 3 ) 

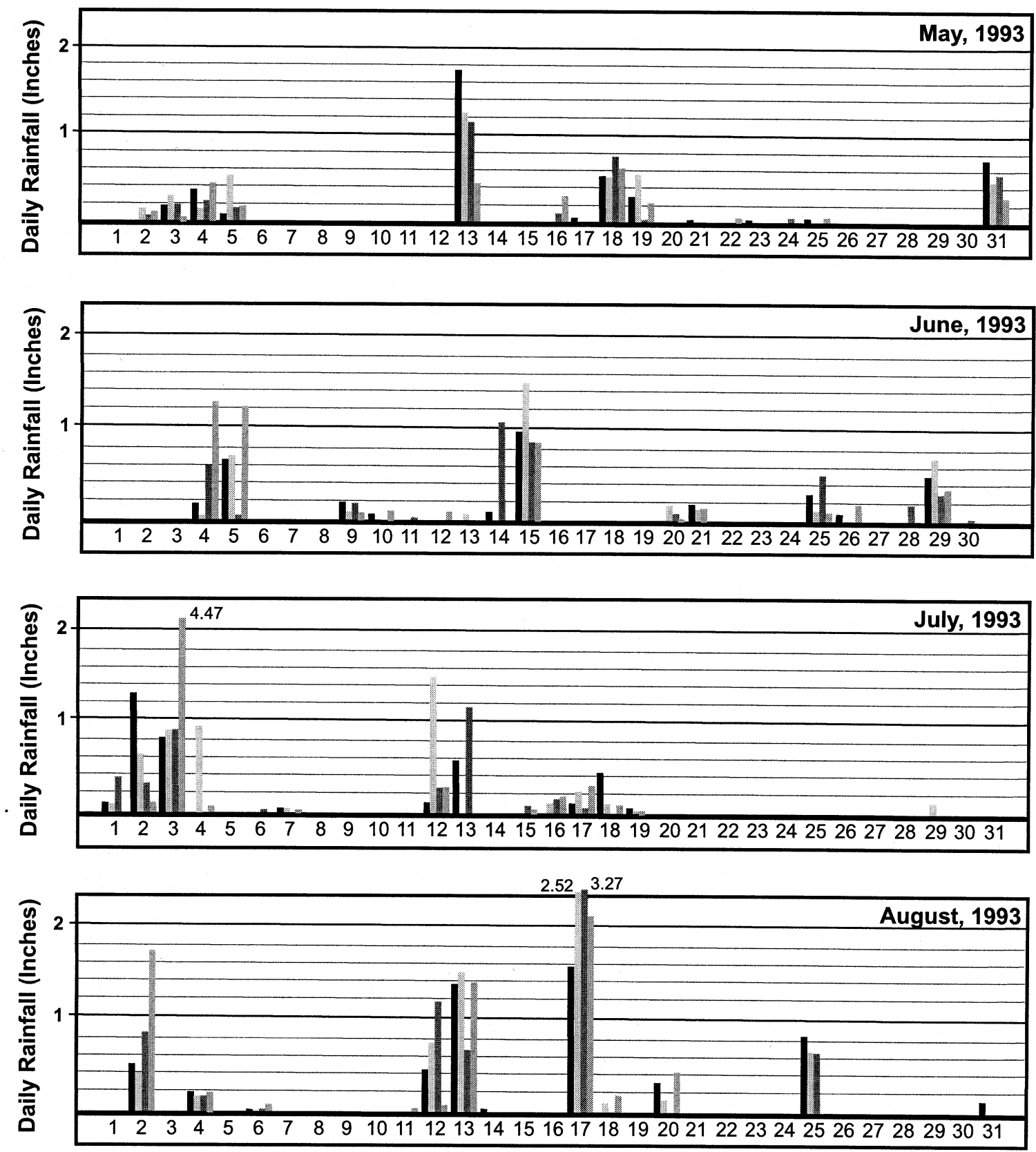

I Wetland Research Site, Jackson and Jennings Counties, IN Seymour NWS Station, Jackson County, IN

North Vernon NWS Station, Jennings County, IN

ScottsburgNWS Station, Scott County, IN

Figure 3. (Sheet 2 of 3 ) 

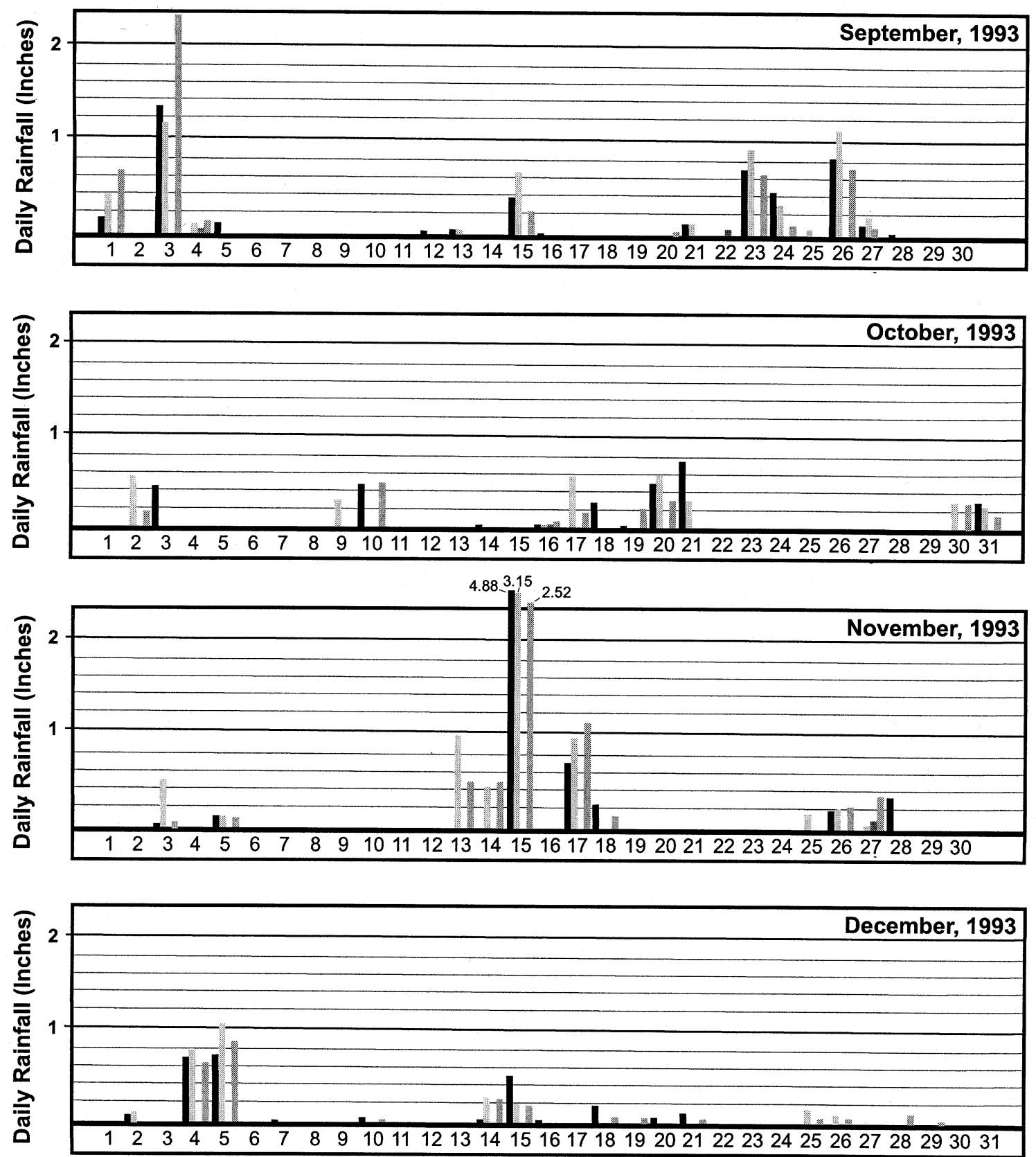

I Wetland Research Site, Jackson and Jennings Counties, IN Seymour NWS Station, Jackson County, IN

I North Vernon NWS Station, Jennings County, IN

Scottsburg NWS Station, Scott County, IN

Figure 3. (Sheet 3 of 3 ) 


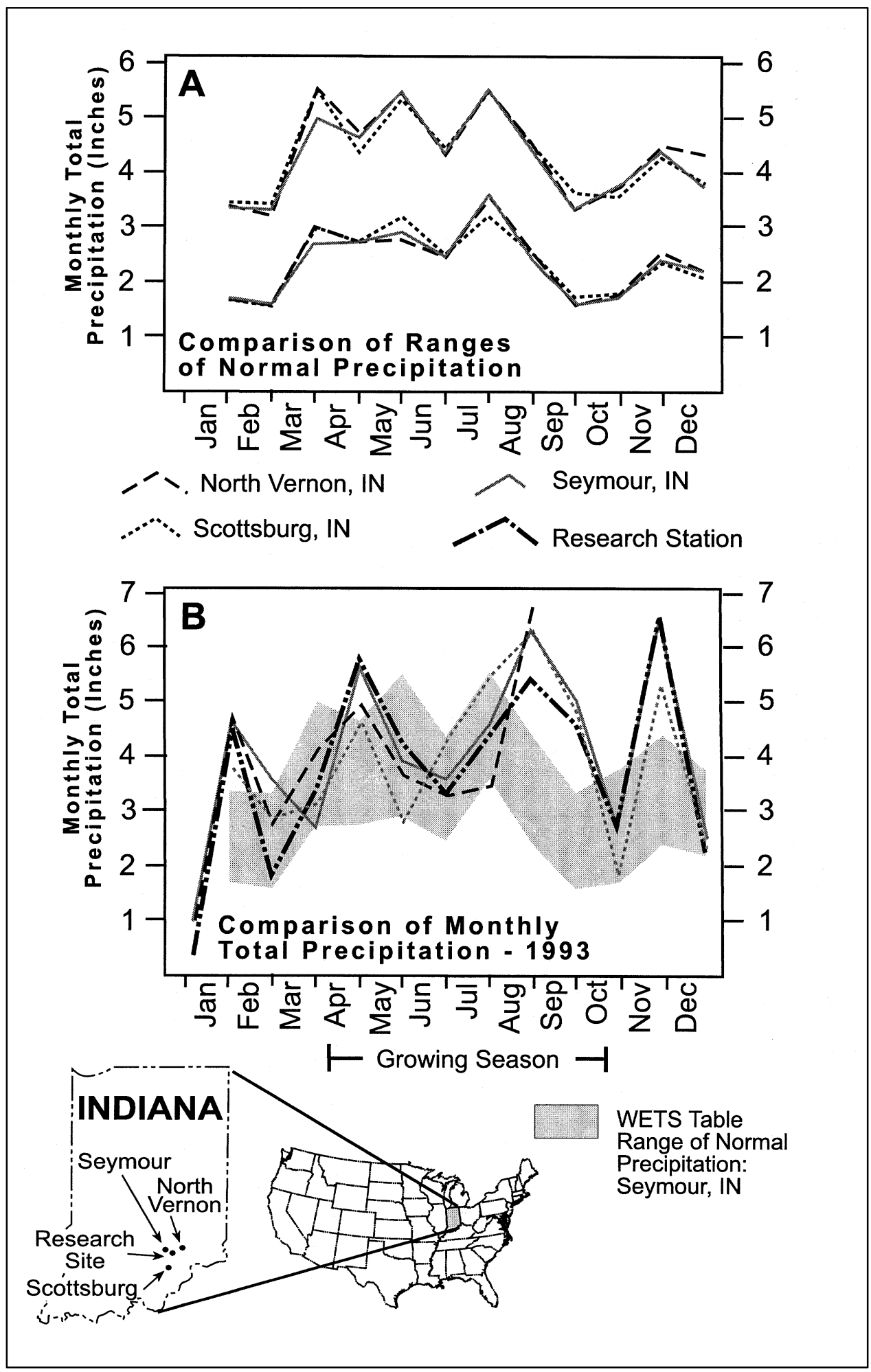

Figure 4. A. Ranges of normal for monthly precipitation at three NWS stations in Indiana (NWCC 1996). B. Actual monthly precipitation totals at three NWS stations and a research station in Indiana, superimposed on a graph of average range of normal monthly precipitation at the NWS stations (gray) 
Figure 4A shows the monthly ranges of normal for the three NWS stations. Because differences between ranges of normal were so small, it is acceptable to use any of these ranges of normal to evaluate precipitation data at the research site. As a general policy, ranges of normal at nearby stations should be compared to assure that elevation and physiography are not producing systematic differences between weather stations.

Comparison of onsite and offsite data (Figure 4B) indicates that precipitation was within the range of normal in February, March, May, June, July, October, and December. In this case these same conclusions would have been reached without the onsite data, but with less confidence. One can envision situations where several nearby NWS stations have similar precipitation amounts that straddle the boundary between normal and above normal; for example, if April precipitation had been slightly less at all stations in Figure 4B. Onsite data are helpful in such cases where data from official stations fall on either side of a boundary of normal.

\subsubsection{Summary of Use of Onsite Rain Gauges}

1. Onsite rain gauges can identify onsite precipitation events that differ significantly from those recorded at nearby NWS stations.

2. Onsite rain gauges should meet minimum quality standards described in NWS Observing Handbook No. 2 (NWS 1989) (pertinent section reproduced in Appendix B).

3. Onsite rain gauges should be installed in somewhat sheltered areas, but the distance from sheltering trees or buildings should be at least twice the height of the trees or buildings.

4. Onsite rain gauges should be read daily, and for a long enough monitoring period to develop a record that can be confidently compared with records from nearby NWS stations.

5. Data from onsite rain gauges need to be compared with data from several nearby NWS stations to check for deviations from regional patterns. Such comparisons can be easily performed by plotting daily data (onsite and NWS) on the same chronological graph.

6. Discrepancies between temporal patterns of onsite and NWS data need to be explained. If unofficial data track the official data for most storm events, then the data can probably be trusted, and an anomalous rainfall record at one site probably reflects genuine geographic variability. However, if the data at the official stations track together and the data from the unofficial site do not, then the unofficial data set should be evaluated for errors. Numerous differences would call into question the data from the onsite rain gauge. 


\section{EVALUATING ANTECEDENT PRECIPITATION CONDITIONS AT A SITE}

This section presents three alternate procedures to evaluate whether precipitation prior to a particular date was within the range of normal for a particular reporting station. The first and simplest method utilizes monthly precipitation data and the WETS Tables, and is taken from the NRCS Engineering Field Handbook (NRCS 1997). The second method evaluates daily precipitation data on the basis of 30-day rolling sums. The third method combines the two procedures.

\subsection{NRCS ENGINEERING FIELD HANDBOOK}

\subsubsection{Background}

The NRCS Engineering Field Handbook (NRCS 1997; hereafter "the NRCS method") presents a procedure to systematically evaluate rainfall conditions for the three-month period prior to the site investigation. The method is summarized below; the complete procedure can be found on pages 24-26 of "Hydrology Tools for Wetland Determination," which can be downloaded as a .pdf file at http://www.wcc.nrcs.usda.gov/water/quality/text/hydrolog.html.

The methodology calculates a numerical rating of prior precipitation by weighting the data for both (1) amount of precipitation, and (2) relative age of a rainfall event (Warne and Woodward 1998; Woodward et al. 1996). These two weighting factors ("departure from normal" and "recentness") are multiplied to give a numerical rating that is used to decide whether the prior precipitation for the entire 3-month period was within the range of normal or not. The procedure is as follows:

\subsubsection{NRCS Method for Estimating Antecedent Moisture Conditions at a Site.}

Using the NRCS rainfall documentation sheet (Figure 5; values entered for an example from Grand Island, NE).

a. Fill out the background information (Weather Station and Growing Season from WETS Table, Figure 1). "Photo date" is the date of a hydrologic observation.

b. Fill in the "Month" column. Usually the " $1^{\text {st }}$ prior month" is the month of the hydrologic observation. When hydrologic observations were made early in a calendar month, the " 1 st prior month" might be evaluated better as the preceding calendar month. The entire month's worth of rainfall is entered in this column because this method assumes that only monthly totals of precipitation are available.

c. Fill in the columns " 3 yrs. in 10 less than" and " 3 yrs. in 10 more than." using information from the station's WETS table (Figure 1).

d. In column "rainfall" enter the actual rainfall that fell in months listed in the "Month" column.

e. Compare the actual rainfall amounts for each month with the ranges of normal you entered in the columns of long-term rainfall records. In the column "Condition dry, wet, normal" enter "dry," "wet," or "normal," depending on the comparison between actual rainfall and long-term ranges of normal. 
f. In the column "Condition value," enter the appropriate "condition value" from the small table immediately below. For example, if the actual rainfall was wetter than normal, then enter condition value "3."

g. Multiply the "condition value" by the "Month weight factor" to obtain the value to enter into the column "Product of previous two columns."

h. Add the three products in the last column to obtain the "sum" at the bottom of that column. The sum should be a whole number between 6 and 18 .

i. Conclude whether the prior period was drier than normal, normal, or wetter than normal by comparing the calculated sum to the small look-up table in the Note below the first three columns of Figure 5.

\subsubsection{Comments on the NRCS Method.}

The NRCS method has the advantages of considering data from the previous three months rather than just one, of weighting those data for length of time since the precipitation contributed to the water budget, of using easily accessible information, and of being simple to apply. It has obvious weaknesses, the most important being the assumption that rainfall was evenly distributed during the month of observation. Nevertheless, the method is a significant improvement on the situation of ignoring antecedent precipitation inputs into site hydrology. Some of the assumptions one must be aware of when using the method are:

- that rain was evenly distributed for the month of observation. The importance of this assumption is magnified by the fact that the "recency" weighting factor is largest for the month of observation.

- $\quad$ that three months is the proper length of time to evaluate antecedent precipitation.

Evapotranspiration becomes more intense during the middle of the growing season and therefore surface and near surface residence times may be much less than three months. Furthermore, antecedent precipitation typically influences flooded, open system wetlands differently than closed depressions or in seeps.

- $\quad$ that snowmelt contributes to wetland hydrology the same as rainfall.

\subsection{METHOD OF ROLLING TOTALS}

\subsubsection{Background}

The NRCS Engineering Field Handbook compares actual precipitation with monthly ranges of normal by accessing published monthly rainfall summaries from NOAA and National Water and Climate Center (NWCC). Precipitation patterns within a particular month are not reflected in monthly totals. Because the period of continuous inundation required for wetland hydrology is less than a month, it is commonly desirable and necessary to utilize and evaluate higher frequency (daily) precipitation data. The 30-day rolling total is technically more sound than monthly totals in that monthly totals are reset to zero at the beginning of each month and therefore may not accurately reflect antecedent rainfall in the middle of the month.

The 30-day rolling total is generated by summing the past 30 days' precipitation. By continually updating a tally of the prior 30-day rainfall totals, one can plot a record of rainfall for the immediately preceding 30 days of rain on a daily basis (for example, Figure 6). Overlaying a plot of range of normal 


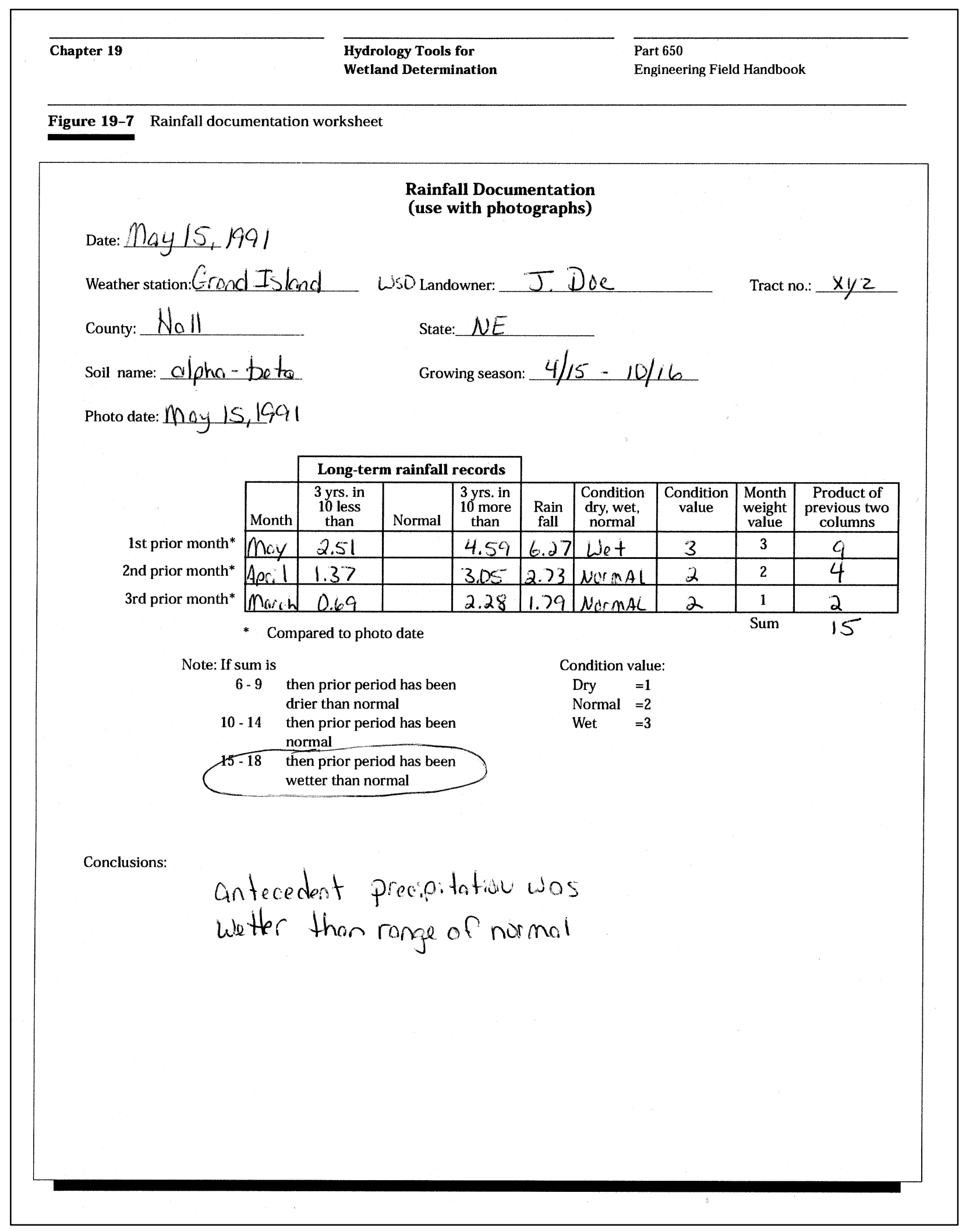

Figure 5. Worksheet to determine whether precipitation was within the range of normal prior to a site visit, taken from the NRCS Engineering Field Handbook, Chapter 19 (NRCS 1997) 


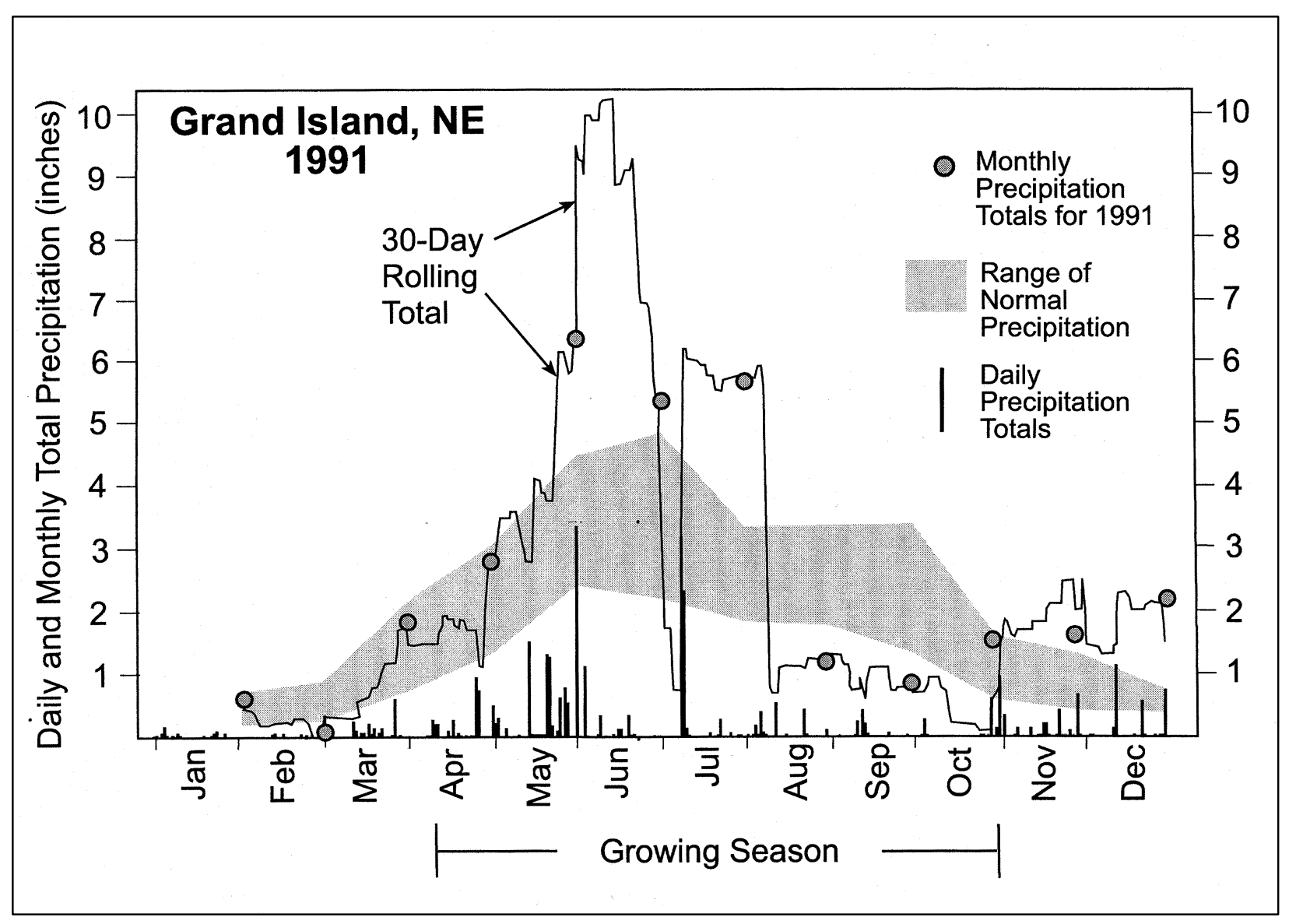

Figure 6. 30-day rolling totals of precipitation at Grand Island, NE, overlaid on graph of daily precipitation and monthly precipitation, with range of normal in gray

precipitation on such a daily plot allows the delineator to evaluate whether antecedent precipitation was greater or less than normal throughout a month rather than just at the beginning or end.

\subsubsection{Procedure of 30-day Rolling Totals}

The procedure of 30-day rolling totals consists of three parts:

1. Calculating and plotting 30-day rolling totals for the time period of interest (Figure 6 and Table 2).

2. Overlaying a plot of monthly ranges of normal on the plot of 30-day rolling totals (Figure 6).

3. Comparing the rolling 30-day sums to the monthly ranges of normal to determine whether antecedent precipitation was within the range of normal.

\section{Preparing a plot of 30-day rolling totals and monthly ranges of normal (Figure 6)}

The graphics needed for the method of 30-day running totals are prepared as follows. Continuing with the Grand Island example, Table 2 shows the 30-day rolling total calculated for February through May 1991. 


\begin{tabular}{|c|c|c|c|c|c|c|c|c|}
\hline \multicolumn{9}{|c|}{$\begin{array}{l}\text { Table 2. Daily Precipitation and 30-day Rolling Totals for Jan-May } 1991 \text { at Grand Island, } \\
\text { NE (NOAA 1992). }\end{array}$} \\
\hline Date & $\begin{array}{c}\text { Daily } \\
\text { Precip } \\
\end{array}$ & $\begin{array}{c}\text { 30-day } \\
\text { Rolling Total } \\
\end{array}$ & Date & $\begin{array}{c}\text { Daily } \\
\text { Precip } \\
\end{array}$ & \begin{tabular}{|c|} 
30-day \\
Rolling Total \\
\end{tabular} & Date & $\begin{array}{c}\text { Daily } \\
\text { Precip } \\
\end{array}$ & $\begin{array}{c}\text { 30-day } \\
\text { Rolling Total } \\
\end{array}$ \\
\hline 1-Jan & & & $15-\mathrm{Feb}$ & & 0.27 & 1-Apr & 0.06 & 1.53 \\
\hline 2-Jan & & & $16-\mathrm{Feb}$ & & 0.27 & 2-Apr & & 1.53 \\
\hline 3-Jan & & & $17-\mathrm{Feb}$ & 0.05 & 0.32 & 3-Apr & & 1.53 \\
\hline 4-Jan & 0.05 & & 18-Feb & 0.01 & 0.33 & 4-Apr & & 1.53 \\
\hline 5-Jan & 0.15 & & $19-\mathrm{Feb}$ & & 0.33 & 5-Apr & & 1.53 \\
\hline 6-Jan & & & $20-\mathrm{Feb}$ & & 0.33 & 6-Apr & & 1.53 \\
\hline 7-Jan & & & $21-\mathrm{Feb}$ & & 0.33 & 7-Apr & & 1.53 \\
\hline 8-Jan & & & $22-\mathrm{Feb}$ & & 0.3 & 8-Apr & & 1.53 \\
\hline 9-Jan & & & 23-Feb & & 0.23 & 9-Apr & & 1.53 \\
\hline 10-Jan & 0.05 & & 24-Feb & & 0.13 & 10-Apr & & 1.53 \\
\hline 11-Jan & & & $25-\mathrm{Feb}$ & & 0.13 & 11-Apr & 0.43 & 1.75 \\
\hline 12-Jan & & & $26-\mathrm{Feb}$ & & 0.13 & 12-Apr & 0.17 & 1.83 \\
\hline 13-Jan & & & $27-\mathrm{Feb}$ & & 0.13 & 13-Apr & 0.17 & 2 \\
\hline 14-Jan & & & $28-\mathrm{Feb}$ & & 0.06 & 14-Apr & & 1.94 \\
\hline 15-Jan & & & 1-Mar & 0.32 & 0.38 & 15-Apr & & 1.94 \\
\hline 16-Jan & & & 2-Mar & & 0.38 & 16-Apr & & 1.79 \\
\hline 17-Jan & & & 3-Mar & & 0.38 & 17-Apr & 0.08 & 1.87 \\
\hline 18-Jan & & & 4-Mar & & 0.38 & 18-Apr & 0.01 & 1.77 \\
\hline 19-Jan & & & 5-Mar & & 0.38 & 19-Apr & 0.21 & 1.93 \\
\hline 20-Jan & & & 6-Mar & & 0.38 & 20-Apr & & 1.84 \\
\hline 21-Jan & & & 7-Mar & & 0.38 & 21-Apr & 0.06 & 1.73 \\
\hline 22-Jan & & & 8-Mar & & 0.38 & 22-Apr & & 1.73 \\
\hline 23-Jan & 0.03 & & 9-Mar & & 0.38 & 23-Apr & & 1.73 \\
\hline 24-Jan & 0.07 & & 10-Mar & & 0.38 & 24-Apr & & 1.73 \\
\hline 25-Jan & 0.1 & & 11-Mar & & 0.38 & 25-Apr & & 1.7 \\
\hline 26-Jan & & & 12-Mar & 0.21 & 0.59 & 26-Apr & & 1.19 \\
\hline 27-Jan & & & 13-Mar & 0.09 & 0.68 & 27-Apr & & 1.19 \\
\hline 28-Jan & & & 14-Mar & & 0.68 & 28-Apr & 0.86 & 2.05 \\
\hline 29-Jan & 0.07 & & 15-Mar & 0.06 & 0.74 & 29-Apr & 0.68 & 2.73 \\
\hline 30-Jan & & 0.52 & 16-Mar & & 0.74 & 30-Apr & & 2.73 \\
\hline 31-Jan & & 0.52 & 17-Mar & 0.15 & 0.89 & 1-May & & 2.67 \\
\hline 1-Feb & & 0.52 & 18-Mar & & 0.89 & 2-May & 0.4 & 3.07 \\
\hline 2-Feb & & 0.52 & 19-Mar & 0.11 & 0.95 & 3-May & 0.18 & 3.25 \\
\hline 3-Feb & & 0.47 & 20-Mar & 0.05 & 0.99 & 4-May & 0.24 & 3.49 \\
\hline 4-Feb & & 0.32 & 21-Mar & 0.09 & 1.08 & 5-May & & 3.49 \\
\hline 5-Feb & & 0.32 & 22-Mar & 0.17 & 1.25 & 6-May & & 3.49 \\
\hline 6-Feb & & 0.32 & 23-Mar & & 1.25 & 7-May & 0.09 & 3.58 \\
\hline 7-Feb & & 0.32 & 24-Mar & & 1.25 & 8-May & & 3.58 \\
\hline 8-Feb & & 0.32 & 25-Mar & & 1.25 & 9-May & & 3.58 \\
\hline 9-Feb & & 0.27 & 26-Mar & 0.03 & 1.28 & 10-May & & 3.58 \\
\hline $10-\mathrm{Feb}$ & & 0.27 & 27-Mar & 0.51 & 1.79 & 11-May & & 3.15 \\
\hline 11-Feb & & 0.27 & 28-Mar & & 1.79 & 12-May & & 2.98 \\
\hline 12-Feb & & 0.27 & 29-Mar & & 1.79 & 13-May & & 2.81 \\
\hline 13-Feb & & 0.27 & 30-Mar & & 1.79 & 14-May & & 2.81 \\
\hline 14-Feb & & 0.27 & 31-Mar & & 1.47 & 15-May & & 2.81 \\
\hline
\end{tabular}


1. In a 3-column table, tally date and daily precipitation for the 120 days preceding a site observation (the three columns in Table 2 are wrapped to fit on the page).

2. Starting with the 30th day, total the precipitation amounts for that day and the preceding 29 days; enter the sum in the third column, "30-day Rolling Total." This tedious calculation can be automated in most personal computer spread sheet software programs by copying and pasting the first instance of the command into subsequent rows of the third column. In Microsoft Excel (Microsoft Corporation 19851997) the command is "=sum(b1:b30)."

3. Plot Column 3 against Column 1 (30-day rolling total against time, as in Figure 6).

4. Superimpose the monthly ranges of normal from the appropriate WETS Table. Plot the ranges of normal for each month at the end of that particular month, rather than the beginning or middle, because the range of normal from the WETS Table is for the preceding days of the month (preceding 28/29, 30, or 31 days).

5. Superimpose the daily rainfall data ("spike graph") to provide details of the distribution of rainfall within the months of interest.

\subsubsection{Determining Whether Tallied Precipitation Was Within Range of Normal}

Deviation from the range of normal precipitation is determined by use of the superimposed plots of 30-day rolling totals and ranges of normal precipitation for the period of interest (for example, Figure 6). Daily precipitation data should also be superimposed on such graphs in order to understand how the 30-day rolling totals evolved.

Using this methodology it is seen that in 1991 at Grand Island, January, March, and April precipitation levels were largely within the range of normal, and February precipitation was slightly below normal. The first half of May was within the range of normal until May 16 when a 1.35-inch rain caused the 30-day total to rise above the range of normal. Between May 23 and May 25, 2.33 inches of rain fell at the weather station, which caused the 30-day rolling sum to rise significantly above normal, where it stayed for the rest of the summer, except for a short period in early July. Scanty rains in the last half of July initiated a drought that lasted well into the fall. November and December precipitation levels were above normal.

\subsubsection{Comments on the Method of 30-day Rolling Totals}

The strength of the method of 30-day rolling totals can be seen by comparing it to the method of monthly totals used by the WETS Tables (Figures 1 and 6). The two methods agree that precipitation levels in January, March, and April were within the range of normal and that February was slightly drier than normal. Note, however, that the monthly tallies of the WETS Tables indicate that May was significantly wetter than normal whereas the more detailed method of 30-day rolling totals detected that the heavy rains of the wet summer did not occur until the middle and, especially, the end of May. Detailed knowledge of rainfall distributions in early May could have been particularly important to wetland scientists because that is shortly after the beginning of the regulatory growing season when field decisions were likely to have been made. The method of 30-day rolling totals provides a more accurate assessment of antecedent moisture conditions at a site than do monthly averages, which artificially zero rainfall totals at the beginning of each month. 
However, the method of rolling sums also artificially zeroes rainfall after 30 days. Note in Figure 6 that 30-day rolling precipitation totals were much above normal for most of July and early August, despite the fact that daily rainfall records show most of July was dry (spike graph at bottom of Figure 6). Furthermore, antecedent precipitation levels fell from much above normal to well below normal within a space of three days in early August. This is a direct consequence of the method of calculating a 30-day rolling sum. A large input remains within the rolling sum for exactly 30 days, and then abruptly drops out of the rolling total. In loamy and finer textured soils, changes in water tables are unlikely to be so abrupt.

The method of rolling totals is often used to track the influence of antecedent precipitation on water levels in monitoring wells. It is well suited for this purpose because each well reading can be compared to an updated tally of antecedent precipitation.

\subsection{COMBINED METHOD OF 30-DAY ROLLING TOTALS AND NRCS ENGINEERING FIELD HANDBOOK WEIGHTING FACTORS.}

Combining the method of 30-day rolling totals with the NRCS Engineering Field Handbook method of weighting antecedent precipitation is appropriate where precipitation influences site hydrology for two or three months.

\subsubsection{Procedure for Combining the Methods of 30-day Rolling Totals and NRCS Engineering Field Handbook Weighting Factors.}

1. On the plot of 30-day rolling totals (Figure 7) mark off 30-day blocks starting backward from the date of interest. Continuing with the Grand Island example, if a wetland is delineated on May 15, the plot of 30-day rolling totals would be blocked off into 30-day blocks: April 16-May 15; March 17-April 15; and February 15 - March 16.

2. Decide whether the 30-day blocks reflect normal, drier than normal, or wetter than normal precipitation by comparing the 30-day rolling totals with the ranges of monthly normal. Some of these decisions will require professional judgment.

3. Record your decisions for the 30-day blocks in the Rainfall Documentation Form in the column labeled "Condition dry, wet, normal" (Table 3).

4. Fill out the subsequent columns of the form as instructed for the Engineering Field Handbook method (Section 4.1.2).

\subsubsection{Comments on the Combined Method}

The combined method rated the three-months' precipitation prior to May 15 as being normal whereas the NRCS Engineering Field Handbook method rated it as wetter than normal (Table 3). The difference is the ability to calculate 30-day increments starting on any date rather than only at the beginning of the calendar month. Frequent use of the combined method will show how difficult it is to decide whether a particular 30-day period of rolling totals falls on one side of a threshold of normal or on the other side. For example, it would be a close call to decide whether the period of April 24 to May 23, 1991, was within or above the range of normal. 


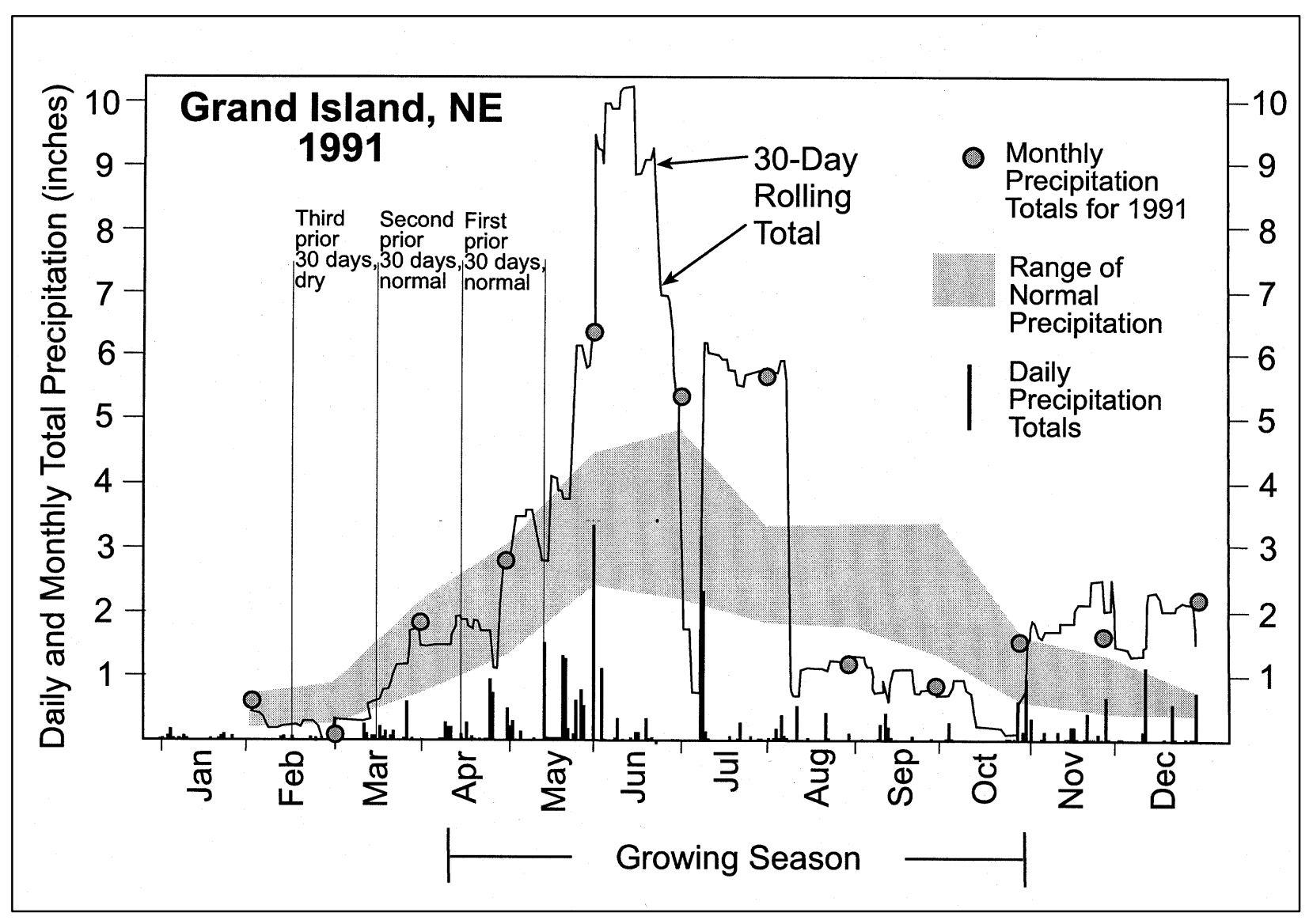

Figure 7. Three 30-day periods prior to May 15, superimposed on Figure 6

\begin{tabular}{|c|c|c|c|c|c|c|c|c|c|}
\hline \multicolumn{10}{|c|}{ Engineering Field Handbook Method } \\
\hline & Month & $30^{\text {th }} \%$ ile & Normal & $70^{\text {th }} \%$ ile & Rainfall & $\begin{array}{l}\text { Dry, Wet, } \\
\text { Normal }\end{array}$ & $\begin{array}{l}\text { Condition } \\
\text { Value }\end{array}$ & $\begin{array}{l}\text { Weight } \\
\text { Value }\end{array}$ & $\begin{array}{l}\text { Product of } \\
\text { Values }\end{array}$ \\
\hline 1 st $\mathrm{mo}$ & May & 2.51 & & 4.59 & 6.27 & Wet & 3 & 3 & 9 \\
\hline $2^{\text {nd }} \mathrm{mo}$ & April & 1.37 & & 3.05 & 2.73 & Normal & 2 & 2 & 4 \\
\hline \multirow[t]{2}{*}{$3^{\text {rd }} \mathrm{mo}$} & March & 0.69 & & 2.28 & 1.79 & Normal & 2 & 1 & 2 \\
\hline & & & & & & & & & $\begin{array}{l}\text { sum }=15 \\
\text { wetter than } \\
\text { normal }\end{array}$ \\
\hline \multicolumn{10}{|c|}{ Combined Method } \\
\hline $1^{\text {st }} \mathrm{mo}$ & $\begin{array}{l}4 / 16- \\
5 / 15\end{array}$ & See Fig 7 & & See Fig 7 & See Fig 7 & Normal & 2 & 3 & 6 \\
\hline $2^{\text {nd }} \mathrm{mo}$ & $\begin{array}{l}3 / 17- \\
4 / 15\end{array}$ & See Fig 7 & & See Fig 7 & See Fig 7 & Normal & 2 & 2 & 4 \\
\hline \multirow[t]{2}{*}{$3^{\text {rd }} \mathrm{mo}$} & $\begin{array}{l}2 / 15- \\
3 / 16\end{array}$ & See Fig 7 & & See Fig 7 & See Fig 7 & Dry & 1 & 1 & 1 \\
\hline & & & & & & & & & $\begin{array}{c}\text { sum }=11 \\
\text { normal }\end{array}$ \\
\hline
\end{tabular}




\subsection{GENERAL OBSERVATIONS ON ASSESSMENTS OF ANTECEDENT PRECIPITATION}

- $\quad$ The WETS Tables alone are quickest and probably sufficient to use when simple generalizations about long-term trends are all that is needed.

- The method of the Engineering Field Handbook will perforce be used when daily precipitation data are not readily available.

- $\quad$ The simple method of 30-day rolling totals is readily used with long sets of monitoring well data because of ease of plotting information. These plots, when superimposed on a daily precipitation spike graph, provide a powerful tool for explaining water well fluctuations.

- The combined method is useful for making decisions regarding individual dates of observation at a site. Whenever feasible, the monthly analyses should be interpreted using the daily data from which the monthly summaries were aggregated.

- $\quad$ The methods of the WETS Tables and rolling totals should be used in conjunction with indices of longer term hydrologic input, such as the Palmer drought indices, the Standardized Precipitation Index, and/or USGS stream gauge analyses (Section 6 below). The longer term record (many months to a year) may show the presence of a prolonged drought; a couple of months of normal rain- fall in the middle of the drought may not raise water tables to levels typical outside of the drought.

- The WETS Tables evaluate the range of normal precipitation in monthly increments. Antecedent precipitation probably does not affect wetland hydrology in monthly or 30-day increments. The Standard Precipitation Index and Palmer drought indices (Section 6) have more flexible periods of evaluation of antecedent conditions.

- Antecedent precipitation is only one part of the water budget. The other parts of the water budget need to be considered when interpreting observed levels of ground or surface water.

- $\quad$ The duration of impact of antecedent precipitation typically varies with the seasons. In the early spring, when evapotranspiration (ET) is low, there is probably a longer duration impact of prior precipitation than later in the summer when ET is high.

- The duration of influence of antecedent precipitation on wetland hydrology does not seem to have been studied. The NRCS hydrologists chose three months as a reasonable length of time to evaluate antecedent precipitation for Food Security Act programs. The National Drought Mitigation Center (NDMC) reports a three-month calculation of their Standardized Precipitation Index at their Web page of drought estimates for the Nation (http://enso.unl.edu/monitor/current.html). In default of site-specific information to the contrary, three months preceding a date of site monitoring seems to be a reasonable length of time to evaluate whether precipitation was within the range of normal.

- There is no way to remove professional judgment in borderline situations. Remember that the limits of the range of normal ( $30^{\text {th }}$ and $70^{\text {th }}$ percentiles) are themselves professional judgments. Moreover, when antecedent precipitation levels are close to thresholds of normal, uncertainties about other parts of the water budget become a major consideration. 


\section{GROWING SEASON}

Guidance of 6 March 1992 (Office of the Chief of Engineers, 6 March 1992, para. 3.b.) allows determination of the regulatory growing season with reference to NRCS soil survey information. In 1992, the most current soil survey information was contained in soil survey reports, which may be more than a decade old. More current growing season information may be obtained from the NRCS WETS Tables at the bottom of the first page of the entry for each reporting station. For most of the Nation the wetland delineation growing season is approximated by the last and first dates with a 50 percent likelihood of $28^{\circ}$ $\mathrm{F}$ frost. In Wooster, $\mathrm{OH}$, for example, the growing season is April 23 to October 21 (Figure 8). The soil survey report (Soil Conservation Service 1984) gives the growing season as April 23 to October 18. The dates differ by three days at the end of the growing season (October 18 vs October 21) because the 1984 information was based on different baseline data (1951-1978 vs 1961-1990).

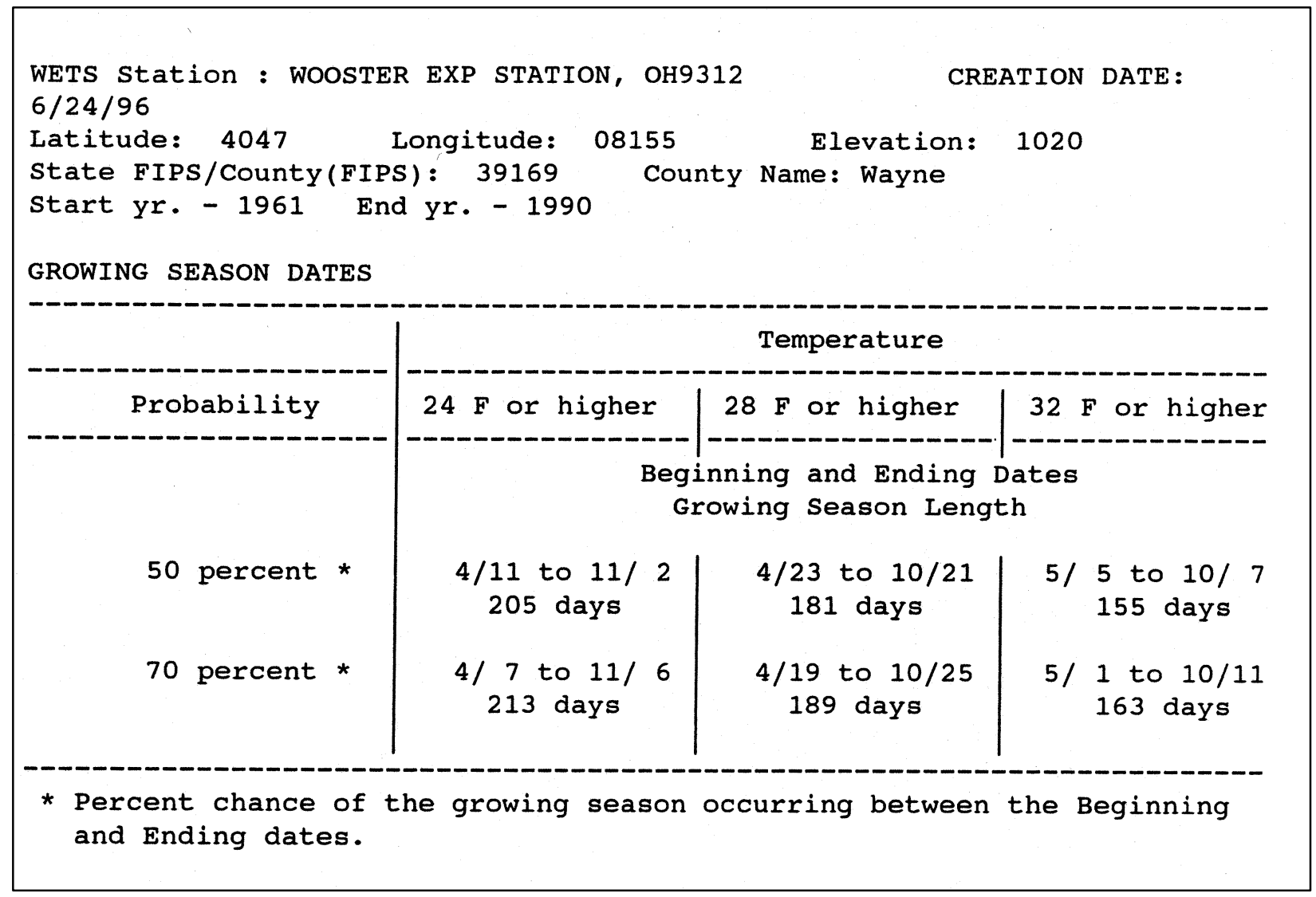

Figure 8. Growing season information as presented in WETS Tables, for Wooster, OH (NWCC 1996) 


\section{DROUGHT ANALYSES ON THE INTERNET}

There are several Internet Web sites that complement the NWCC WETS Tables by (1) providing near-real time precipitation information and (2) providing long-term frequency analyses of regional patterns of drought and moisture excess. These Web sites are not substitutes for analyses of site-specific data using the WETS Tables because of trade-offs made to develop real-time, regional assessments. However, one should utilize Web sites in order to get a sense of long-term climatic trends in the region. Three analyses are discussed here: (1) Palmer drought indices, (2) Standard Precipitation Index (SPI), and (3) USGS stream gauge data. The Palmer index is reported for the previous week and for previous months. The SPI is available for the previous month. USGS data are reported for the previous day, week, and month. All are reported as or can be converted to frequency probabilities.

The Palmer analyses incorporate precipitation, evapotranspiration, and regional soil properties and the SPI analyzes precipitation alone. The USGS analyses complement the Palmer and SPI analyses because they come from independent sources of information (stream flows vs weather). The authors recommend that wetland scientists consult both the USGS Web site and one of the climate Web sites to assess near-real time drought conditions. Final decisions involving quantitative evaluations of hydrology should be postponed until site-specific precipitation data can be collected and compared with the WETS data.

The NDMC provides maps of eight different indices or climatic conditions related to drought or moisture excess at http://enso.unl.edu/monitor/current.html. Indices and sites commonly do not map drought or moisture excess the same in the different climate divisions of the country. Users of these indices should compare them with each other to determine which ones seem most appropriate for their part of the Nation.

\subsection{PRELIMINARY NATURE OF NEAR-REAL TIME ANALYSES}

Near-real time drought indices are calculated from preliminary data that have not undergone quality-control protocols. Therefore, the Palmer drought indices and the Standardized Precipitation Index should probably not be used in reports until the indices have been recalculated with official data; this is especially true of the weekly updates of the Palmer indices published by the Climate Prediction Center (Section 6.2, below). Quality control is usually completed after three months time for the drought indices. The updated calculations are inserted into published files automatically, so indices for the preceding three months should be considered preliminary and those four months or older can be assumed official (R. Heim, NCDC, personal communication, July 1999). Changes in SPI data after quality control are usually so small that SPI indices are not updated on the NDMC Web pages (M. Svoboda, NDMC, July 1999, personal communication), the disclaimer at their Web site notwithstanding:

http://enso.unl.edu/ndmc/watch/datadis.htm.

Real-time stream gauge data, too, are preliminary and need to undergo quality-control protocols before being cited. The USGS disclaimer says that "data users are cautioned to consider carefully the provisional nature of the information before using it for decisions that concern personal or public safety or the conduct of business that involves substantial monetary or operational consequences" (USGS 1999a: http://water.usgs.gov/provisional.html).

\subsection{PALMER DROUGHT INDICES}

Every month the NCDC publishes four Palmer Drought Indices: Palmer Drought Severity Index (PDSI), Modified Palmer Drought Severity Index (MPDSI), Palmer Hydrological Drought Index (PHDI), and Palmer Z Index at the URL: http://www.ncdc.noaa.gov/onlineprod/drought/main.html.(Figure 9). The 


\section{Palmer Drought Data}

\section{Precipita tion (Inches)}

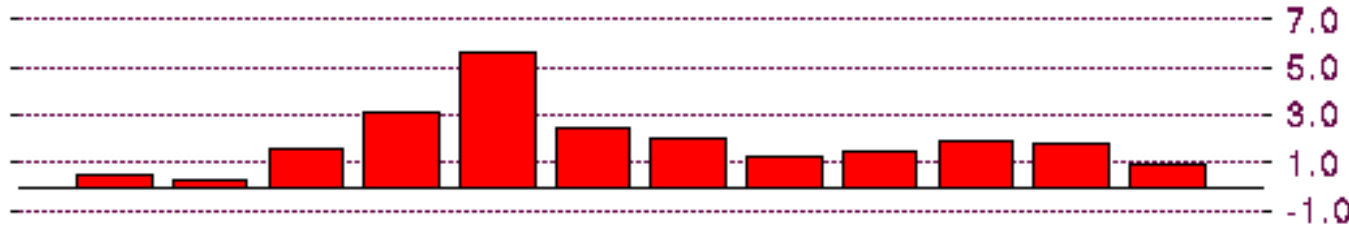

Pulner'Z ladex

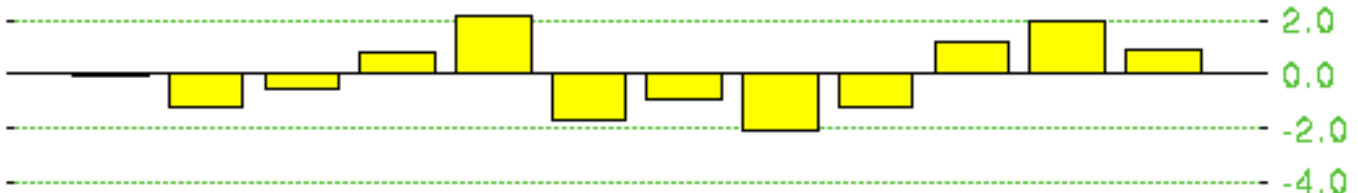

Modificd Palmer Drought Severily ladex

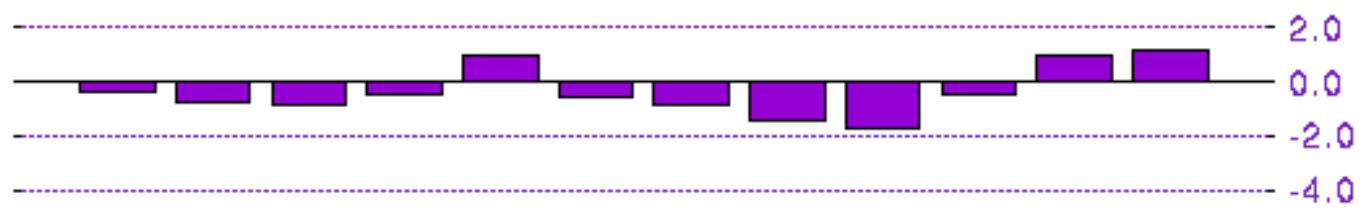

Palmer Hydrological Drougbt ladex

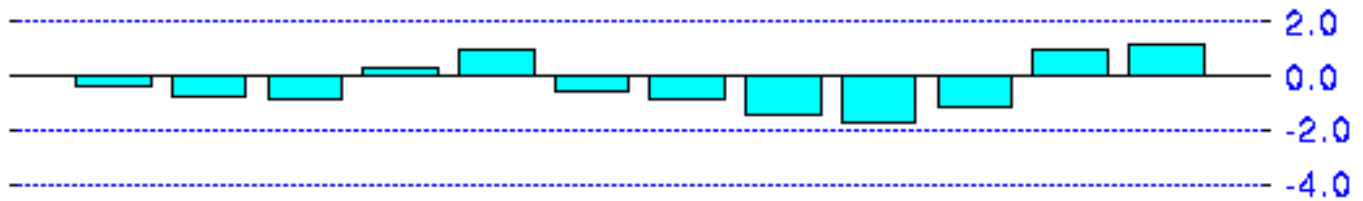

Palmer Drought Scverity ladex

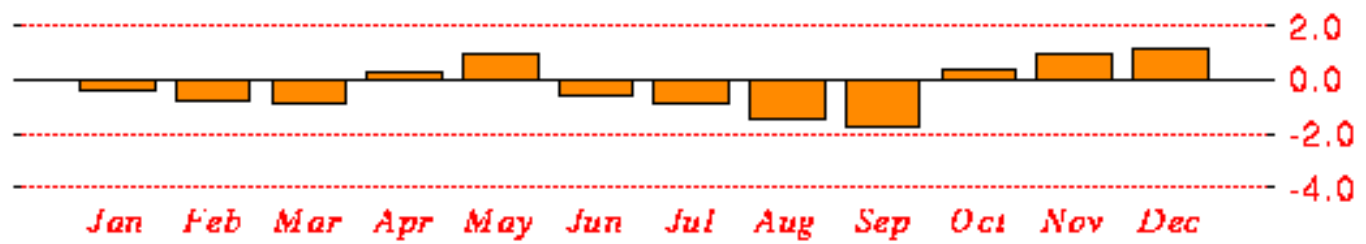

Nebraska-Division 05: 1991 (Monthly Averages)

Figure 9. Palmer drought indices for Climate Division 5, NE, (includes Grand Island) for 1991 (http://www.ncdc.noaa.gov/onlineprod/drought/xmgrg2.html;NCDC, nd) 
Climate Prediction Center also publishes the PDSI on a weekly basis at:

http://www.cpc.ncep.noaa.gov/products/analysis_monitoring/regional_monitoring/palmer.gif,

(Figure 10). Each Palmer index models both deficit and excess of precipitation, and each is calculated as

a function of precipitation and temperature over a period of weeks to months. Evapotranspiration and soil moisture content are inferred from the measured precipitation and temperature data. These indices are widely used by state and Federal agencies to classify drought in the Nation. The Palmer indices complement the WETS Tables in that they integrate several components of the hydrologic budget. The Palmer indices also are sensitive to climatic patterns that are longer than just a month or two.

The PDSI, MPDSI, and PHDI differ from each other in rapidity of response to change in precipitation and temperature patterns: the PDSI responds most rapidly, the PHDI most slowly, and the MPDSI at an intermediate rate (Karl and Knight 1985). The PDSI should probably be used to approximate meteoric drought in precipitation-driven wetlands. The PHDI would be more appropriate to approximate drought in groundwater-driven wetlands. Usually the three drought indices can be interchanged with each other for wetlands purposes because most of the time the differences between them are smaller than the error of extrapolating from the regional scale of the indices to the site-specific scale of a wetlands permit. Remember, for site-specific evaluations the drought indices provide a longterm, regional context in which to interpret the more locally specific information of the WETS Tables. The Palmer Z-index is probably the least useful for wetlands purposes because it provides a short-term adjustment to the PDSI that reflects short-term precipitation deviations from the longer term PDSI.

Differences between the Palmer indices are discussed in more detail at

$$
\begin{aligned}
& \frac{h t t p: / / w w w . n c d c . n o a a . g o v / o n l i n e p r o d / d r o u g h t / r e a d m e . h t m l}{\text { and }} \\
& \text { http://enso.unl.edu/ndmc/enigma/indices.htm\#pdsi }
\end{aligned}
$$

Except for the $\mathrm{Z}$ index, positive numbers in these indices reflect wetter than median conditions, and negative numbers reflect drier than median conditions (Table 4). Note that in analogy to the WETS Tables, the range of normal in this scheme is from the $28^{\text {th }}$ to $72^{\text {nd }}$ percentiles rather than the $30^{\text {th }}$ to $70^{\text {th }}$ percentiles. These differences are probably insignificant because the confidence intervals about these climatic statistics are likely greater than the differences between these two ranges of normal (P. Pasteris, NWCC, personal communication, 1999). The Palmer indices are calculated from data from 1931 to the present, whereas the WETS Tables are calculated for the most recent three decades.

More important than the fine differences between the Palmer indices, however, is the fact that these indices are regional in nature and are not site-specific. Hydrology at a particular site may differ from the regional pattern because of localized rainfall events and because of site-specific soil conditions. For example, the PDSI (Figure 9) indicates that drought conditions in June and July 1991 were slightly below median and within the range of normal in Division 5 of Nebraska, which includes Grand Island, NE, and that the Division averaged approximately 2.5 and 2 inches of rain in those months, respectively. The precipitation record at Grand Island itself, though, reports that 5.25 and 5.74 inches of rain fell there in June and July 1991, respectively (Figure 1).

Advantages of the Palmer Drought Indices are:

- $\quad$ Data are current.

- The drought indices integrate precipitation, soil moisture, and evapotranspiration into one value.

- The information is easily accessible. 


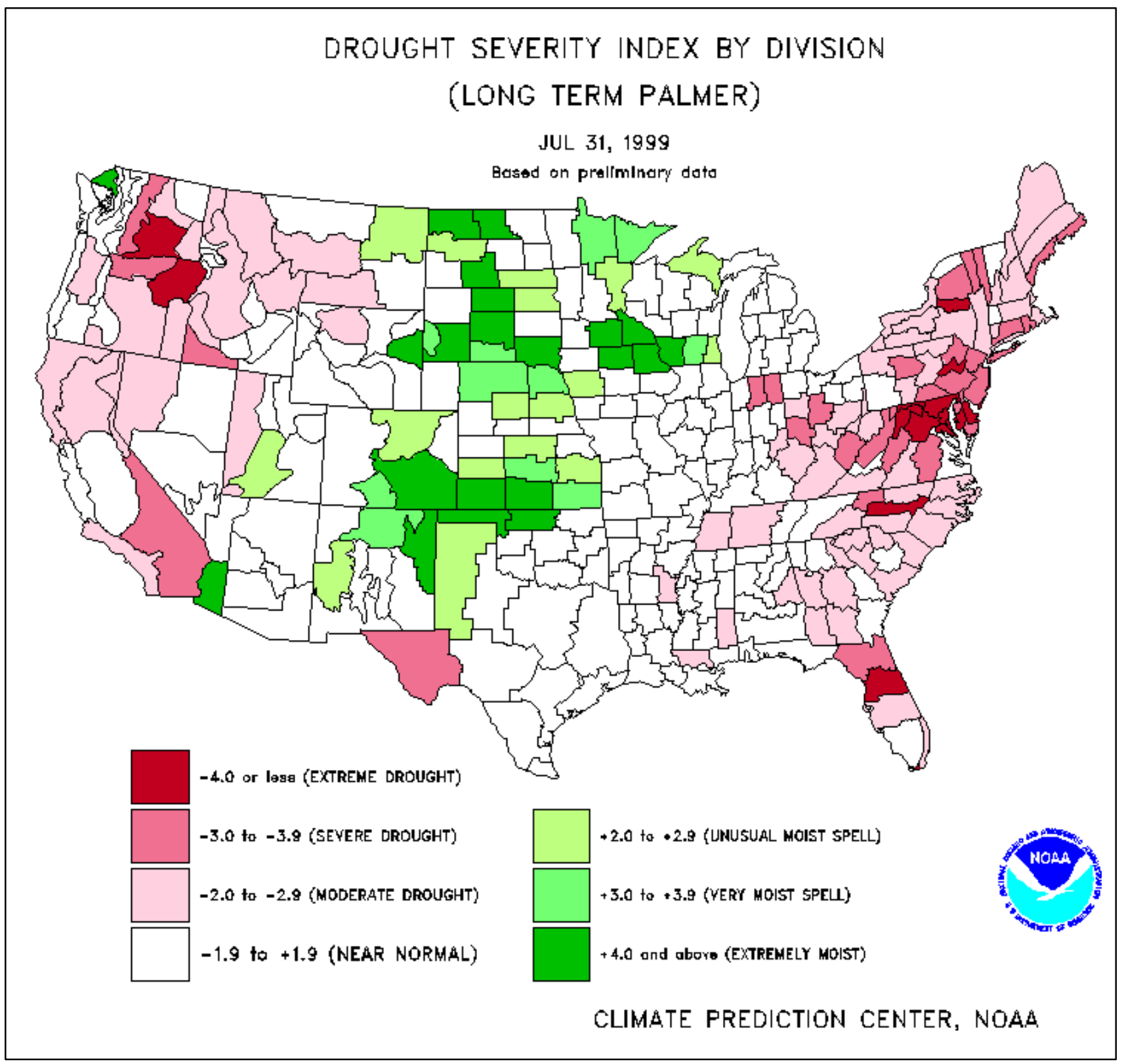

Figure 10. Example of Palmer Drought Severity Index by climate division for the Nation from provisional data at the Climate Prediction Center

(http://www.cpc.ncep.noaa.gov/products/analysis monitoring/regional monitoring/palmer.gif: NCDC,nd) 


\begin{tabular}{||l|l|l||}
\hline \multicolumn{2}{||l||}{ Table 4 . Palmer Classes for Wet and Dry Periods (NCDC 1994). } \\
\hline $\begin{array}{l}\text { Approximate Cumulative Frequency } \\
\text { \% (percentile) }\end{array}$ & $\begin{array}{l}\text { Palmer Drought Severity Index } \\
\text { Modified Palmer Drought Severity } \\
\text { Index Palmer Hydrologic Index }\end{array}$ & Palmer Z Index \\
\hline$\geq 96$ & $\geq 4.00$ & $\geq 3.5$ \\
\hline 90 to 95 & 3.00 to 3.99 & 2.5 to 3.49 \\
\hline 73 to 89 & 1.5 to 2.99 & 1.0 to 2.49 \\
\hline 28 to 72 & -1.49 to 1.49 & -1.24 to 0.99 \\
\hline 11 to 27 & -1.50 to -2.99 & -1.25 to -1.99 \\
\hline 5 to 10 & -3.00 to -3.99 & -2.00 to -2.74 \\
\hline$\leq 4$ & $\leq 4.00$ & $\leq 2.75$ \\
\hline
\end{tabular}

- $\quad$ Data can be converted to percentile frequencies from Table 4.

- $\quad$ The NCDC Web site publishes data for both national and historic coverage (Figures 10 and 11).

Disadvantages of the Palmer Drought Indices are:

- $\quad$ The Palmer indices do not distinguish between snowfall and rainfall.

- The conversion to percentiles is only approximate given the resolution of the graphs at the URL.

- $\quad$ Indices are not site-specific.

- The most recent indices are provisional and subject to change, so should not be reported in legal documents.

- Some of the assumptions in calculating soil moisture content may not be valid for the specific site being evaluated.

Utility:

Palmer drought indices complement WETS Table analyses by (1) evaluating evapotranspiration and soil moisture content as well as precipitation inputs and (2) providing longer term analyses than do the USDA Engineering Field Handbook and associated methods (Section 4 above). The most appropriate Palmer or SPI index should be used to determine occurrence of long-term drought or excess in a region once the indices have been recalculated with official data. Real-time Palmer indices should be consulted to get a sense of regional drought patterns.

\subsection{STANDARDIZED PRECIPITATION INDEX (SPI)}

The Standardized Precipitation Index (SPI) is a relatively new index that reports precipitation totals as exceedence frequencies for the Nation's 350 climate divisions. It differs from the WETS Tables 

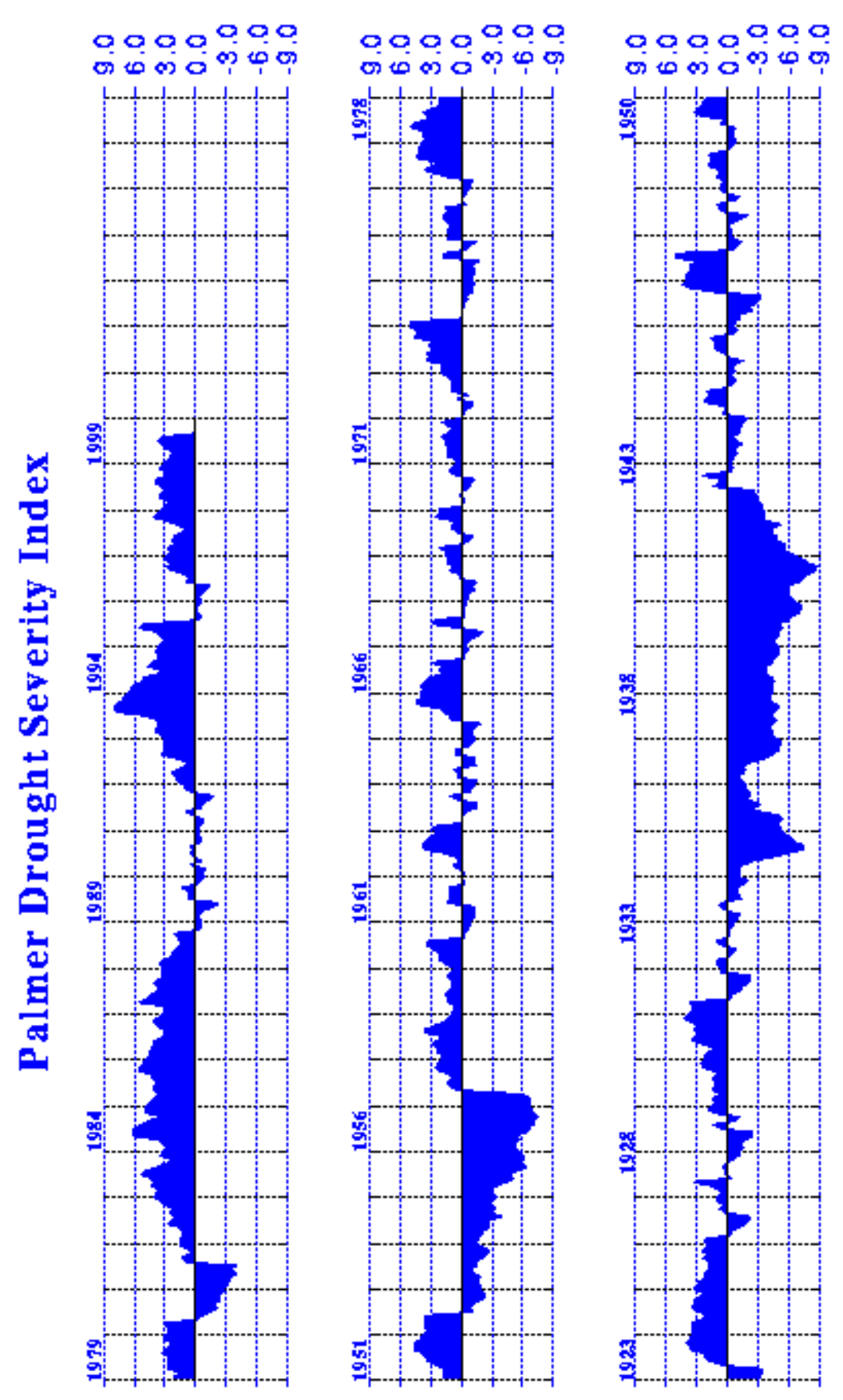

0000000

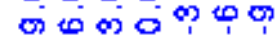

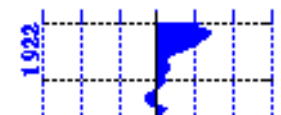

응 흐

ㅇํㅇ

Ш

เ

현

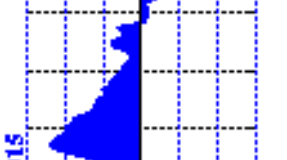

句

음 궁

$\frac{\text { D }}{2}$

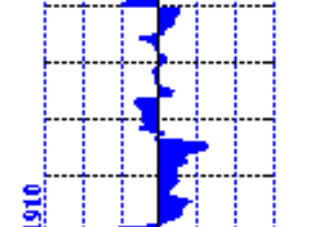

운
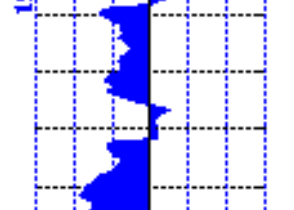

표

8

$\sum$

잉

$\frac{1}{\pi}$

苑

言 흥

ᄒ̀

ํㅡㅁ

言

ญ

$\ddot{6}$

추 웛

뭉

은

은

高

뇽

흥

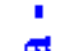

응 르

엉

प⿺

음 음 
in that it calculates exceedence frequencies for several different time periods (1-, 3-, 6-, 9-, and 12-month periods of accumulated precipitation). SPI information is available at:

\author{
http://enso.unl.edu/ndmc/watch/watch.htm\#sectiona (scroll to hyper text link "Current \\ Standardized Precipitation Index Maps") \\ or \\ http://www.wrcc.dri.edu/spi/spi.html.
}

The SPI itself is a numerical index varying between -2 or less and +2 or more. Values between -0.99 and +0.99 represent precipitation amounts with exceedence frequencies between 16 and 84 percentile (Table 5). This is a wider middle range of exceedence frequencies than used by either the WETS Tables or the Palmer indices. Thus, it is difficult to compare the SPI with them. The Western Regional Climate Center (http://www.wrcc.sage.dri.edu/spi/spi.html) uses the SPI raw data set to create curves of percentile exceedence frequency vs time (months prior to query date). These curves are much more useful than the SPI itself because they show all percentile levels between 0 and 100, including the threshold levels used by the WETS Tables and the Palmer indices. Exceedence frequency percentiles are available in graphical format (Figure 12) for twenty time periods preceding the current calendar month, going back five years. Interpretations of SPI's calculated at different time scales are discussed at http://enso.unl.edu/ndmc/watch/interp.htm.

Both the plot of precipitation percentiles for various preceding time periods (Figure 12) and the NRCS Engineering Field Handbook method provide calculated estimates of cumulative precipitation inputs for more than one preceding month. The NRCS method weights earlier months progressively less whereas the SPI calculates exceedence frequencies without any weighting factors. It is up to the user to decide which time period is of greatest significance to his or her needs when using the SPI. In some situations two months' preceding precipitation may explain water levels whereas in other situations it may be several months.

Advantages of the SPI Web site are:

- This is the only easily accessible analysis that the authors know of that presents precipitation exceedence frequency data for time periods longer than one month for all the climatic divisions of the Nation.

- $\quad$ Regional patterns of drought or excess are quickly observed from the Web site; the WETS Tables present only one station at a time.

- $\quad$ Exceedence frequency percentiles are not limited to discrete class thresholds, such as $30^{\text {th }}$ and $70^{\text {th }}$ percentiles for the WETS Tables.

Disadvantages are:

- $\quad$ Indices are not site-specific.

- Calculated exceedence frequencies are not weighted for length of time prior to a month of interest, in contrast to the method of the NRCS Engineering Field Handbook (Section 4.1).

- Indices published at this Web site are usually a couple of months old.

- $\quad$ As of this writing, historic SPI's are archived only back to 1996 (http://enso.unl.edu/ndmc/watch/watch.htm). 


\begin{tabular}{||l|l|l||}
\hline \hline \multicolumn{3}{||l||}{ Table 5. Exceedence Thresholds and Percentiles for SPI Values } \\
\hline SPI & Exceedence Threshold & Percentile \\
\hline 2.00 or more & 2.3 percent & 97.7 \\
\hline 1.50 to 1.99 & 4.4 percent & 95.6 \\
\hline 1.00 to 1.49 & 9.2 percent & 90.8 \\
\hline 0 to 0.99 & 15.9 percent ${ }^{2}$ & 84.1 \\
\hline 0 to -0.99 & 84.1 percent ${ }^{2}$ & 15.9 \\
\hline-1.00 to -1.49 & 90.8 percent & 9.2 \\
\hline-1.50 to -1.99 & 95.6 percent & 4.4 \\
\hline-2.00 or less & 97.7 percent & 2.3 \\
\hline $\begin{array}{l}1 \\
2\end{array}$ National Drought Mitigation Center (1996). \\
replaced with values in this table (Mark Svoboda, NDMC, July 1999, personal communication).
\end{tabular}

Utility:

- $\quad$ The SPI Web site reports cumulative precipitation in terms of percentiles for many different time scales. It can provide a longer term perspective on drought than do the analyses recommended for the WETS Tables. The SPI analyzes only precipitation and, therefore, complements the Palmer indices, which reflect many assumptions about soil moisture characteristics and evapotranspiration. The SPI has been most widely used in the West, which is the region where the Palmer indices might be weakest due to questionable assumptions about snowmelt, runoff, and spatial homogeneity of drought.

\subsection{USGS STREAM GAUGE DATA}

The USGS provides near-real-time streamflow data and summary graphs from around the Nation at http://water.usgs.gov/realtime.html. Real-time gauge station data for individual streams and lakes can be accessed by clicking on the U.S. map and following the menus. The national and state maps of streams are color coded by percentile classes, including one class that is comparable to the range of normal defined on the WETS Tables. Real-time data for individual streams are accessed through the state map Web pages. Many state pages provide 20-, 50-, and 80-percentile thresholds for gauge data for individual streams; these percentiles are presented at the bottom of the page with recent gauge data in graphical format (Figure 13).

Exceedence frequencies of historic stream gauge data are more difficult to access on the Internet. Historic data can be found at http://waterdata.usgs.gov/nwis-w/US/. USGS State Representatives can then supply frequency analyses for specific gauges and dates. A directory of State Representatives is at: http://water.usgs.gov/staterep.html. Further information on the USGS stream gauging program can be found at http://water.usgs.gov/public/pubs/circ1123/overview.html\#HDR1 (Wahl et al. 1995). 


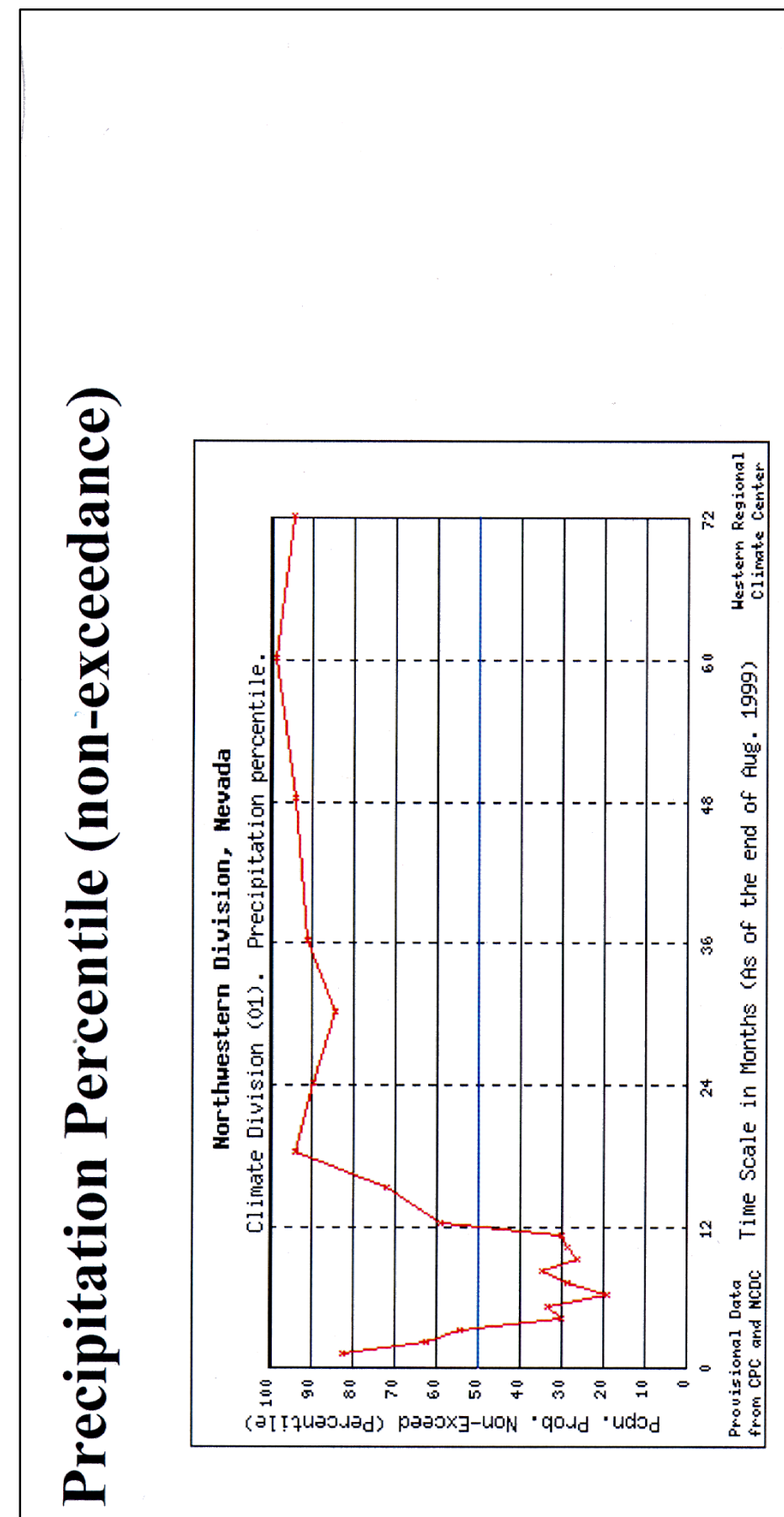

ซ் పั

䒿於

包

을.

気

里吉

흐음

สี 그

帘 :

를

क्ष

․․

识

矛?

응

祍.

올 를

क \&

ษ

ॠँ

ㄷํㅇํㅇ

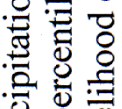

웡

옹

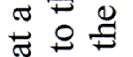

믕

喅壱

记 总

용

을

馬击

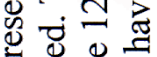

总焉

원

해용요

녕

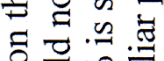

도을융

.

두은

동 문은

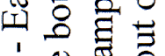

-

Oे 


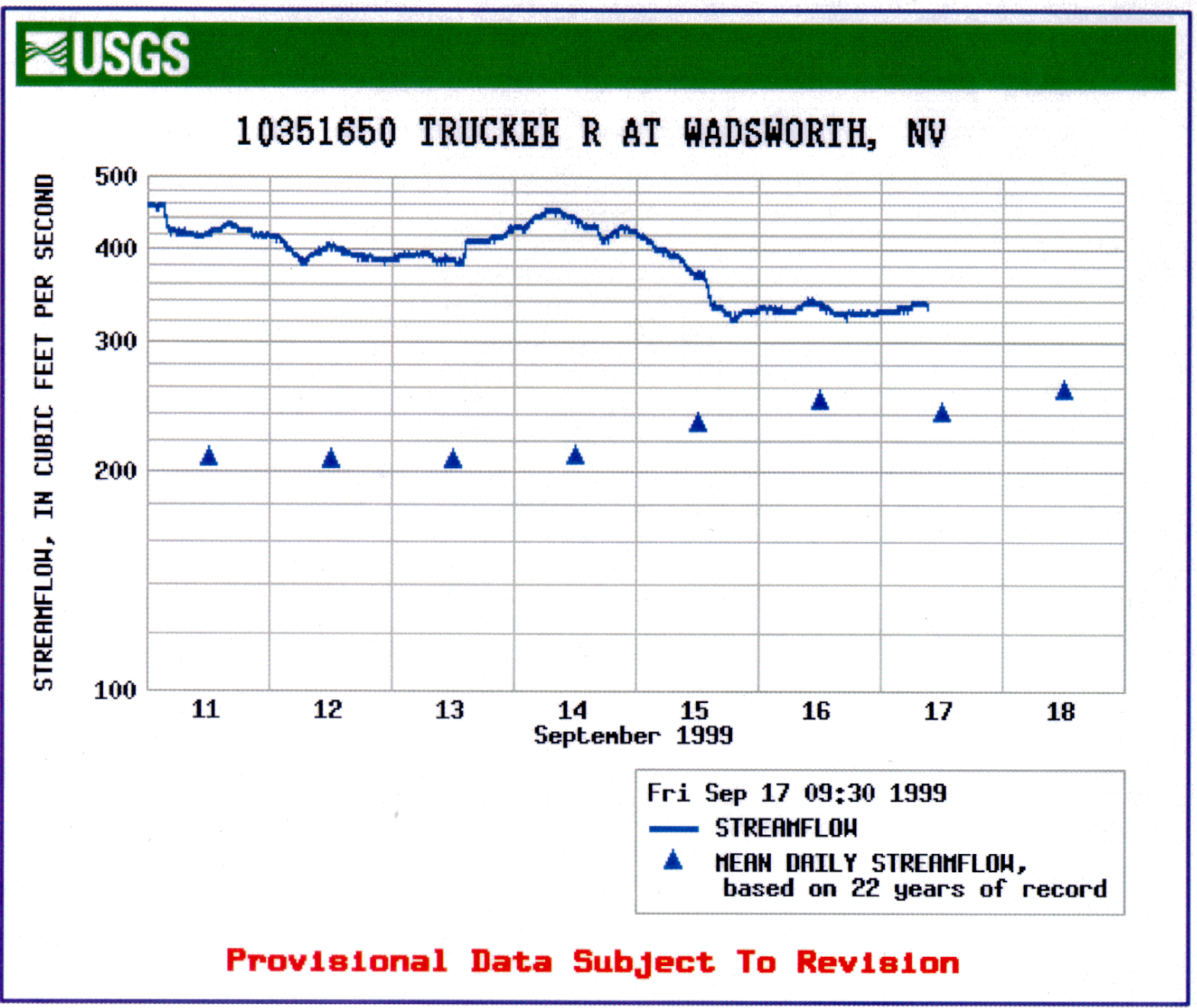

Daily Mean Flow Statistics for 09/17 based on 22 years of record, in $\mathrm{ft}^{3} / \mathrm{s}$ \begin{tabular}{|l|l|l|}
\hline Latest flow $\square$ percent 50 percent 20 percent \\
\hline
\end{tabular} 09/17 09:30 Minimum Mean Maximum exceedance exceedance exceedance

\begin{tabular}{|c|c|c|c|c|c|}
\hline 335 & 14 & 241 & 1,700 & 30 & 66 \\
\hline $\begin{array}{c}\text { Percent exceedance means that 80, 50, or } 20 \text { percent of all daily mean } \\
\text { flows for 09/17 have been greater than the the value shown. }\end{array}$ \\
\hline
\end{tabular}

Figure 13. Example of USGS streamflow graph at USGS website, including table of exceedence thresholds (http://water.usgs.gov/realtime.html; USGS 1999b) 
Advantages of this information are:

- $\quad$ Current information is available.

- Streamflow rates integrate several elements of the hydrologic budget, including precipitation, groundwater flows, runoff, and evapotranspiration.

- $\quad$ Regional patterns of drought or excess are quickly observed from the Web site; the WETS Tables present only one station at a time.

- The data are reported in exceedence frequency ranges rather than just absolute elevations or rates.

Disadvantages are:

- $\quad$ Hydrologic regimes at some sites may not correlate with streamflows.

- Exceedence frequency information on historical data is cumbersome to obtain.

- $\quad$ There are fewer stream gauges reported at the USGS Web site than there are NWS stations reporting in the NWCC WETS Tables (2100 vs 8000+; Harry Lins, USGS Office of Surface Water, personal communication, July 1999).

- $\quad$ Exceedence frequencies are calculated for the period of record rather than for a set time period, so calculated percentiles are not strictly comparable between gauges.

Utility:

- $\quad$ The stream gauge data at this URL reflect hydrologic conditions upstream of the gauging stations. They therefore complement the indices of precipitation inputs in evaluating hydrologic conditions at nearby investigation sites. Because of the provisional nature of the data, the information at the site should not be used in formal reports before consulting the state USGS Water Resources division office to verify the accuracy of the preliminary data presented on the Web site. 


\section{GEOGRAPHIC VARIATION IN PRECIPITATION}

Common experience tells us that daily precipitation varies even within a radius of a few miles. Consequently, there is always the concern that precipitation affecting a site may vary significantly from that recorded at the nearest weather station. Therefore, rain gauges are often installed onsite in research situations.

If onsite rain gauge data are not available, determine whether or not precipitation was within the range of normal at NWS stations of comparable elevation within a radius of 30 miles (30 miles being the radius that the National Climatic Data Center [1995] uses to select neighboring stations for estimating missing data). If temporal variation was comparable among the stations evaluated, assume that precipitation at the site in question varied in the same way as the majority of the stations evaluated.

An example from the Reno/Tahoe area of California and Nevada provides insight to geographic variation in precipitation. Figure 14 shows the precipitation levels as percentiles of monthly precipitation in 1979 at four different weather stations in California and Nevada: Colfax, CA; Tahoe, CA; Virginia City, NV, and Reno, NV. These stations are located up to 85 miles apart in four orographically distinct regions: the western foothills of the Sierra Nevada, the crest of the Sierra Nevada, the eastern foothills of the Sierra Nevada, and the eastern rain shadow desert in Nevada. Absolute differences in average annual precipitation range from 7.5 inches at Reno to 46.5 inches at Colfax. The year 1979 was chosen because total precipitation was approximately average and there were no missing values at those stations that year. Station characteristics are summarized in Table 6.

Several lessons can be drawn from Figure 14 and Table 6:

- Despite geographic differences, overall patterns of rainfall are similar across the orographic rainfall divide.

- The further precipitation deviates from the mean, the more similar records tend to be (note fluctuations from June to July, and September through December).

- The greater the distance from a site, the greater the deviation in precipitation pattern. Here, the most distant station, Colfax, showed the greatest deviation from the common pattern (wetter than normal January and February, drier than normal August).

- $\quad$ Precipitation should be compared within geographically similar regions. Note that precipitation in May at the two desert sites was on the dry side of normal and in the mountains was wetter than normal. 


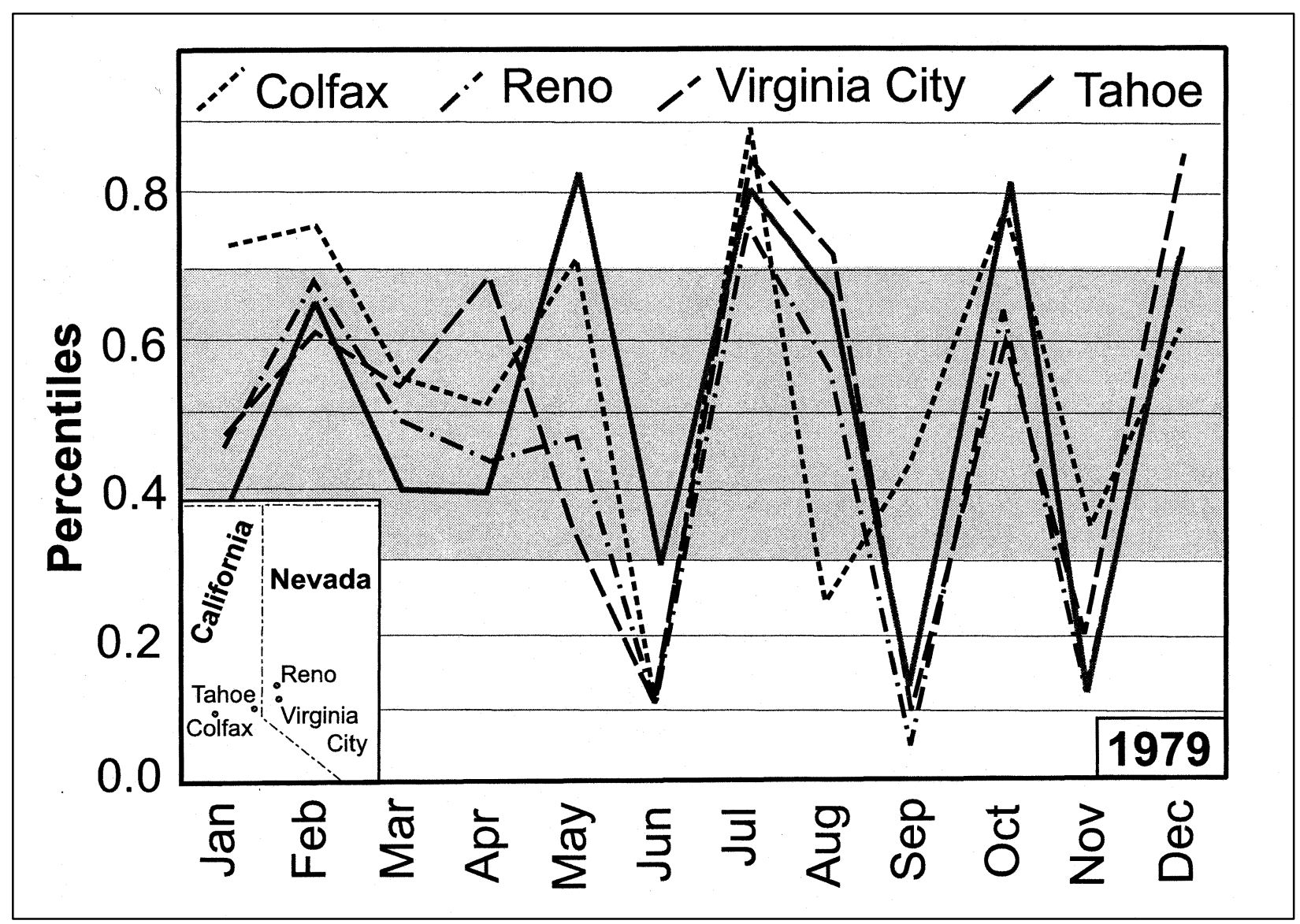

Figure 14. Precipitation patterns across the Sierra Nevada divide expressed as percentiles of monthly precipitation (NWCC 1996). Normal precipitation is between the $30^{\text {th }}$ and $70^{\text {th }}$ percentiles (shaded light gray). See text for further discussion

\begin{tabular}{||l|l|l|l|l||}
\hline \multicolumn{5}{||l||}{ Table 6. Characteristics of Contrasting Weather Stations in the Tahoe/Reno Region. } \\
\hline \hline & Colfax, CA & Tahoe, CA & Virginia City, NV & Reno, NV \\
\hline \hline $\begin{array}{l}\text { Distance from Reno, } \\
\text { miles }\end{array}$ & 85 & 33 & 18 & 0 \\
\hline Elevation, feet & 2410 & 6230 & 6340 & 4400 \\
\hline $\begin{array}{l}\text { Ave. annual precip., } \\
\text { inches }\end{array}$ & 46.5 & 32.3 & 14.85 & 7.53 \\
\hline Geography & $\begin{array}{l}\text { Western foothills of } \\
\text { Sierra Nevada range }\end{array}$ & $\begin{array}{l}\text { Sierra Nevada } \\
\text { mountains }\end{array}$ & $\begin{array}{l}\text { Virginia Range of Basin } \\
\text { \& Range Province }\end{array}$ & $\begin{array}{l}\text { Truckee Basin of Basin } \\
\text { and Range Province }\end{array}$ \\
\hline $\begin{array}{l}\text { Climate (Trewartha } \\
\text { 1968) }\end{array}$ & Temperate Oceanic & Temperate Continental & $\begin{array}{l}\text { Semi-arid, temperate } \\
\text { boreal }\end{array}$ & Arid, temperate boreal \\
\hline \hline
\end{tabular}




\section{COMPARING DATA FROM MONITORING WELLS AND RAIN GAUGES}

Antecedent precipitation is often compared monitoring well data. Therefore, two examples of such comparisons are provided, one from a site where water levels in wells track precipitation inputs closely, and a second where the response is less well defined. The methodology requires overlaying time series analyses of wells and precipitation adjacent to each other. A template for these figures is in Appendix C.

Figure 15 shows the second of three years of data from a site with rapid water well response to precipitation inputs. The well is located in the Columbus, $\mathrm{OH}$, area at a slope break at a floodplain-upland transition. Water levels were read twice daily by an automatic recording device. The soils are likely to conduct shallow interflow in the silt loam surface above a relatively impermeable argillic horizon (Soil Conservation Service 1980). Therefore, precipitation enters the soil and 40-inch-deep water well by direct infiltration and by interflow from upslope. The argillic horizon allows relatively little discharge from or recharge to deeper groundwater. Note the short duration peaks in water level response to precipitation inputs during the spring of 1997. These are what one would expect from interflow inputs rather than from groundwater discharge. These flashy spikes tend to start at the boundary of the silt-loam topsoil and clayloam argillic horizon in April, May, November, and December.

There were two water level spikes in September 1997 at the study site and only one large precipitation event. The second spike probably resulted from a locally heavier thunderstorm input at the study site than at the rain gauge seven miles away. Other wells onsite also recorded the second spike in late September, so the discrepancy between water levels and rainfall records cannot be attributed to monitoring well malfunction.

The rapidity of water level response at this site is striking. In late August it took less than a week for water levels to drop to the top of the argillic horizon, despite the heavy rains in the first half of the month. It seems appropriate to evaluate antecedent precipitation for 30 days rather than several months in this setting. The sluggish water table drop to $2 \frac{1}{2}$ feet or more in the late summer or early fall probably reflects one of two possibilities: (1) There really was a water table in the argillic horizon and water tables dropped out of it as slowly as the well records indicate; or (2) water from the A and B1 horizons ran into the well and seeped out into the nearly saturated argillic horizon only slowly. Considering the sluggish drop in water tables in midsummer when evapotranspiration was high, the second explanation is worth checking out with a drawdown test in the field (Warne and Smith 1995).

Figure 15 also shows the difference between monthly, daily, and 30-day rolling sums of precipitation data. Monthly sums would indicate that May was a wet month, but the 30-day rolling totals show most of May to have been normal in precipitation. The daily data provide the explanation for the difference, in that almost half of the month's rain fell in the last three days. Here the 30-day rolling totals depict precipitation inputs more accurately than does the monthly sum.

Figure 16 is an example of a system where water levels fluctuate more slowly in response to precipitation inputs. The soils here (Boone Creek, IL) are shallow mucks (16-23 inches thick) over alluvium. The wetland hydrology has strong groundwater discharge components as well as overbank flooding (Richardson et al., 1997). Furthermore, the muck soils hold water much longer than do the shallow topsoils of the Columbus, OH, area shown in Figure 15. Both years of data in Figure 16 show a significant drop in water levels during the summer, due to evapotranspiration. However, precipitation inputs were much higher in May 1996 than in May 1995, delaying the spring evapotranspirative drawdown by about a month. After the heavy rains in May and June 1996 abated, groundwater levels dropped to their 1995 depths, but four heavy rain storms in July and August induced water levels that 







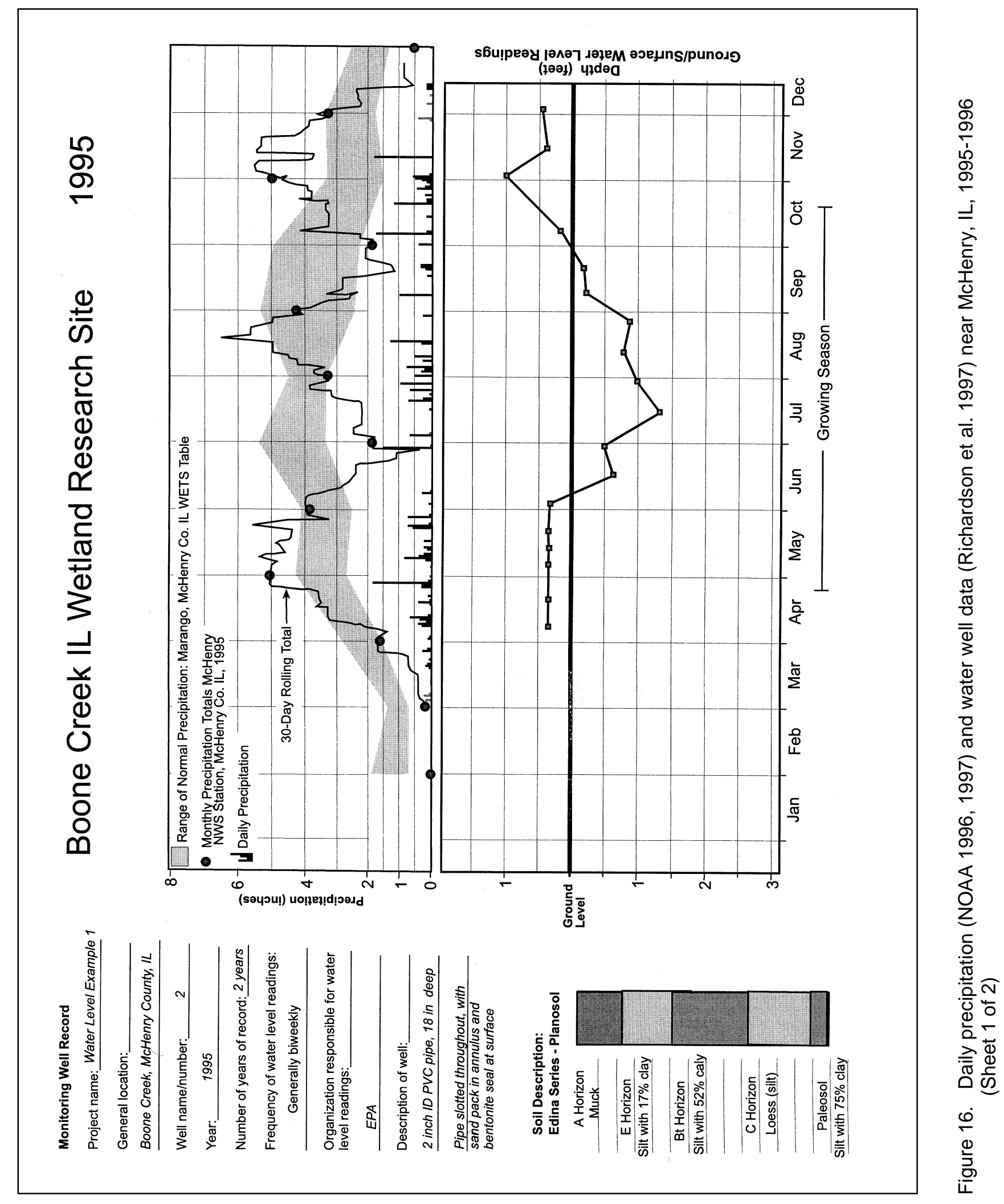




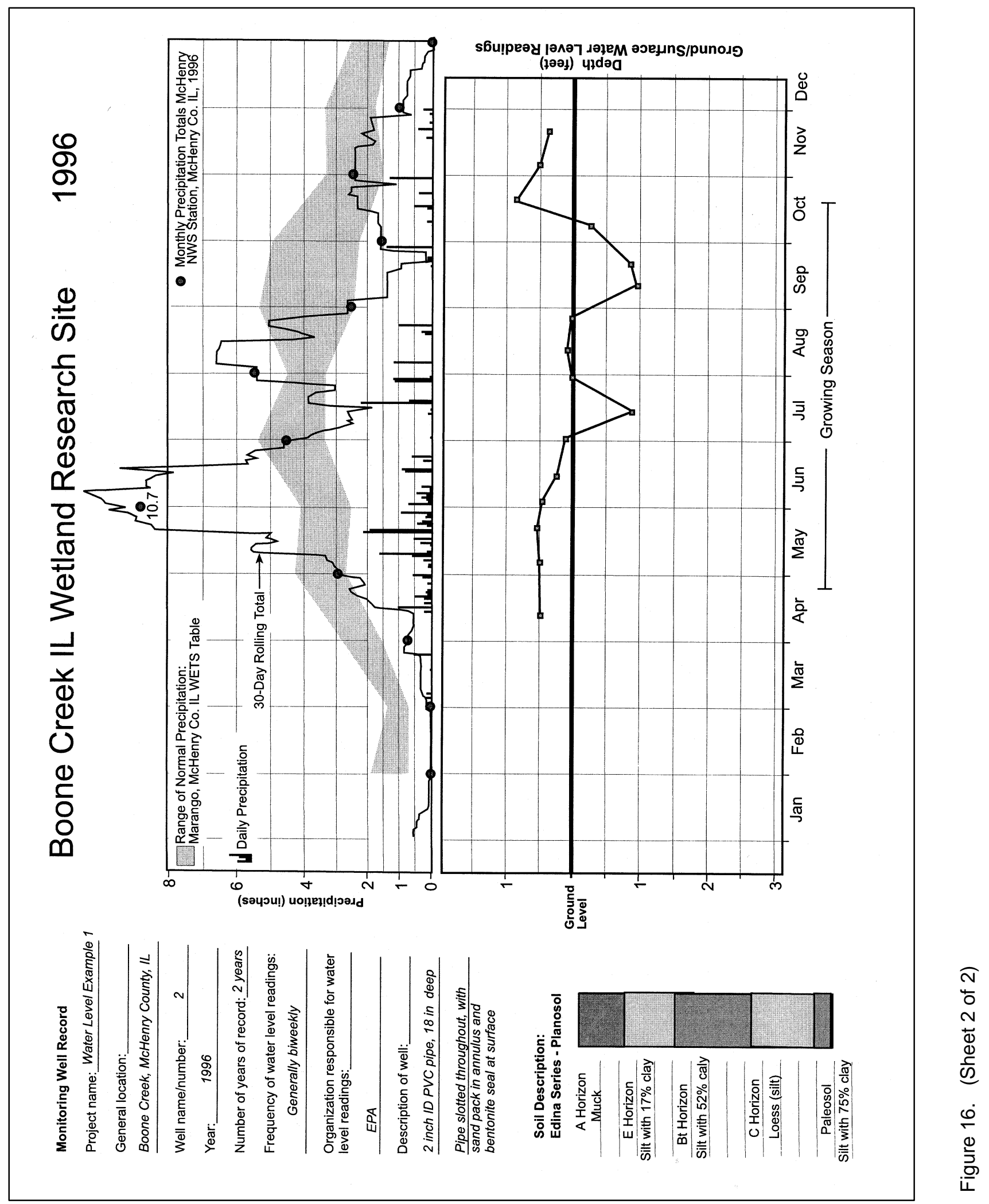


were much higher than in 1995. Note that after the August 23, 1996, rain storms the water levels stayed high for a few days to a week, but two weeks later had dropped to their 1995 levels.

These two examples - shallow, mineral, interflow system versus muck soil on the floodplain of gaining stream - indicate the advantages of daily precipitation data from NWS sources as opposed to monthly data from the WETS Tables in interpreting the overall hydrology of a site. In the Ohio example the responses to rain and evapotranspiration were rapid and would have been inexplicable or missed altogether without daily data; in the mucks of Illinois water tables dropped more slowly after the rains stopped. In both cases daily data were important in interpreting water table fluctuations and understanding key processes driving the hydrology of the sites. 


\section{STATISTICAL BACKGROUND AND COMMON PROBLEMS}

\subsection{GAMMA DISTRIBUTION: INTRODUCTION TO THE STATISTICS OF NORMAL PRECIPITATION}

Fundamental to precipitation data analysis is the fact that precipitation data for most of the Nation do not fit a bell curve ("normal distribution"). The reason for this is that the probability distribution ${ }^{3}$ for precipitation is not symmetrical. The left-hand tail of the distribution is bounded by zero, because there cannot be less than zero precipitation in any given time period. The right-hand tail, on the other hand, has no theoretical upper limit. The statistical evaluation method that best describes precipitation data is called a gamma distribution, which is a theoretical curve similar to the Gaussian distribution but skewed to the right.

To explain the gamma curve and probability distributions more fully, let's pursue the comparison between normal and gamma curves. For example, if you wanted to know something about the heights of 30 students in a class, you would find the mean and standard deviation of the sample ${ }^{4}$ and develop a normal curve. In a similar fashion, meteorologists take the 30-year-long sample of a particular month's precipitation data (30 Aprils, for example) and fit that sample to a gamma curve. Neither sample of 30 individuals (heights or rainfall months) fits its theoretical curve exactly, but experience has shown that the populations ${ }^{4}$ of student heights or rainfall months are best described by their respective theoretical curves. (See Appendix D for a more technical discussion of frequency distributions of precipitation and temperature data.)

Figure 17 shows the frequency distribution of a sample set of monthly precipitation totals in two formats: a simple histogram and the smoothed curve of the gamma distribution for the population inferred from that sample. X-axes are the same for both graphs: inches of April precipitation at Grand Island, NE. In concept, the $\mathrm{Y}$-axes are the same, too: frequency of the $\mathrm{X}$-axis amounts. In the histogram, the $\mathrm{Y}$-axis frequency is simply the number of April precipitation months with a given amount of rain divided by the total number of Aprils sampled, for example, $9 / 30=0.3$ for the second bar (1.00-1.99 inches). The mathematics are not quite so straightforward for the Y-axis for the idealized curve in Figure 17 but the concept is the same: increasing probability of occurrence with increasing height on the Y-axis. A principal advantage of the calculated gamma curve is that it allows interpolation and extrapolation based on the existing data.

The histogram and gamma curve in Figure 17 have similar shapes, and both of them depict the same qualitative concept: the likely rainfall amounts in April at Grand Island, NE. The histogram of the 30-year sample (Figure 17) is limited to Aprils between 1961 and 1990. Most Aprils during those three decades had between 1 and 3 inches of rain at Grand Island. A few Aprils were wetter; two were very

\footnotetext{
3 Probability distributions are patterns of occurrence for populations of data. The best known probability distribution is the "normal distribution;" this is also known as a "bell curve" or a "Gaussian distribution." Many, but not all, natural phenomena fit a normal distribution. For example, plant heights within a species fit a normal distribution; radioactive decay is best described by a Poisson distribution; and precipitation fits a gamma distribution.

4 "If a set of data consists of all conceivably possible (or hypothetically possible) observations of a given phenomenon, we call it a population; if a set of data consists of only a part of these observations, we call it a sample" (Freund 1988; emphasis added). For example, the amounts of precipitation at Grand Island, NE, for the thirty Aprils between 1961 and 1990 comprise a sample; the population from which the sample was taken consists of all possible amounts of April precipitation at Grand Island since the last significant climatic change. The discipline of statistics analyzes data from samples to infer general patterns about populations.
} 


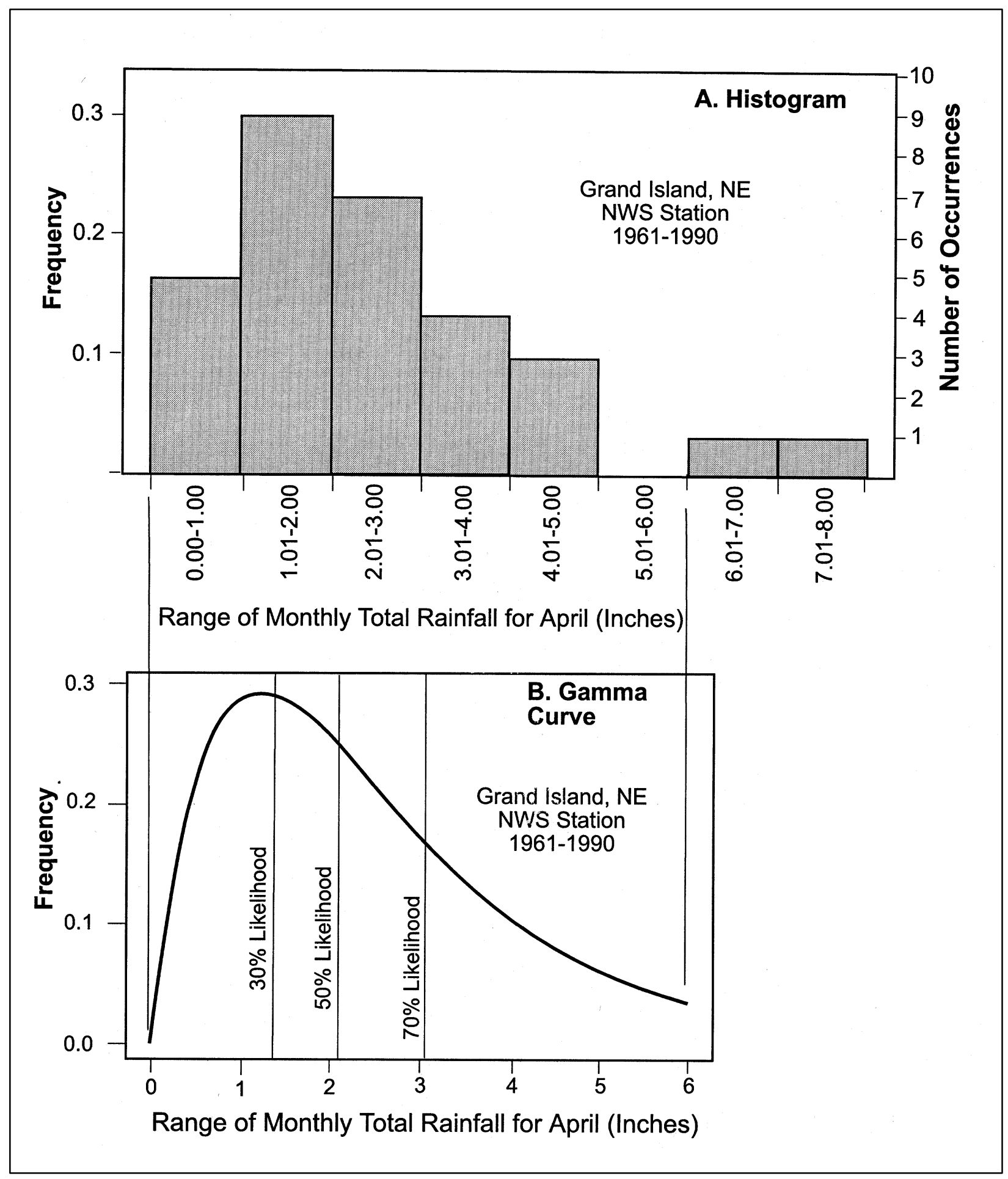

Figure 17. Histogram and gamma distribution for same set of precipitation data (Aprils 1961-1990, Grand Island, NE; (NWCC 1966)). X-axis is inches of April precipitation in both figures. $\mathrm{Y}$-axis is a measure of relative frequency, for example, second bar in Figure 17A is $\mathrm{n}_{\mathrm{i}} / \mathrm{n}_{\text {total }}=9$ months $/ 30$ months $=0.3$. Y-axis in gamma distribution is also relative frequency, but idealized to total number of possible occurrences 
much wetter, with between 6 and 8 inches of rain. If you think of the histogram as having tails, the righthand tail is longer than the left-hand tail; the data are skewed to the right.

The gamma curve for the population of April precipitation at Grand Island (Figure 17) is estimated by fitting an idealized curve to the 30 -year sample. Comparing the gamma curve and the histogram, it is obvious that some Aprils in Grand Island will have between 5 and 6 inches of precipitation. There is no rational explanation for that gap in the 30-year sample other than random chance. The gamma distribution smooths the 30-year sample data to fill in such gaps and describes the gamma curve that fits the 30 -year sample most closely.

The three vertical lines marked " 30,50 , and $70 \%$ likelihood" on the gamma curve indicate the precipitation amounts at the $30^{\text {th }}, 50^{\text {th }}$, and $70^{\text {th }}$ percentile levels, from left to right. The $30^{\text {th }}$ and $70^{\text {th }}$ percentile levels represent the lower and upper thresholds of normal April precipitation at Grand Island (although other boundaries of normal such as $25^{\text {th }}$ and $75^{\text {th }}$ percentiles could be calculated). Half of the Aprils are predicted to have less than the $50^{\text {th }}$ percentile level, 2.09 inches. These values can be calculated from the frequency distribution of 30 monthly rainfall values, too, by rank ordering the 30 values and lopping off the nine highest and nine lowest values. When this is done, ranges of normal are 1.39 and 2.79 inches.

Two points need to be made about the comparison of the histogram and gamma curve.

- Average April precipitation is not in the middle of the frequency distribution. Average April precipitation is the arithmetic mean of the 30 Aprils in the histogram. This is 2.50 inches (Figure 1). The middle of the frequency distribution of April precipitation amounts is the $50^{\text {th }}$ percentile. This is 2.09 inches. The average is greater than the median value because the probability distribution is skewed to the right.

- The ranges of normal April precipitation are slightly different using the histogram and the gamma curves: 1.39 to 2.79 inches versus 1.37 to 3.05 inches, respectively. This difference underscores the difference between samples and populations of data. The gamma curve gives the preferred estimate, which is the one found in the WETS Tables, because it is determined from the statistically smoothed 30-year sample.

\subsection{ARID LANDS}

In contrast to the humid east and south, monthly precipitation levels in arid lands vary greatly from year to year and may include zero precipitation for months on end. For example, Figure 18 reports July precipitation for 1961-1990 in Mojave, CA. Note that 19 of the 30 Julys within the three-decade reporting period had zero precipitation. It is obvious that the most likely precipitation level in July at Mojave, CA, is no rainfall at all. Normal precipitation is 0.00 to $0.08 \mathrm{inch}$; that is, the wettest 30 percent of the Julys between 1961 and 1990 had more than 0.08 inch of rain, and the driest 30 percent of the Julys between 1961 and 1990 had 0.00 inch of rain. In fact, the concept of "less than normal" has no meaning in this extreme climate. "Average" precipitation, too, has little meaning in deserts, because of how extremely skewed the distribution is; the arithmetic mean $(0.16 \mathrm{inch})$ is twice as high as the highest "normal" rainfall (0.00-0.08 inch). 


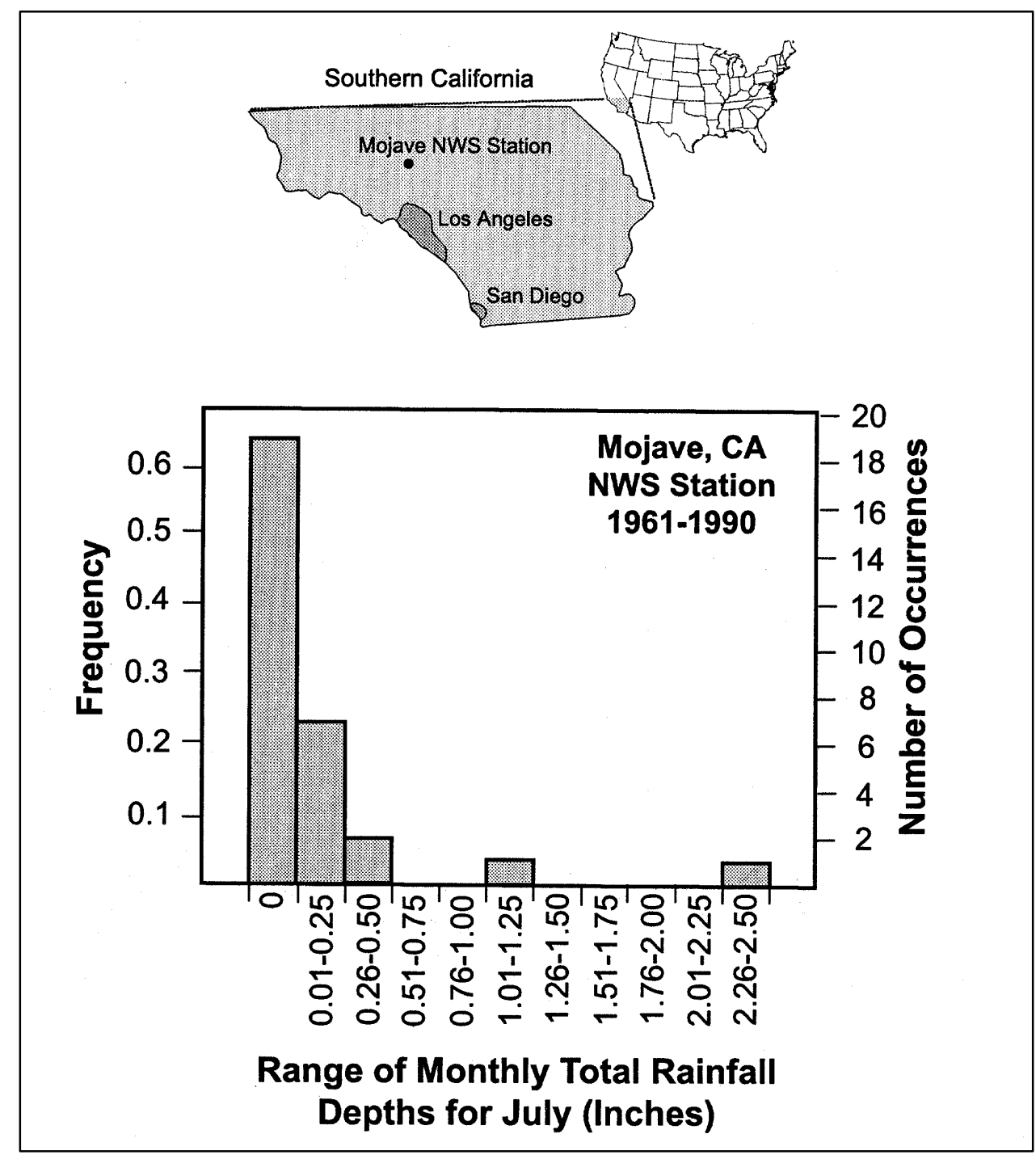

Figure 18. Histogram of July precipitation at Mojavé, CA, for 1961 to 1990 . Note that more than half of the Julys had zero precipitation (NWCC 1996)

\subsection{BIMODAL PRECIPITATION}

Many people assert that the majority of years have either very high or very low precipitation amounts. They feel that Junes, for example, are either wet or dry, with relatively few Junes having intermediate amounts of rainfall. This would imply that the June rainfall distribution is bimodal, and, hence, the unimodal gamma distribution does not describe the probability distribution of precipitation in their part of the country. Meteorologists, however, have analyzed precipitation records around the world and found that precipitation in the vast majority of places is best described by a unimodal model, although rain falls in some places in the tropics with truly bimodal frequency distributions (Granger 1987).

Two regions of the country where this misconception is most common are the arid West and the hurricane zone of the Southeast. Analyses of longer term precipitation records in the arid West (70 years at Ogden, UT, and 60 years at Bakersfield, CA; NWCC 1996) show that the right-hand tail of the frequency distributions tends to be flat, so these precipitation distributions are still unimodal. Along the 
Southeast and Gulf Coasts and in the Caribbean, late summer and autumn tropical storms may seem to cause truly bimodal rainfall distributions. Even these distributions, however, are usually unimodal over a long period of record. Compare, for example, the 30-year vs 96-year records at Raleigh, NC (Figure 19); although June is not in the height of he hurricane season, the 30-year record shows a strong possibility of bimodality. Histograms of major cities along the south Atlantic and Gulf coasts from Wilmington, NC, to Galveston, TX, throughout the summer and autumn indicate that tropical storms do not create bimodal precipitation distributions in the region, possible exceptions being southern Florida and Puerto Rico. 


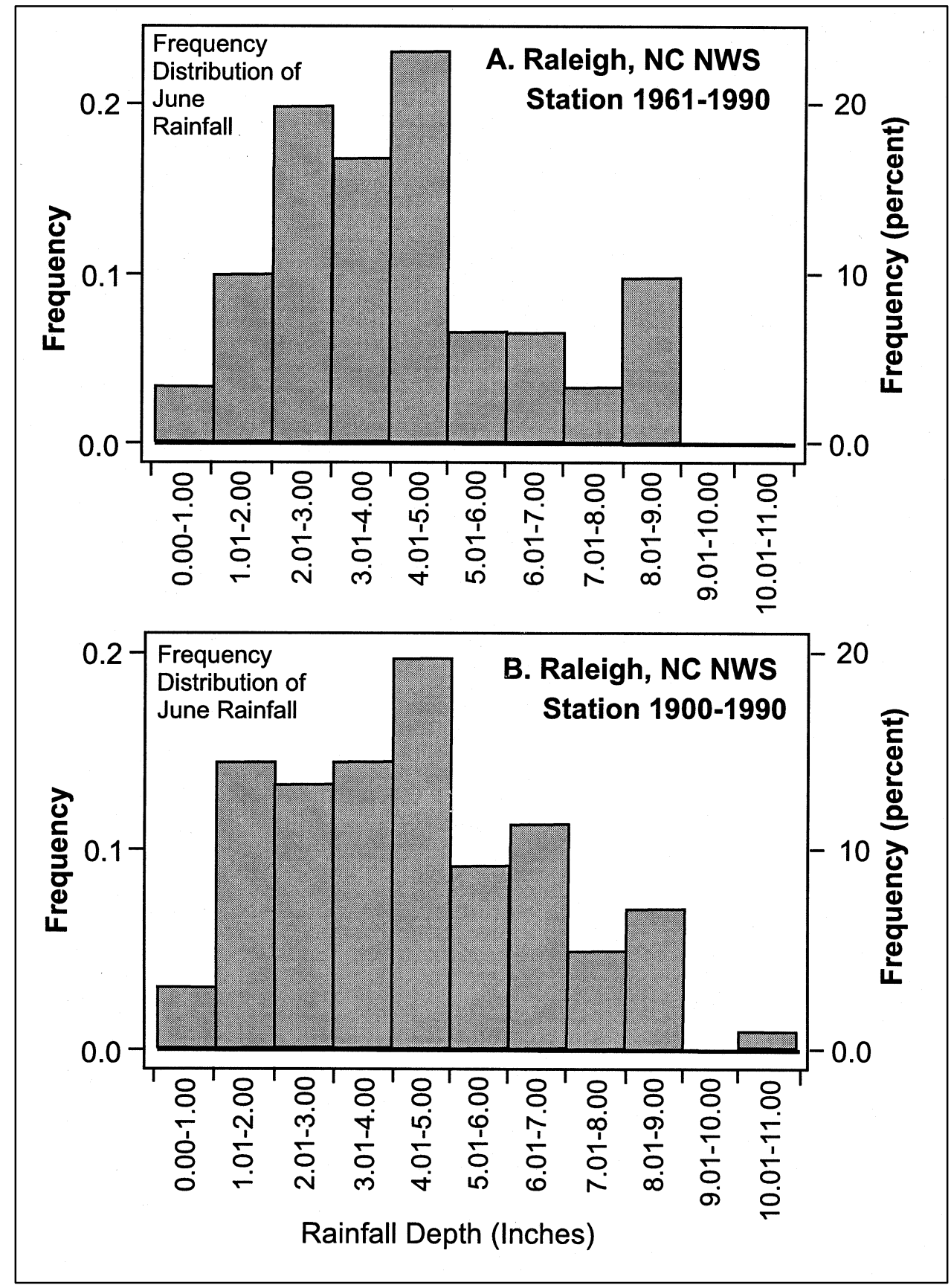

Figure 19. Frequency distributions of June precipitation at Raleigh, NC. The 30-year record (1961-1990, top graph) shows the possibility of bimodal precipitation with a second small peak at the end of the right-hand tail. The total record (1900-1990, bottom graph), however, shows the distribution to be unimodal. The $X$-axis is inches of June precipitation; $\mathrm{Y}$-axis is the frequency of Junes with $\mathrm{X}$-axis amounts of precipitation (NWCC 1996) 


\section{SUMMARY AND RECOMMENDATIONS}

\subsection{SUMMARY}

1. Characterization of the long-term hydrology of a site requires evaluation of meteorologic conditions prior to and during the assessment period.

2. Evaluation of meteorologic conditions typically involves determining whether current precipitation is normal, wetter than normal, or drier than normal during the assessment period. This requires knowledge of both historic rainfall frequencies and rainfall amounts at the time of assessment.

3. WETS Tables, which were generated by the NWCC for more than 8000 NWS stations across the U.S., provide information for determining the range of normal rainfall conditions for a site. WETS Tables also provide accurate assessments of the growing season for a site.

4. Precipitation amounts at the time of the assessment can be obtained from the Regional Climate Centers and State Climatologists. The UCAN network should provide real-time precipitation records in late 1999.

5. Onsite rain gauges may be used to identify daily differences between precipitation onsite and at NWS stations, and are particularly valuable in areas where geographic distribution of rainfall is patchy.

6. Relatively quick and easy-to-follow methods are presented to evaluate antecedent precipitation at a site. These include:

a. Method of NRCS Engineering Field Handbook

b. Method of 30-day rolling totals

c. Method combining (a) and (b) above

7. Regional measures of drought and precipitation excess are available on a near real-time basis at Internet Web sites run by the NCDC and the NDMC.

\subsection{RECOMMENDATIONS}

1. Precipitation antecedent to a date of hydrologic monitoring should always be evaluated to determine whether it was within the range of normal for the site.

2. The NRCS WETS Tables should be used to determine monthly ranges of normal precipitation unless other frequency distributions are available that are more site-specific.

3. When practicable, records of daily precipitation should be used to interpret monthly totals for deviation from range of normal..

4. When practicable, a default duration of three months, weighted for recency, should be used to decide whether antecedent precipitation was within the range of normal prior to a date of monitoring. If local information is available about the duration of influence of precipitation on hydrology, that local knowledge should be used to select the proper length of precipitation record to evaluate prior to a date of monitoring. 
5. Wetland scientists with field responsibilities should keep up with regional patterns of drought or excess by referring to the various drought maps published by the NDMC and other sources of information on variation of climate (for example, state climatological experts). Local experience should guide selection of indices (Palmer, SPI, USGS streamflow, etc.) that seem to work best in the scientist's particular region.

6. Regional data published by the NDMC should be used to complement the more locally specific WETS Tables, not to replace the WETS Tables.

7. Growing season dates reported in the WETS Tables are often preferable to those published in county soil survey reports because climate data are more recent.

8. If precipitation data are gathered from non-NWS stations, those data should be compared to daily records from surrounding NWS stations.

9. Wetland evaluations that use monitoring wells should provide comparisons of rainfall to groundwater levels. 


\section{REFERENCES}

Environmental Laboratory. (1987). "Corps of Engineers wetlands delineation manual," Technical Report Y-87-1. U.S. Army Engineer Waterways Experiment Station, Vicksburg, MS.

Finkelstein, P. L., D. A. Mazzarella, T. J. Lockhart, W. J. King, and J. H. White. (1983). Quality assurance handbook for air pollution measurement systems: Volume IV. Meteorological measurements. US EPA Environmental Monitoring Systems Laboratory, Research Triangle Park, NC.

Freund, J. E. (1988). Modern Elementary Statistics. Prentice-Hall, Englewood Cliffs, NJ.

Granger, O. E. (1987). "Precipitation distribution," pp. 690-697, in The Encyclopedia of Climatology, (J. E. Oliver and R. W. Fairbridge, eds). Van Nostrand Reinhold Co., New York..

Jenkinson, B. J., and D. P. Franzmeier. (1996). Soil moisture regimes of some toposequences in Indiana. pp. 49-68, in Preliminary Investigations of Hydric Soil Hydrology and Morphology in the United States, J. S. Wakeley, S. W. Sprecher, and W. C. Lynn (eds). Wetland Research Program Technical Report WRP-DE-13, U.S. Army Engineer Waterways Experiment Station, Vicksburg, MS.

Karl, T.R., and R.W. Knight. (1985). Atlas of Monthly Palmer Moisture Anomaly Indices (1931-1984) for the Contiguous United States, July 1985. Historical Climatology Series 3-9. National Climatic Data Center, Asheville, NC.

Kunkel, K. E., and A. Court. (1990). Climatic means and normals-A statement of the American Association of State Climatologists (AASC). Bull. Am. Meteorological Society 71:201-204.

Microsoft Corporation. (1985-1997). Microsoft Excell 97 SR2. United States of America.

National Climatic Data Center. (nd). Climate division drought data: graphing options. http://www.ncdc.noaa.gov/onlineprod/drought/main.html (accessed July 18, 1999).

National Climatic Data Center. (1994). Time bias corrected divisional temperature-precipitation-drought index. TD-9640. March 1994. http://www.ncdc.noaa.gov/onlineprod/drought/readme.html (accessed June 16, 1999).

National Climatic Data Center. (1995). U.S. National 1961-1990 Climate Normals, Climatography of the United States No. 81, Monthly Station Normals. NOAA, National Climatic Data Center, Asheville, NC. (Internet address: http://www.ncdc.noaa..gov/normals/us/normals clim81.html; September 29, 1995).

National Drought Mitigation Center. (1996). Drought indices. http://enso.unl.edu/ndmc/enigma/indices.htm\#spi.

National Oceanographic and Atmospheric Administration. (1992). Climatological data: Nebraska, 1991. Volume 96. Asheville, NC.

National Oceanographic and Atmospheric Administration. (1994). Climatological data: Indiana, 1993. Volume 96. Asheville, NC. 
National Oceanographic and Atmospheric Administration. (1996). Climatological data: Illinois, 1995. Volume 96. Asheville, NC.

National Oceanographic and Atmospheric Administration. (1997). Climatological data: Illinois, 1996. Volume 96. Asheville, NC.

National Oceanographic and Atmospheric Administration. (1998). Climatological data: Ohio, 1997. Volume 96. Asheville, NC.

National Water and Climate Center. (1996). Climate Analysis for Wetlands by County. Internet Web site http://www.wcc.nrcs.usda.gov/water/wetlands.html (June 24, 1996).

National Weather Service. (1989). Cooperative Station Observations, National Weather Service Observing Handbook No. 2, Silver Spring, MD.

Natural Resources Conservation Service. (1997). "Hydrology Tools for Wetland Determination," Chapter 19, in Engineering Field Handbook, Part 650, 210-vi-EFH. USDA Natural Resources Conservation Service. Washington, DC.

Office of the Chief of Engineers. 6 March (1992). "Clarification and interpretation of the 1987 Manual." Memorandum for SEE Distribution. Washington, DC.

Richardson, J. L., J. P. Tandarich, and M. J. Vepraskas. (1997). "Soils of natural and created wetland biosequences," Chapter 3 and Appendix BC, in "Studies of wetland biosequences of the glaciated Great Lakes region: wet prairie to deep marsh," Unpublished report to U.S. Environmental Protection Agency, Grant No. X995166-02-3, June 30, 1997. USEPA, Region V, Chicago, IL.

Smith, J. A. (1993). “Chapter 3. Precipitation.” pp. 3.1-3.47, in Handbook of Hydrology, D. R. Maidment, (ed.), McGraw-Hill, Inc., New York.

Soil Conservation Service. (1980). Soil survey of Franklin County, Ohio. USDA Soil Conservation Service, Washington, DC.

Soil Conservation Service. (1984). Soil survey of Wayne County, Ohio. USDA Soil Conservation Service, Washington, DC.

Trewartha, , G. T. (1968). An Introduction to Climate, $4^{\text {th }}$ ed. McGraw-Hill Book Co., New York.

United States Geological Survey. (1999a). Provisional data disclaimer. http://water.usgs.gov/provisional.html May 25, 1999.

United States Geological Survey. (1999b). Real-time water data. http://water.usgs.gov/realtime.html (updated July 27, 1999).

Wahl, Kenneth L.,Wilbert O. Thomas, Jr., and Robert M. Hirsch. (1995). Overview of the stream-gaging program. U.S. Geological Survey Circular 1123, Reston, VA. (Internet Web site http://water.usgs.gov/public/pubs/circ1123/overview.html\#HDR1; July 1999). 
Warne, A. G., and L. M. Smith. (1995). Framework for wetland systems management: Earth resources perspective. Technical Report WRP-SM-12. U.S. Army Engineer Waterways Experiment Station, Vicksburg, MS.

Warne, A.G., and D.E. Woodward. (1998). Methods to evaluate the hydrology of potential wetland sites: Wetland Research Program Technical Note HY-DE-4.1, U.S. Army Engineer Waterways Experiment Station, Vicksburg, MS.

Western Regional Climate Center. (nd). Precipitation percentile (non-exceedence). http://www.wrcc.dri.edu/cgi-bin/spiMAIN.pl?2601+spi1+pert72, accessed July 19, 1999.

Woodward, D.E., S. Jacobsen, A.G. Warne, M. Fritz, and V. Backland. (1996). Course Handbook, Hydrology Tools for Wetland Determination: Natural Resources Conservation Service National Employee Development Center, Fort Worth, TX.

World Meteorological Organization. (1996). Guide to meteorological instruments and methods of observation. Sixth edition. WMO-No. 8. Secretariat of the World Meteorological Organization, Geneva, Switzerland. 
APPENDIX A

ADDRESSES FOR COLLECTION AND ANALYSIS OF METEOROLOGICAL DATA 


\begin{tabular}{|c|c|}
\hline \multicolumn{2}{|c|}{$\begin{array}{l}\text { Table A-1. } \\
\text { Internet Addresses Relevant to Wetland Jurisdictional Hydrologic Assessments }\end{array}$} \\
\hline Subject & Internet Address \\
\hline $\begin{array}{l}\text { Current weekly and monthly precipitation data for } \\
225 \text { US cities }\end{array}$ & $\begin{array}{l}\text { http://www.nnic.noaa.gov/products/analysis_monitoring/cdus/prcp } \\
\text { temp_tables/ }\end{array}$ \\
\hline Geomorphology resources & http://tgl.geology.muohio.edu/gbook/gresources.html \\
\hline National Archives (historical photography) & http://www.nara.gov/nara/naildata.html \\
\hline NOAA National Oceanic Data Center & http://www.nodc.noaa.gov/index.html \\
\hline NOAA hydrologic information & http://www.nws.noaa.gov/oh/hic/hydrolinks.html \\
\hline NWS Regional Climatic Data Centers & http://met-www.cit.cornell.edu/other_rcc.html \\
\hline Remote Sensing - general information & http://www.utexas.edu/depts/grg/gcraft/notes/remote/remote.html \\
\hline Soils data & http://www.statlab.iastate.edu:80/soils-info/ \\
\hline $\begin{array}{l}\text { U.S. Army Engineer Waterways Experiment Station } \\
\text { Wetland Delineation Manual and other wetland } \\
\text { documents }\end{array}$ & http://www.wes.army.mil/el/wetlands/wlpu bs.html \\
\hline $\begin{array}{l}\text { U.S. Geological Survey Stream gaging and other } \\
\text { water resource data }\end{array}$ & http://water.usgs.gov/ \\
\hline $\begin{array}{l}\text { U.S. Geological Survey procedures for stream } \\
\text { gaging }\end{array}$ & http://water.usgs.gov/public/pubs/circ1123/index.html \\
\hline State Climatologists & http://www.ncdc.noaa.gov/ol/climate/aasc.html\#STATES \\
\hline UCAN (site in progress) & http://www.wcc.nrcs.usda.gov/bbook/bb20.html \\
\hline Hydrology Tools Method & http://www.wcc.nrcs.usda.gov/water/quality/text/hydrolog.html \\
\hline Palmer Drought Indices & $\begin{array}{l}\text { http://www.cpc.ncep.noaa.gov/products/analysis_monitoring/ } \\
\text { regional_monitoring/palmer.gif }\end{array}$ \\
\hline Standardized Precipitation Index & http://enso.unl.edu/ndmc/watch/watch.htm\#sectiona \\
\hline Stream Gauge Analyses & http://water.usgs.gov/realtime.html \\
\hline Various Drought Indices & http://enso.unl.edu/monitor/current.html \\
\hline $\begin{array}{l}\text { U.S. Geological Survey Earth Resource Observation } \\
\text { Systems (EROS) maps and aerial photographs }\end{array}$ & http://edcwww.cr.usgs.gov/eros-home.html \\
\hline WETS Tables & http://www.wcc.nrcs.usda.gov/water/wetlands.html \\
\hline
\end{tabular}




\section{REGIONAL CLIMATE CENTERS}

(Internet version: http://met-www.cit.cornell.edu/other_rcc.html)

For AR, LA, MS, OK, TN, TX

Southern Regional Climate Center; 254 Howe-Russell Bldg.; Louisiana State University; Baton Rouge, LA 70803

Phone: (504) 388-5021; FAX: (504) 388-2912; http://www.srcc.lsu.edu/

For CO, KS, ND, NE, SD, WY

High Plains Regional Climate Center; 15 L.W. Chase Hall; University of Nebraska; Lincoln, NE 68583-0728

Phone: (402)-472-6709; Fax: (402)-472-8763; http://hpccsun.unl.edu/

For IL, IN, IO, KY, MI, MN, MO, OH, WI

Midwestern Climate Center; 2204 Griffith Drive; Champaign, IL 61820

Phone: (217) 244-8226; FAX (217) 244-0220; http://mcc.sws.uiuc.edu/

For CT, DE, MA, MD, ME, NH, NJ, NY, PA, RI, VA, WV

Northeast Regional Climate Center; 1123 Bradfield Hall; Cornell University; Ithaca, NY 14853-1901

Phone: (607) 255-1751; FAX (607) 255-2106; http://met-www.cit.cornell.edu/

For AL, FL, GA, NC, SC, VA

Southeast Regional Climate Center; 1201 Main Street Suite 1100; Columbia, SC 29201

Phone: (803) 737-0800; FAX (803) 253-6248 ; http://water.dnr.state.sc.us/climate/sercc/

For AK, AZ, CA, HI, ID, MT, NM, NV, OR, UT, WA

Western Regional Climate Center; 5625 Fox Avenue / P.O. Box 60220; Reno, NV 89506-0220

Phone: (702) 677-3106; Fax: (702) 677-3243 ; http://www.wrcc.sage.dri.edu/

\section{NATIONAL WATER AND CLIMATE CENTER}

Natural Resources Conservation Service; National Water and Climate Center; 101 S.W. Main, Suite 1600; Portland, OR 97204

Phone: (503) 414-3031; FAX (503) 414-3101; http://www.wcc.nrcs.usda.gov/wcc.html

\section{STATE CLIMATOLOGISTS}

http://www.ncdc.noaa.gov/ol/climate/aasc.html\#STATES 


\section{APPENDIX B}

\section{NWS Guide on Rain Gauges}

Excerpts from Observing Handbook No. 2, pp. 6-19 


\subsection{TNTRODUCTION}

There are two types of precipitation: liquid and solid. Liquid precipitation includes rain and drizzle. Since precipitation, by definition, falls to the ground, dew (which forms where it is found) is not precipitation. Solid precipitation includes snow, hail, ice pellets, etc. Precipitation is measured in terms of its depth:

a) Iiquid (including the water equivalent of solid precipitation which has melted) to the nearest hundredth of an inch, and

b) solid to the nearest tenth inch.

\subsubsection{PRECIPITATION GAGES}

In its simplest form, a precipitation gage is an open-mouthed can with straight sides, installed with the open end upward and sides vertical. Precipitation gages are also called rain gages. Improved gages record the amount of precipitation falling per unit time on a chart (usually a punch tape or rotating drum). See section 2.2 below.

\subsubsection{EXPOSURE OF GAGES}

The exposure of a rain gage is very important for obtaining accurate measurements. Gages should not be located close to isolated obstructions such as trees and buildings, which may deflect precipitation due to erratic turbulence. Gages should not be located in wide-open spaces or on elevated sites, such as tops of buildings, because of wind and the resulting turbulence problems. The best location is where the gage is uniformly protected in all directions, such as in an opening in a grove of trees. The height of the protection should not exceed twice its distance from the gage. As a general rule, the windier the gage location is, the greater the precipitation error will be.

Wind shields (exhibit 2.1) may be used to minimize the loss of precipitation. This loss is much greater during snowfall than rainfall, so shields are seldom installed at cooperative stations unless at least 20 percent of the annual precipitation falls in the form of snow.

In areas where heavy snowfall occurs; e.g., mountainous areas in the western U.S., gages are mounted on towers at a height considerably above the maximm level to which snow accumulates, at or somewhat below the level of tree tops. see exhibit 2.2 .

Good exposures are not always permanent. Man-made alterations to the area and the growth of vegetation may change an excellent exposure to an unsatisfactory one in a very short time, necessitating the moving of precipitation gages to sites having better exposures. 


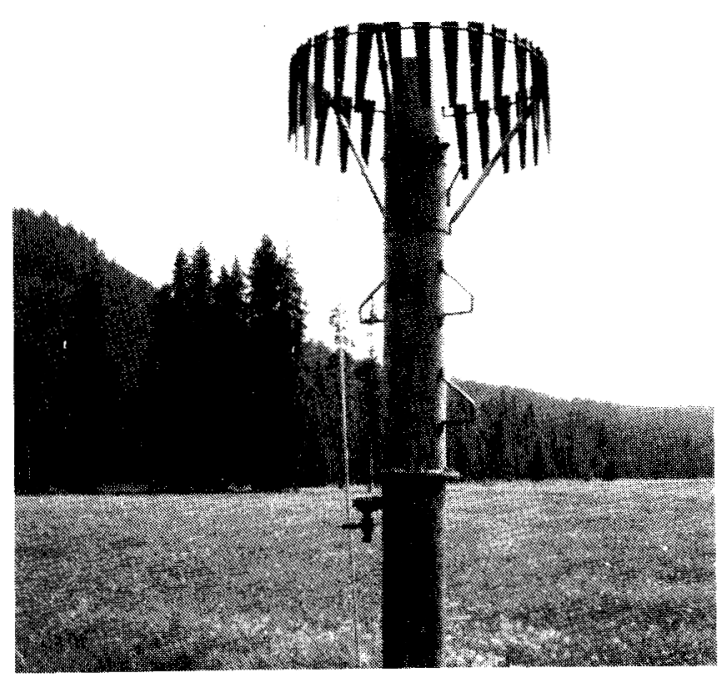

Exhibit 2.1: Wind Shield

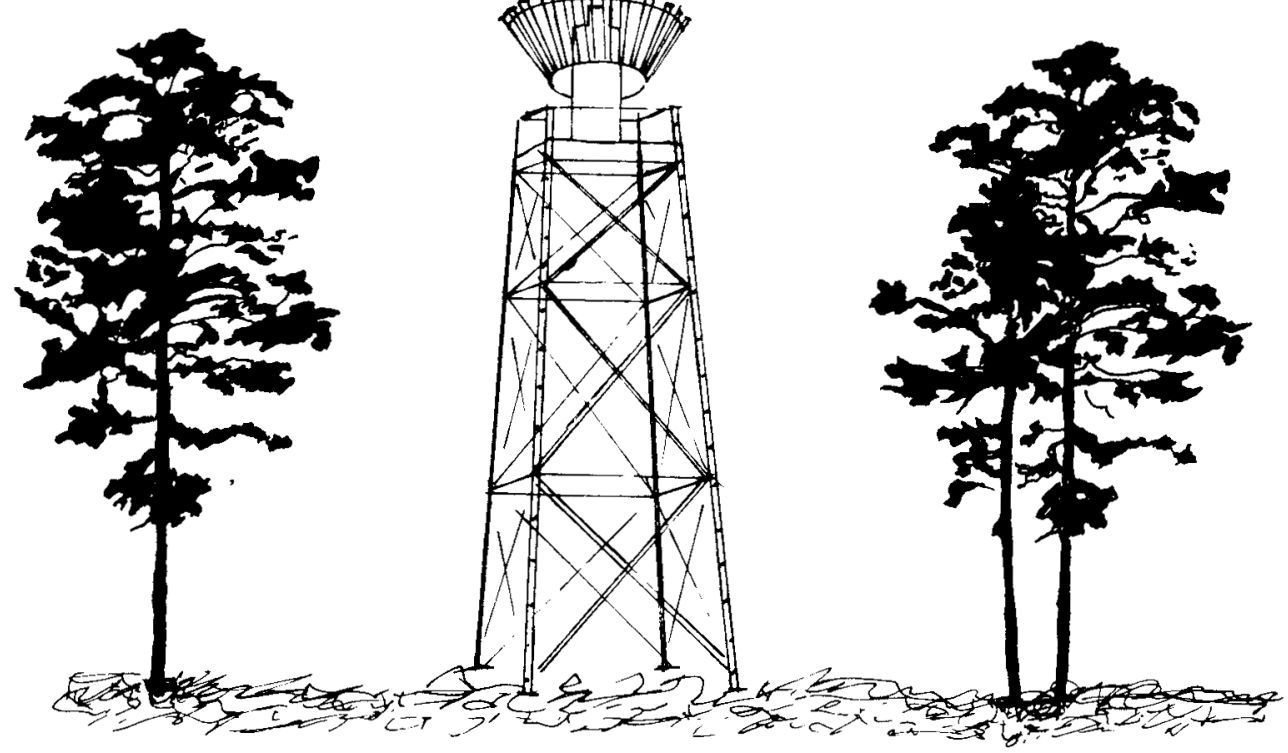

Exhibit 2.2: Snow Tower 


\subsection{TYPES OF PRECIPITATION GAGES}

The specific types of gages now being used for measuring precipitation are:

a) Nonrecording

1) 8-inch gage

2) 4-inch gage b) Recording (weighing type)

1) Belfort (Fischer \& Porter) gage

2) Universal gage

These are described below.

\subsubsection{EIGHT-INCH NONRECORDING GAGE}

This gage (exhibits 2.3 and 2.4) consists of the large diameter outer can (in the left-center of exhibit 2.4), a smaller diameter measuring tube inside it (right-center), a funnel that connects the above two (right), a measuring stick (bottom), and a support (left in exhibit 2.4). The outer can and top of the funnel are 8 inches in diameter. The funnel directs precipitation into the measuring tube, which is 20 inches tall and holds exactly 2 inches of rainfall (additional rainfall will flow into the overflow can). This ten-toone ratio makes it possible to read rainfall amounts to the nearest hundredth of an inch. The measuring stick is marked at .01 inch intervals.

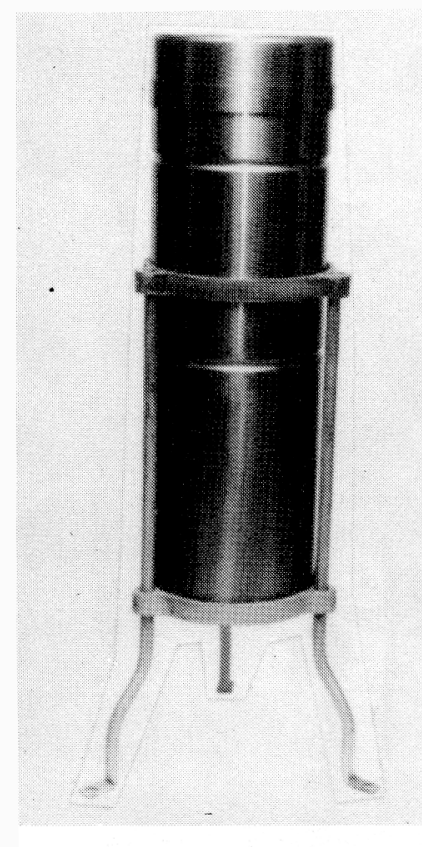

Exhibit 2.3: Eight-Inch Nonrecording Gage, Assembled

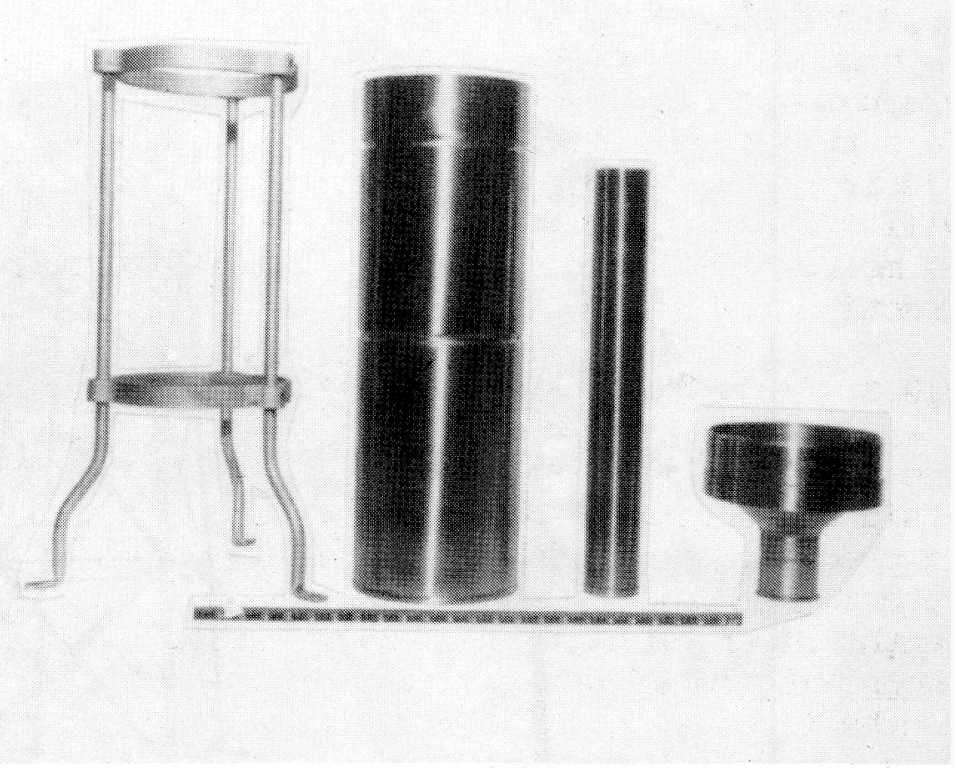

Exhibit 2.4: Eight-Inch Nonrecording Gage, Unassembled 


\subsubsection{INSTALIATION AND MAINTENANCE}

The metal support (exhibit 2.4, left side) must be firmly mounted on a horizontal platform to prevent it from being blown or knocked over. The top of the gage must be horizontal. This should be checked by laying a carpenter's level across the open top of the gage in two directions, one crossing the other at right angles. If the top is not level in both directions, report this to the NWS representative. If you level the gage, please add a note to the observation form giving the date the defect was discovered and the date corrected.

Leaks in the tube or overflow can should be reported promptly to the NWS representative.

\subsubsection{FOUR-INCH NONRECORDING GAGE}

The four-inch gage (exhibit 2.5) consists of the outer overflow can (lower left), measuring tube (center), a funnel (top) that catches the precipitation and directs it into the tube, and a mounting bracket with screws (lower right). The gage is made of clear plastic. No measuring stick is needed because the measuring tube is graduated to hundredths of an inch. This tube holds exactly one inch of precipitation. Any additional amount will fall into the overflow can and can be measured as with the eight-inch gage (section 2.2.1).

\subsubsection{WEIGHING-TYPE RECORDING GAGE}

The weighing-type recording gage is designed to record the rate and amount of precipitation. The precipitation rate is measured in hundredths or tenths of an inch per unit time. The amount is measured in hundredths or tenths of an inch. These gages consist of a receiver with an inside diameter of exactly 8 inches that funnels precipitation into a collector mounted on a weighing mechanism.

There are two types of weighing gages used by the NWS:

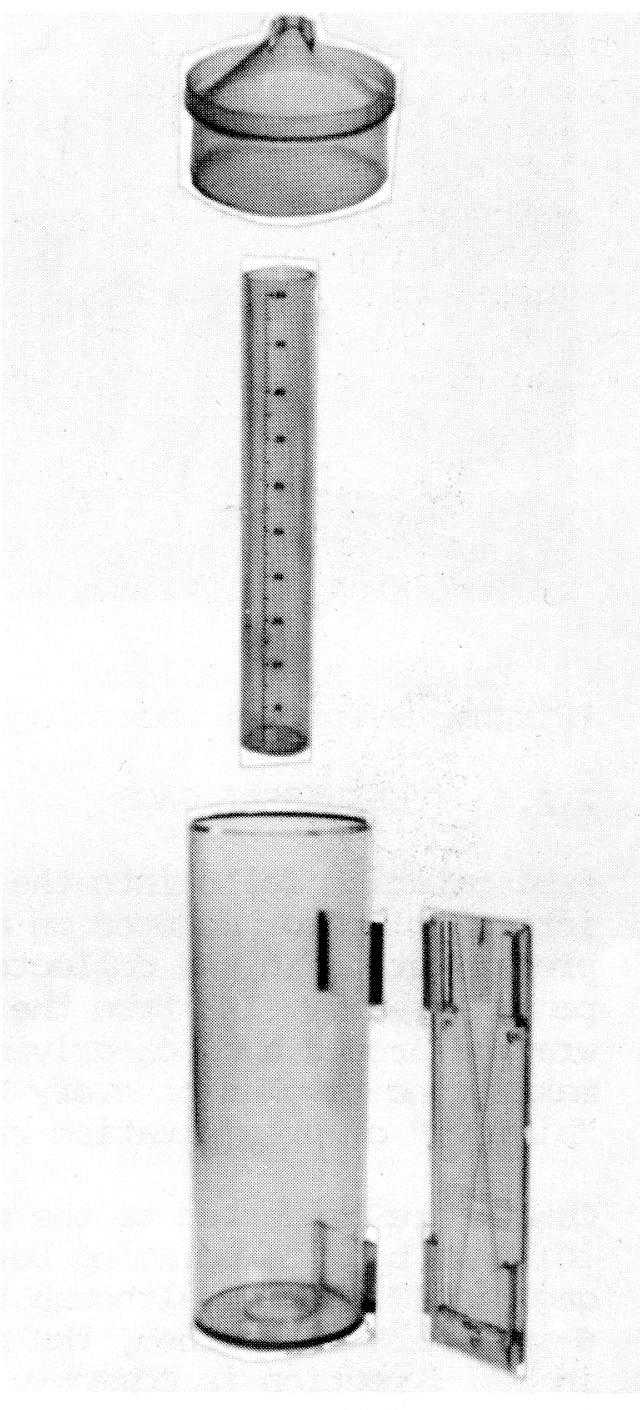

Exhibit 2.5: Four-Inch Nonrecording gage 


\section{PRECIPITATION}

a) The punched tape type, manufactured by Belfort Instruments or Fischer \& Porter (exhibit 2.6), and:

b) The universal type (exhibit 2.7).

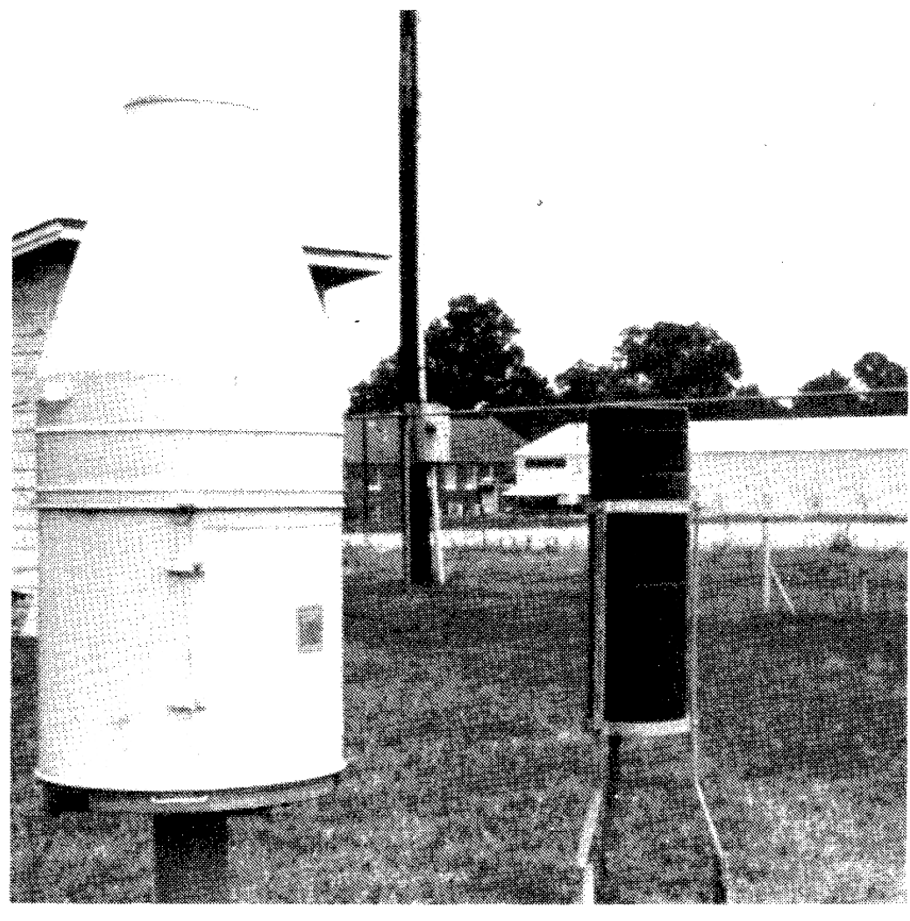

Exhibit 2.6: Belfort

(Fischer \& Porter) Recording Gage

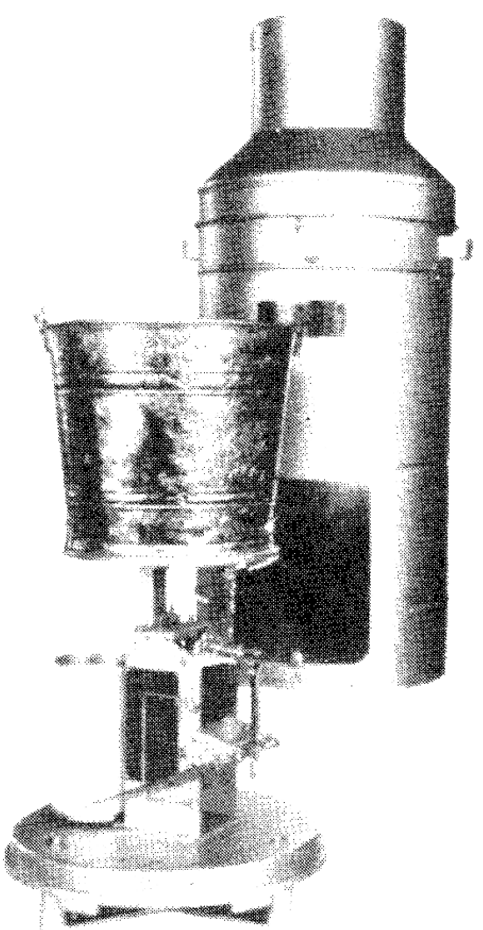

Exhibit 2.7: Universal Recording Gage

\subsubsection{UNIVERSAL GAGE}

Precipitation falls into the universal gage receiver, where it is funneled into a collector mounted on a weighing mechanism. The weight of the precipitation in the collector compresses a spring, which is connected to a pen (ink) arm. Ink from the pen leaves a trace on a paper chart, which is wrapped around a clock-driven cylinder. The cylinder rotates continuously, making one revolution every 24 hours. Ink tracings on the chart provide a "history" of precipitation rates and amounts.

Charts are graduated to the nearest .05 inch and may be read to the nearest .01 inch by interpolating between the graduations. The total capacity of the gage is 12 inches, although the chart is graduated to only 6 inches. When the 6-inch mark is reached, the pen of the chart reverses direction. The reverse in pen direction is commonly referred to as "dual traverse." 


\section{PRECIPTTATION}

\subsubsection{CALIBRATTON AND EQUTPMENT PROBLEMS}

The gage requires occasional calibration and other adjustments to maintain its accuracy. This will be done by inspectors with special equipment. Clock failure, or any trouble that cannot be corrected as described below, should be reported immediately to the NWS representative.

\subsubsection{GAINING ACCESS TO BUCKET AND CHART MECHANISM}

You will need access to the chart and bucket in order to read or change the chart, wind the clock, or empty the bucket. Most universal gages have an inspection door large enough to provide access to the clock and chart. On gages with inspection doors too small for this, you can remove the receiver (top) and outer shield to gain access.

\subsubsection{PREPARATION OF CHARIS}

Enter the following information in the spaces provided on the chart before putting the chart on the cylinder:

a) Station name as specified by the NWS representative.

b) Date and local time, to the nearest minute, that the pen will be placed on the new chart.

Cross out P.M. when it is morning or A.M. when it is afternoon. When Daylight Saving Time is in use locally, enter "D" following A.M. or P.M. For example, if the chart is changed in the morning, enter A.M.D.

\subsubsection{INSTAIJTNG AND REMOVING CHARTS}

Charts should be changed on all of the following occasions.

a) At least once a week.

b) On the first day of each month.

c) Within 24 hours after precipitation has ended.

Do not change the chart during rain that is heavy enough to wet the trace and cause the ink to spread. Rather than change the chart, empty the bucket during heavy rain when the bucket may overflow or the capacity of the chart may be exceeded.

When installing and removing charts, make a vertical mark about 1/4 inch long on the chart (trace) by gently touching the weighing mechanism which moves the pen. This mark will serve as a time check for the office receiving the chart. If the pen is not making a trace on the chart, place a small dot on the chart 
PRECIPITATION

to mark the position of the pen. Draw a circle around the dot to identify it, and enter a note of explanation on the chart (e.g., "chart removed") .

\subsubsection{CHANGING CHARTS ON GAGES WITH LARGE INSPECTION DOORS}

a) Open the inspection door and make a time check on the chart.

b) Remove the pen from the chart by shifting the pen bar forward.

c) Remove the receiver.

d) Empty and replace the bucket, except when charged with antifreeze or when oil has been used to retard evaporation.

e) Raise the outer shield (if so equipped) and rest it on the vertical guides.

f) Grasp the cylinder at the top with one hand and, with the other, gently lift it over the spindle.

g) Release the clip holding the chart. Avoid touching or storing the chart in a way that will cause the trace to be smeared before it dries.

h) Wind the clock. Caution: the clock may stop if wound too tightly.

i) Wrap the new chart around the clock cylinder so the time reads left to right, and so the chart fits smoothly and snugly on the clock cylinder. The chart base must uniformly contact the flange or cylinder.

j. Replace the clip. Check to be sure that corresponding ends of each "inch" line coincide where they meet. The exposed end of the chart must extend $1 / 4$ inch to the right of the clip.

k. Replace the cylinder. Lower it gently over the spindle until the gears mesh.

1. Re-ink the pen. Return it almost to the surface of the chart. Make sure it reads within .025 inch of the last reading on the previous chart. It should read zero, however, if you have emptied the bucket, unless the NWS representative specified some other value.

$\mathrm{m}$. With the pen almost touching the chart, turn the cylinder until it reads three hours fast, then turn it back so it reads the correct time. Be sure the time is correctly written on the chart.

n. Return the pen to the chart. Touch the weighing mechanism to make a vertical time check on the chart. Replace the shield and receiver. 
PRECIPITATION

\subsubsection{CHANGING CHARTS ON GĀGES WITH SMALL INSPECTION DOORS}

Use the following method on gages having small inspection doors.

a) Remove the receiver and shield (exhibit 2.6).

b) Make a time check or identify the pen position on the chart by touching the weighing mechanism.

c) Shift the pen bar forward and lift the pen from the chart.

d) Empty and replace the bucket, except when charged with antifreeze.

e) Grasp the chart cylinder at the top with one hand, and with the other, gently lift it over the spindle. Release the clip holding the chart, taking care not to smear the ink.

f) Wind the clock. Wrap the new chart around the clock cylinder so the time reads from left to right, and so the chart fits smoothly and snugly. The chart base must uniformly contact the flange of the cylinder.

g) Replace the clip. Check to be sure that corresponding ends of each "inch" line on the charts coincide. The exposed end of the chart must extend 1/4 inch to the right of the clip.

h) Replace the cylinder. Lower it gently over the spindle until the gears mesh.

i) Re-ink the pen and return it almost to the surface of the chart. Note the amount the pen indicates on the chart. It should indicate the same value (within .025 inch) as before the chart was changed. It should read zero if the bucket was emptied unless the NWS representative has specified that it read some other value at the time of the last calibration.

j) Return the pen to the chart. Touch the weighing mechanism to make a vertical time check on the chart.

k) Replace the shield and receiver.

\subsubsection{COMPLETING THE CHĀRIS}

After removing the chart from the gage, enter the following.

a) The local time and date of removal, as in section 2.2.4.3.b.

b) Ân arrow ( $\downarrow$ ) with the word "on" at the place the timecheck was made when the chart was installed. 
PRECIPITATION

c) An arrow $(\downarrow)$ with the word "off" at the place the timecheck was made when the chart was removed.

d) Notes that will explain unusual or missing parts of the trace. Inspect the weighing gage daily to be sure the clock is running and the pen is making a trace. If the clock has stopped and cannot be restarted, turn the cylinder forward 1/2 inch each day until the clock is replaced. The chart need not be replaced until the time or precipitation range has been used or the clock is replaced. Contact the NWS representative promptly for a replacement clock.

\subsubsection{BEIFORT (FISCHER \& PORTER) PUNCH TAPE GAGE}

Belfort Instrment Co. took over manufacturing of this gage in the early $1980^{\prime}$ s. It is gradually replacing the universal weighing gage. Precipitation amounts are recorded at 0.10 inch increments. The maximum capacity is 19.5 inches. A machine punches holes in a paper tape on a moving scroll every 15 minutes. Although the punch tape is designed for automatic machine processing, it may be read visually by summing the values of the holes punched. Punches are made for the following values: $0.1,0.2,0.4,0.8,1.0,2.0,4.0$, 8.0 and 10.0 inches. For a precipitation amount of 3.7 inches, the following punches would be made: $2.0,1.0,0.4,0.2$ and 0.1 inches, the sum of which equals 3.7 inches.

An illustrated instruction bulletin is provided with each instrument. It should be consulted for details on any specified model. The following sections refer to the Model \#35B155911XX1 with an electronic timer - the most recent model produced.

The Belfort gage shown in exhibit 2.7 is powered by a 6.75 volt DC battery. The measuring device consists of:

a) a collection bucket for receiving and storing precipitation,

b) a weighing device for measurement, and

c) an indicator dial showing the amount of precipitation collected to the nearest whole inch.

\subsubsection{OPERATION AND MATNTENANCE}

The NWS representative will place the gage in operation and explain its operation to the observer. The observer should do the following.

a) Inspect the gage weekly to assure that the tape is at the proper time. Red figures on the left side of the tape indicate the days. Make a dial reading and enter it on the observer form. If the time indicated on the tape is in error by more than an hour (4 spaces), reset it to the correct time. Make a notation of this on the tape. Refer to section 2.2.5.2 for 
instructions on setting the tape to the correct time. Do not make manual punches before adjusting or removing the tape.

b) If the reading on the indicator dial is near or exceeds 10 inches, either remove and empty the collector or unhook the plastic drain tub from the rim and lower to the drainage position, diverting the stream away from the instrument. CAUTION: do not spill or empty where oil and antifreeze will damage the grass or other vegetation. Replace the collector on the force post. Fasten the drain tube hook firmly over the edge of the collector. Rotate the zero adjustment knob until the code disk pointer is at the exact "zero" position. Add one pint of oil (supplied by the NWS representative) to the collector. During the time of year when snow or freezing weather may be expected, you must remove the funnel and you must add antifreeze to the collector. Replace the hood.

c) As soon as possible after the beginning of each month (or as requested), remove the recorded portion of the tape. Advance the tape so about 20 inches of blank tape are included following the punched portion. Remove the tape by slipping it off the end of the take-up spool. Mark the date, time of removal (indicating standard or daylight time), and station name and number on the recording tape. Include any other information that may be helpful in processing the tape.

d) Check the amount of tape remaining on the spool. If there is enough for the next entire month, rethread the loose end of the tape from the supply roll onto the take-up spool. Install a new roll of tape when necessary. Make sure that the printed side of the tape is right-side-up when facing the front of the instrument and that the tape is threaded through the punch arm assembly and paper guide.

e) Set the tape to the correct time (section 2.2.5.2) and mark the day and month on it.

f) Remove and empty the chad tray.

g) Put the punched tape for the past month in one of the mailers supplied by the NWS representative and mail. Be certain that a mailing address has been stamped on the mailer. If not, obtain the address from the NWS representative and request new mailers that are properly addressed.

h) Close and fasten the door with both latches to keep out dust and moisture. Insert the latch cover in its retainer on the base of the gage. The slot near the top should be over the padlock eye on the hood. The latch cover need not be installed if it is not necessary to lock the gage. 


\subsubsection{SETTING THE TAPE TO THE CORRECT TIME}

The electronic timer will trigger the gage to punch every 15 minutes. The power switch must be "ON." When the leads from the timer are connected to the battery, the recorder will punch 33 seconds after pushing the manual punch button. The best time to change the tape is immediately after a routine punch-out. This will allow 15 minutes to change the tape without missing any readings.

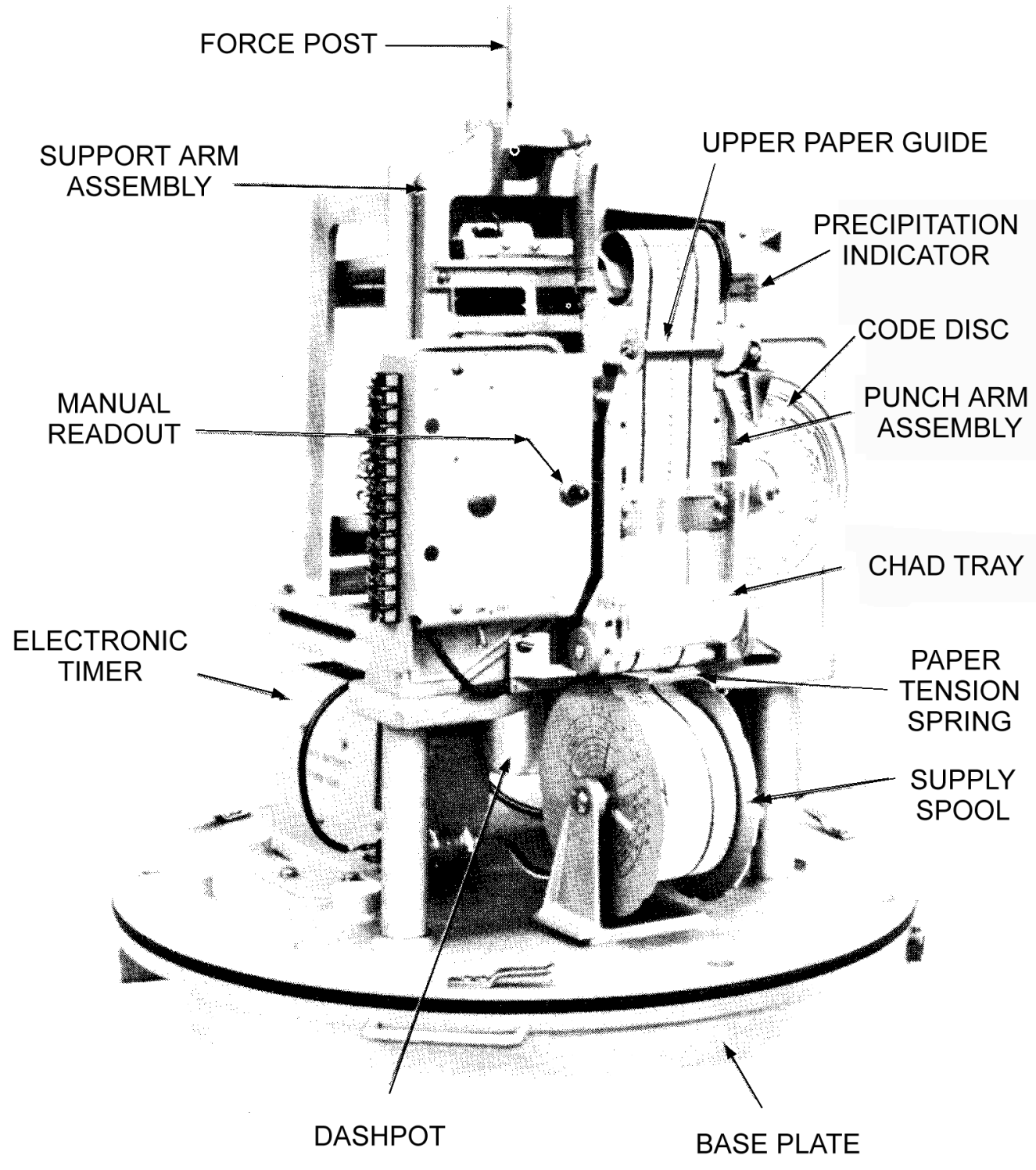

Exhibit 2.8: Belfort Recorder - Front View with Cover Removed 
PRECIPITATION

Set the tape to the correct time, as follows.

a) With the power switch "OFF," feed the tape through the die block onto the take-up spool. Continue feeding the tape until the first time line to appear above the die block reads two hours before the current time. see exhibit 2.8.

b) Turn the power switch to the "ON" position and push the button to advance the tape at least 8 lead punches or until the time line on the tape corresponding to the next 15-minute time interval is lined up with the holes in the punch block. Next, draw a line across the tape just above the punching block, using a felt tip pen. Write the date and time on the tape. This reference will determine the actual start of the record. The next punch should occur at the next 15-minute clock interval and it should agree with the time shown by the tape within 15 minutes. Hold the button down 5 seconds for each punch.

\subsubsection{WINIER OPERATION}

During the season when frozen precipitation (except hail) or freezing temperatures are likely to occur, both of the above types of gages need to be winterized, as described below.

a) At the start of winter, remove the funnel from the collector. Snow rings (on some universal gages) should be installed in place of the funnel.

b) Empty the bucket or collector and replace it in the gage. Remove and replace the collector very slowly on Belfort gages to avoid breaking a cable in the mechanism.

c) On the universal gage, turn the adjusting knob so the pen reads zero on the chart. On the Belfort gage, rotate the zero adjusting knob until the code disk pointer is at the exact position.

d) On the universal gage, pour one quart of antifreeze (supplied by the NWS representative) into the bucket. Do not use commercial antifreeze or add water.

On the Belfort gage, pour two quarts of the above antifreeze into the collector. Do not add water.

e) Make no adjustments to the gage after antifreeze has been added. The pen should rest between the 1 and 2 inch Iines after antifreeze has been added to the universal recorder. The dial on the Belfort gage should read between 2 and 3 inches.

f) Enter a note on the chart or tape identifying the time and date the gage was charged with antifreeze. 


\subsubsection{ROUTINE MAINTENANCE}

Take the following actions during the year.

a) Stir the antifreeze solution occasionally during the winter, especially after rain or snow, to help maintain a uniform mixture.

b) Empty the universal recorder bucket when the pen reaches approximately the 5-inch level. Empty or drain the Belfort gage when the 10-inch level is reached. Do not adjust the pen in either case.

c) Change charts on universal gages, as follows:

1) On the first day of each month.

2) After each measurable rain or snow.

3) Once each week.

Change tapes on the Belfort gage on the first of each month.

d) Notify your NWS representative when additional antifreeze materials are needed.

e) Mail recorded data as instructed by the NWS representative.

2.3 HOW TO MEASURE RAINFALL

2.3.1 BELFORT GAGE

See section 2.2 .5 for instructions on reading the Belfort gage.

\subsubsection{UNIVERSAL GAGE}

The universal gage may be read directly from the trace on the drum. If the gage did not read zero at the last observation time, subtract the previous reading from the current reading.

\subsubsection{FOUR-INCH NONRECORDING GAGE}

The four-inch clear plastic gage may be read directly by observing the marks etched in the measuring tube. This tube holds up to one inch of water. If more than an inch of rain has fallen, empty the water in the measuring tube, pour the water in the overflow cylinder into the tube, measure it, and add this to the amount originally in the measuring tube. Repeat this if more than two inches have fallen. When finished, put the emptied measuring tube back inside the empty outer cylinder and replace the funnel on top. 


\section{PRECIPITATION}

\subsubsection{EIGT-INCH NONRECORDING GAGE}

Remove the funnel and insert the measuring stick into the bottom of the measuring tube, leaving it there for two or three seconds. The water will darken the stick. Remove the stick and read the rainfall amount from the top of the darkened part of the stick. Example: if the stick is darkened to three marks above the 0.80 inch mark (the longer horizontal white line beneath the 0.80 ), the rainfall is .83 inch.

If the measuring tube is full (indicating at least two inches of rain), empty the tube carefully to avoid spilling any water back into the overflow can. Allow a few seconds for all the water to drain from the tube. Then pour the water from the overflow can into the measuring tube. Measure this amount and add it to the two inches already emptied from the tube. If more than four inches of rain has fallen, the measuring tube will be filled at least twice.

When finished, put the emptied measuring tube back inside the empty outer can and replace the funnel on top.

\subsection{MEASURING THE WATER EQUTVALENT OF SNOWFALI}

The Belfort and universal gages measure precipitation by weighing it. Thus, snow falling into these gages is automatically measured, and no melting is required. This value is the water equivalent. If snow or ice is stuck to the inside of the funnel, it should be scraped loose and allowed to fall into the antifreeze solution before taking a reading.

For nonrecording gages, remove the funnel and measuring tube from the outer - can during winter or whenever snow is likely to fall. The water equivalent of frozen precipitation that has fallen into the gage can be determined by following these steps.

a) Bring the overflow container that contains the snow into a warm building.

b) Wait for the snow to melt.

c) Pour the melted snow into the measuring tube.

d) Measure this as you would measure rain.

Melting the snow can be accelerated by carefully measuring an amount of warm water in the measuring tube, pouring this in the overflow can with the snow, letting the snow melt, measuring the total amount of melted precipitation, then subtracting the amount of water added.

Take care not to leave water standing in the gage if the temperature is expected to drop below freezing, as this can bend and crack it, causing leaks. 


\section{APPENDIX C}

\section{FORMS}

1. Antecedent Precipitation Evaluation For Wetland Determination

2. Sample Table Used To Calculate 30-Day Rolling Totals

3. Evaluation of Local Rainfall Station and Data

4. Template for Graph of Time vs Precipitation and Water Levels in Wells 


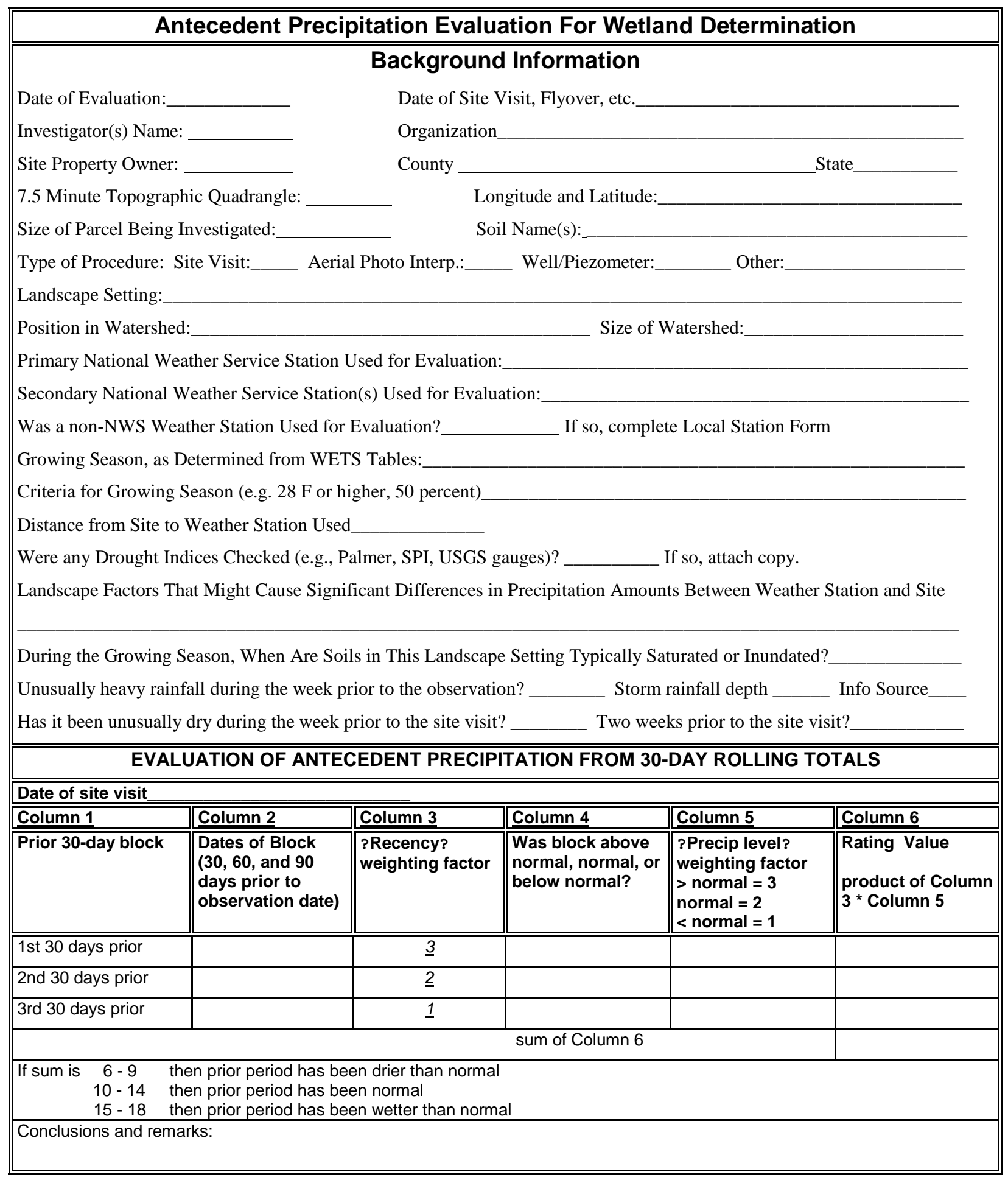




\begin{tabular}{|c|c|c|c|}
\hline \multicolumn{4}{|c|}{ Daily Precipitation and 30-day Rolling Totals } \\
\hline & Col. A & Col. B & Col. C \\
\hline Row \# & Date & Daily Precip & 30-Day Rolling Total \\
\hline \multicolumn{4}{|l|}{1} \\
\hline \multicolumn{4}{|l|}{2} \\
\hline \multicolumn{4}{|l|}{3} \\
\hline \multicolumn{4}{|l|}{4} \\
\hline \multicolumn{4}{|l|}{5} \\
\hline \multicolumn{4}{|l|}{6} \\
\hline \multicolumn{4}{|l|}{7} \\
\hline \multicolumn{4}{|l|}{8} \\
\hline \multicolumn{4}{|l|}{9} \\
\hline \multicolumn{4}{|l|}{10} \\
\hline \multicolumn{4}{|l|}{11} \\
\hline \multicolumn{4}{|l|}{12} \\
\hline \multicolumn{4}{|l|}{13} \\
\hline \multicolumn{4}{|l|}{14} \\
\hline \multicolumn{4}{|l|}{15} \\
\hline \multicolumn{4}{|l|}{16} \\
\hline \multicolumn{4}{|l|}{17} \\
\hline \multicolumn{4}{|l|}{18} \\
\hline \multicolumn{4}{|l|}{19} \\
\hline \multicolumn{4}{|l|}{20} \\
\hline \multicolumn{4}{|l|}{21} \\
\hline \multicolumn{4}{|l|}{22} \\
\hline 23 & & & \\
\hline 24 & & & \\
\hline 25 & & & \\
\hline 26 & & & \\
\hline 27 & & & \\
\hline 28 & & & \\
\hline 29 & & & \\
\hline 30 & & & $=\operatorname{sum}(\mathrm{B} 1: \mathrm{B} 30)$ \\
\hline 31 & & & $=\operatorname{sum}(B 2: B 31)$ \\
\hline 32 & & & Etc \\
\hline 33 & & & $"$ \\
\hline 34 & & & $"$ \\
\hline 35 & & & " \\
\hline 36 & & & " \\
\hline 37 & & & “ \\
\hline 38 & & & $"$ \\
\hline 39 & & & $"$ \\
\hline 40 & & & " \\
\hline 41 & & & " \\
\hline 42 & & & $"$ \\
\hline 43 & & & $"$ \\
\hline 44 & & & $"$ \\
\hline 45 & & & " \\
\hline
\end{tabular}

MS Excel Command MS Excel Command 


\section{Evaluation of Local Station and Data}

Investigator should refer to NWS Observing Handbook No. 2 ?Cooperative Station Observations?

(1989) or its update for guidance on weather station location, operation, and maintenance

Please describe the following characteristics of the local weather station

Describe type and model of rain gauge.

Who owns and operates the rain gauge?

Describe additional weather parameter collected other than rainfall, and instruments used for collection

How long has information been collected at the station?

How often is data collected?

What is the information used for?

6. Describe the landscape setting of the rain gauge and provide a sketch map showing principal topographic features, and distance from buildings, large trees and other structures.

7. Attach graph comparing daily precipitation data of non-NWS and nearby NWS stations. 

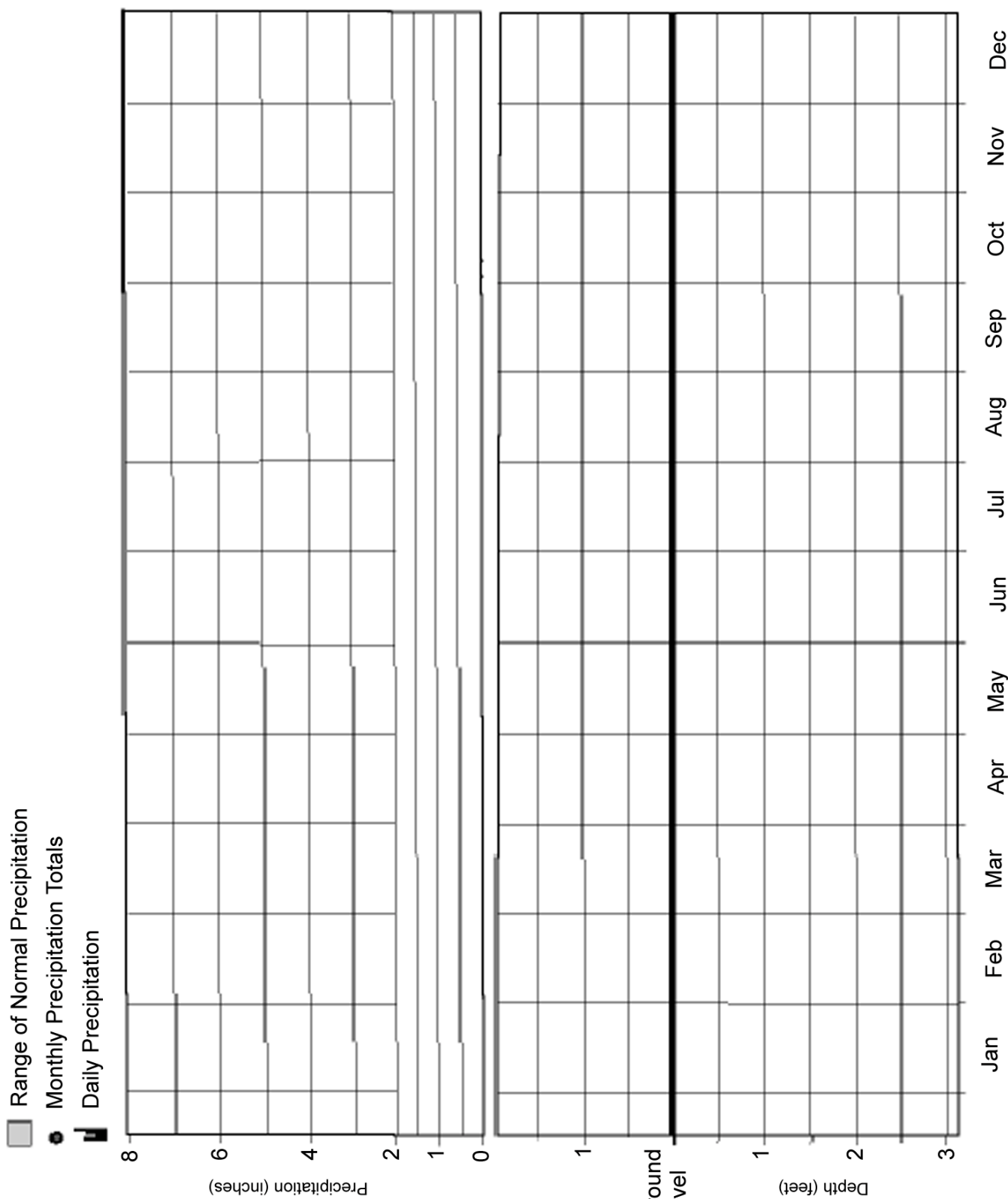

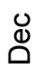

한

요

ळ

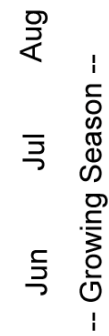

$\stackrel{\pi}{2}$

京

$\stackrel{\bar{\omega}}{2}$

윤

蹇

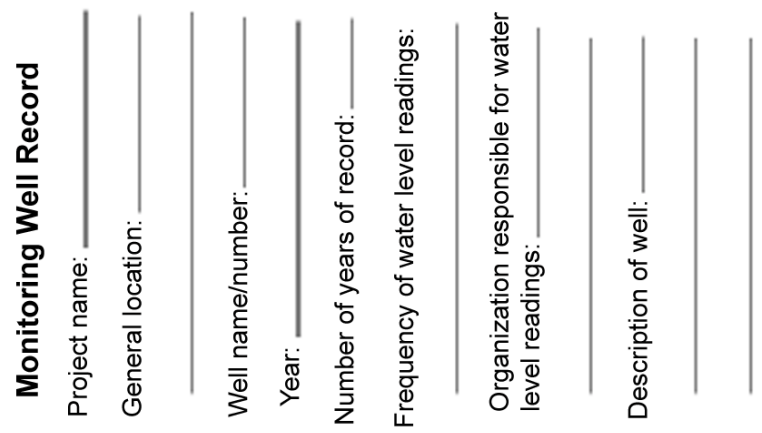
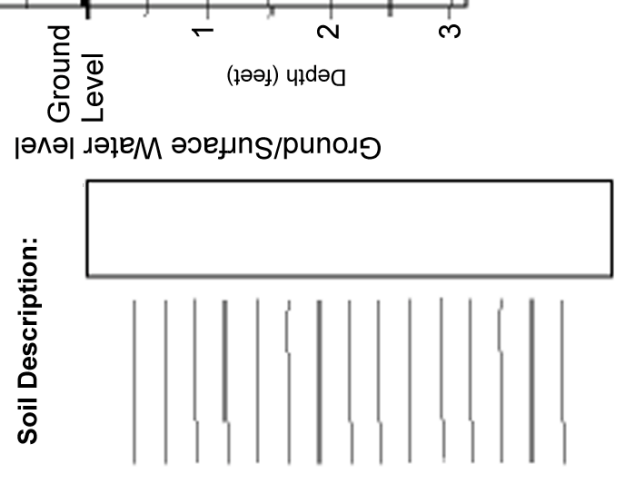


\title{
APPENDIX D
}

\section{COMPARISON OF PROBABILITY DISTRIBUTIONS FOR TEMPERATURE AND PRECIPITATION DATA}

\author{
by Phil Pasteris \\ USDA-Natural Resources Conservation Service \\ National Water and Climate Center
}

The WETS Tables are derived from two basic climate elements, temperature, which is used to determine growing season length, and precipitation, which is used to determine the normal range of precipitation for each month. These climate elements have distinctively different statistical properties. Daily temperature is a. continuous function that can report both positive and negative values. On the other hand, daily precipitation amounts are discrete, intermittent, and can never be negative. Many areas of the country can report a significant number of zeros during an individual month which can significantly affect the shape of the statistical distribution. For the purposes of statistical modeling, temperature is essentially an "unbounded" climate element and exceedence probabilities can be approximated using a Gaussian or normal distribution. Visually, the normal distribution looks like a bell curve. Daily temperature values can exhibit noticeable asymmetry, but are usually much more symmetrical than daily precipitation values. In order to use the Gaussian distribution to estimate exceedence probabilities, it is necessary to fit two distribution parameters to the data, the mean and standard deviation. These parameters are easily obtained using basic statistical analysis methods. The WETS Table growing season length and start/end dates are modeled with a normal distribution (NRCS-NWCC, 1995).

In contrast to temperature, precipitation is "bounded" on the left by zero and in theory "unbounded" on the right. When determining monthly averages constructed as the sum of, say, 30 daily precipitation values, there are fewer positive numbers going into this sum than is the case for the average monthly temperature, but the more important difference has to do with the distribution of the underlying daily precipitation amounts. Typically most daily precipitation values are zero, and most of the nonzero amounts are small. That is, distributions of daily precipitation amounts are usually very strongly skewed to the right (Wilks 1995).

Generally, the distribution of sums of 30 such values is also skewed to the right, although not so extremely except in dry climates. In humid climates, the distribution of seasonal (i.e., 90-day) precipitation totals begins to approach the Gaussian, but even annual precipitation totals at arid locations can exhibit substantial positive skewness.

In order to estimate exceedence probabilities for monthly precipitation totals, one commonly used choice is the gamma distribution. In addition to the mean and standard deviation calculated for the Gaussian distribution, two additional parameters are calculated; alpha, the shape parameter and beta, the scale parameter.

The gamma distribution takes on a wide variety of shapes depending on the value of the shape parameter, alpha. For an alpha less than 1, the distribution is strongly skewed to the right and for very large values of alpha, the gamma distribution approaches the Gaussian in form. 
The role of the scale parameter, beta, effectively is to "stretch" or "squeeze" (i.e., to scale) the gamma density function to the right or left, depending on the overall magnitudes of the data values represented. The alpha parameter is estimated using a polynomial approximation and beta is then calculated using alpha and the sample mean. The WETS Table monthly normal range for precipitation is modeled with a gamma distribution (NWCC 1995; excerpted immediately below).

\section{Technical Definition of Ranges of Normal from USDA National Water and Climate Center (http://www.wcc.nrcs.usda.gov/water/wets doc.html\#Section4b; May 15, 1995)}

\section{Probability Category Definitions}

Five categories of temperature and precipitation departures have been defined and are in widespread use. These categories were defined by the National Climatic Data Center (NCDC). The five quantitatively defined categories (Table D1) are qualitatively referred to as MUCH ABOVE NORMAL, ABOVE NORMAL, NORMAL, BELOW NORMAL, AND MUCH BELOW NORMAL (NCDC 1984).

$\begin{array}{lr}\text { CATEGORY } & \text { Z-SCORE } \\ \text {------------ } & \text { Z }>1.282 \\ \text { Much Above Normal } & -0.524<Z<=1.282 \\ \text { Above Normal } & -0.524<=Z<=0.524 \\ \text { Normal } & -1.282<=Z<-0.524 \\ \text { Below Normal } & Z<-1.282\end{array}$

Table D1. Class limits for the Z-score categories.

\section{Temperature Categories Used for Growing Season Calculations}

Monthly and annual temperatures are usually well represented by the normal distribution; therefore, the Z-score (or standardized departure from average) was used to classify, by category, the growing season length. The growing season Z-score is calculated as $\mathrm{z}(\mathrm{I})=(\mathrm{T}(\mathrm{I})-\mathrm{T}(\mathrm{avg})) / \mathrm{s}$, where $\mathrm{T}(\mathrm{I})$ is the growing season length associated with a given Z-score, $\mathrm{z}(\mathrm{I}), \mathrm{T}(\mathrm{avg})$ is the mean annual growing season length over the selected period (e.g. 1961-1990), and $\mathrm{s}$ is the standard deviation of the annual growing season lengths over the selected period (e.g. 1961-1990).

For example, MUCH ABOVE NORMAL would represent any amount greater than a 1.282 standard departure above the mean. In a normal distribution, the NORMAL category will contain $40 \%$ of the values. The ABOVE NORMAL and BELOW NORMAL categories will each contain $20 \%$ of the values, and the MUCH ABOVE and the MUCH BELOW categories will each contain 10\% of the values.

The 30\% category shown in the WETS Table represents the class limit values associated with the NORMAL category Z-values of -0.524 and 0.524 .

\section{Precipitation Category Definitions}

The same Z-score categories apply to precipitation; however, monthly and annual precipitation exceedence probabilities are calculated from fitting the observed monthly data to a two-parameter gamma distribution. 
The two-parameter gamma distribution is asymmetrical and is used with continuous random variables such as precipitation. Its probability density function has a lower limit of 0 and an upper limit of infinity. The distribution was fit using the method outlined by the Soil Conservation Service (1985).

\section{References}

National Climatic Data Center. (1984). Atlas of Monthly and Seasonal Temperature Departures from the Long-Term Mean (1895-1983) for the Contiguous United States. Historical Climatology Series 3-4, U.S. Department of Commerce, National Climatic Data Center, Asheville, NC.

National Water and Climate Center. (1995). Technical Definition of Ranges of Normal from USDA National Water and Climate Center (http://www.wcc.nrcs.usda.gov/water/wets_doc.html\#Section4b; May 15, 1995)

Soil Conservation Service. (1985). Selected Statistical Methods, National Engineering Handbook, Section 4 Hydrology, Chapter 18. U.S. Department of Agriculture, Washington DC, pp. 18-7 - 18-8.

Wilks, D. S. (1995). "Statistical Methods in Atmospheric Sciences." Academic Press, San Diego, CA. 


\section{APPENDIX E}

\section{Notation}

$\begin{array}{ll}\text { ET } & \text { Evapotranspiration } \\ \text { NCDC } & \text { National Climatic Data Center } \\ \text { NDMC } & \text { National Drought Mitigation Center } \\ \text { NOAA } & \text { National Oceanic and Atmospheric Administration } \\ \text { NRCS } & \text { Natural Resources Conservation Service } \\ \text { NWCC } & \text { National Water and Climate Center } \\ \text { NWS } & \text { National Weather Service } \\ \text { Palmer Indices } & \\ \text { PDSI } & \text { Palmer Drought Severity Index } \\ \text { MPDSI } & \text { Modified Palmer Drought Severity Index } \\ \text { PHDI } & \text { Palmer Hydrologic Drought Index } \\ \text { RCC } & \text { Regional Climate Center } \\ \text { SPI } & \text { Standardized Precipitation Index } \\ \text { UCAN } & \text { Unified Climate Access Network } \\ \text { URL } & \text { Uniform Resource Locator } \\ \text { USDA } & \text { United States Department of Agriculture } \\ \text { USGS } & \text { United States Geological Survey } \\ \text { WETS } & \text { name without meaning } \\ \text { WSO } & \text { Weather Service Office }\end{array}$




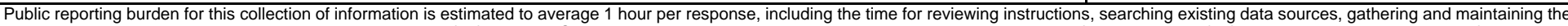

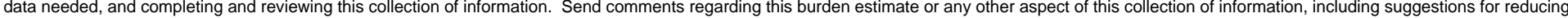

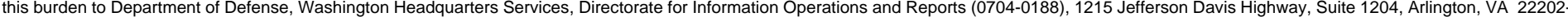

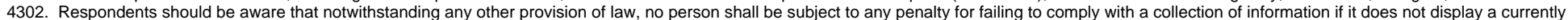
valid OMB control number. PLEASE DO NOT RETURN YOUR FORM TO THE ABOVE ADDRESS.

\begin{tabular}{l|l|l} 
1. REPORT DATE (DD-MM- $Y Y Y Y)$ & 2. REPORT TYPE & 3. DATES COVERED (FrOm - TO)
\end{tabular}

April 2000

\section{TITLE AND SUBTITLE}

Final Report

Accessing and Using Meteorological

Data to Evaluate Wetland Hydrology

5a. CONTRACT NUMBER

5b. GRANT NUMBER

5c. PROGRAM ELEMENT NUMBER

6. AUTHOR(S)

Steven W. Sprecher, Andrew G. Warne

\section{5d. PROJECT NUMBER}

5e. TASK NUMBER

5f. WORK UNIT NUMBER

8. PERFORMING ORGANIZATION REPORT NUMBER

ERDC/EL TR-WRAP-00-1

Environmental Laboratory

3909 Halls Ferry Road

Vicksburg, MS 39180-6199

9. SPONSORING / MONITORING AGENCY NAME(S) AND ADDRESS(ES)

10. SPONSOR/MONITOR'S ACRONYM(S)

U.S. Army Corps of Engineers

Washington, DC 20314-1000

11. SPONSOR/MONITOR'S REPORT NUMBER(S)

\section{DISTRIBUTION / AVAILABILITY STATEMENT}

Approved for Public Release; distribution is unlimited

\section{SUPPLEMENTARY NOTES}

\section{ABSTRACT}

The Corps of Engineers Wetlands Delineation Manual recommends that "preceding weather conditions must be considered" when interpreting observations of water at possible wetland sites. Sources of meteorologic information are described in this report, and suggestions for analysis of relationships between local and regional weather and site hydrology are provided.

Monthly precipitation data from more than 8,000 National Weather Service (NWS) stations have been analyzed, compiled, and made available on the Internet by the USDA National Water and Climate Center in the format of WETS Tables. These tables report $30^{\text {th }}$ and $70^{\text {th }}$ percentile exceedence frequencies for monthly precipitation, which generally define the range of normal precipitation. Suggestions for presentation of WETS Table data are provided. A method for calculating rolling sums of daily rainfall to enhance the accuracy of hydrologic assessments of sites is presented. The USDA Natural Resources Conservation Service has devised a method for systematically assessing antecedent weather conditions at a site; this method is described and suggestions to enhance the accuracy of this approach are provided.

Regional patterns of drought and precipitation excess can be tracked using the Palmer drought indices, the Standardized Precipitation Index, and/or real-time gauge data. Contemporary conditions are standardized as percentiles of long-term records at Web sites reporting these analyses for climate divisions in each state.

\section{SUBJECT TERMS}

Hydrology Rainfall Wetlands

Meteorology Weather WETS tables

\begin{tabular}{|c|c|c|c|c|c|}
\hline 16. SECURITY CLA & IFICATION OF: & & 17. LIMITATION & 18. NUMBER & 19a. NAME OF RESPONSIBLE PERSON \\
\hline $\begin{array}{l}\text { a. REPORT } \\
\text { UNCLASSIFIED }\end{array}$ & $\begin{array}{l}\text { b. ABSTRACT } \\
\text { UNCLASSIFIED }\end{array}$ & c. THIS PAGE & & 96 & $\begin{array}{l}\text { 19b. TELEPHONE NUMBER (include area } \\
\text { code) }\end{array}$ \\
\hline
\end{tabular}




\section{4. (Concluded).}

The statistics of precipitation frequency analysis and some of the pitfalls in using site-specific and regional data are discussed. Analyses of regional precipitation patterns are probably sufficient when observations of hydrology are not quantified. Personnel engaged in projects requiring quantification of onsite hydrology, however, should gather precipitation data on or close to the site on a daily basis. Daily data not gathered from official NWS stations should be compared with daily records from stations included in the WETS Tables network. These analyses should then be superimposed on the long-term patterns available from Web sites reporting regional analyses of climate divisions. 
Destroy this report when no longer needed. Do not return it to the originator. 